\title{
A PHYSIOLOGICAL STUDY OF THE CLI- MATIC CONDITIONS OF MARYLAND AS MEASURED BY PLANT GROWTH
}

(A second contribution from data obtained under the auspices of the Maryland State Wenther Service, in 1914)

Dissertation submitted to the Board of University

Studies of the Johns Hopkins University in conformity with the requirements for the degree of Doctor of

Philosophy

By

F. MERRILL HILDEBRANDT

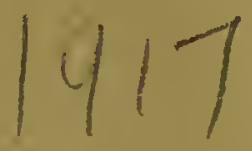

\section{BALTIMORE}

June, 1917

[R mprinted mom Phyorozogical Rhimarches, 2: 341-405. 1921] 



\title{
A PHYSIOLOGICAL STUDY OF THE CLI- MATIC CONDITIONS OF MARYLAND AS MEASURED BY PLANT GROWTH
}

(A second contribution from data obtained under the auspices of the Maryland State Weather Service, in 191\%)

\section{Dissertation submitted to the Board of University Studies of the Johns Hopkins University in conformity with the requircments for the degree of Doctor of \\ Philosophy}

\author{
By \\ F. NERRILL HILDEBRANDT \\ 1
}

\section{BALTIMIORE}

June, 1918 
5600
.115

Gift

Ordar: :

SAY 18 LRE

$\therefore \vdots$ 


\title{
A PHYSIOLOGICAL STUDY OF THE CLIMATIC CONDITIONS OF MARYLAND, AS MEASURED BY PLANT GROWTH ${ }^{1}$
}

\author{
A Second Contribution from Data Obtained Under the Auspices of \\ the Maryland State Weather Service, in 1914
}

\section{F. MERRILL HILDEBRANDT}

\begin{abstract}
${ }^{2}$
The present paper presents the results obtained from a study of a series of observations on the climatic complexes for nine different stations in Maryland for the summer of 1914, as the effectiveness of each complex was automatically integrated by soybean plants grown for a period of 4 weeks from the seed, new seeds being planted every 2 weeks. Corresponding instrumental observations were also studied.

The field work was carried out by Dr. Forman T. McLean, under the joint auspices of the Maryland State Weather Service and the Laboratory of Plant physiology of the Johns Hopkins University. McLean ${ }^{3}$ has presented an account of the plan and methods by which the observational data were obtained and he also made a thorough study of the growth data for soy-bean, for the stations at Oakland and Easton, his main results and conclusions having been set forth in his publications.

The study with which the present paper deals involved all the climatic and soy-bean data obtained by McLean; it thus included data for nine different localities well distributed throughout the state. The plants for all stations and for all periods were treated practically alike, excepting for the climatic conditions of the several localities. The same soil was used for all cultures. The values obtained from the plant measurements, made after 2 and after 4 weeks of growth, therefore constitute comparative and quantitative descriptions of the total influence exerted by all the climatic conditions upon the plants, and they exhibit the seasonal march of this climatic resultant in terms of the responses of the different sets of cultures. The plant measurements themselves, and the values derived from them, form perhaps the most important contribution in the present paper. The graphs of these values depict the seasonal march of each climatic complex, not after the manner of the instrumental readings usually employed in the study of climate, but as measures of the effectiveness of the climatic complex to favor or retard the growth of the standard plant, the latter being employed as a "living instrument" or indicator of climatic effectiveness. ${ }^{4}$

The plant measurements employed are: (1) stem height, (2) leaf area, (3) leafproduct (length multiplied by width), (4) dry weight. The climatic values used are: (1) air temperature, (2) the evaporating power of the air, (3) sunlight intensity and duration. Values to represent the temperature efficiency for growth are derived from the temperature records by means of the Livingston physiological temperature indices

\footnotetext{
3 Botanical contribution from the Johns Hopkins Hospital University, no. 60. This work was practically completed in 1917 , but war conditions delayed its publication.

2 This abstract was preprinted, without ehange, from these types and was issued as Physiological Researches Preliminary Abstracts, vol. 2, no. 8, May, 1921. Physiol. Res, 2: 129-208, 1917. A brief account had appeared earlier:-Idem. Relation of climate to plant growth in Maryland. Monthly Weather Rev. 43: 65-72. 1915.

4 Livingston, B. E., and McLean, F. T. A living climatological instrument. Science 43: 362. 1916.
}

3 McLean, Forman T. A preliminary study of climatic conditions in Maryland, as related to plant growth
\end{abstract}


All of the measurements, both plant and climatic, are expressed relatively, so that they may be compared for different stations and for different periods.

Considering the soy-bean plaut (as here employed) as a standard plant or indicator for the measuremento of climatic efficiency to produce plant growth, it appears that, for the season of 1914, the climatic complexes for some culture periods were more efficient in this sense than might be expected from an attempt to interpret the corresponding climatic data, while the complexes for other periods were actually less efficient to produce soy-bean growth than might be surmised from the corresponding climatic values. No successful method has yet been brought forward by which the value of a climatic complex, to produce growth in any plant form, may be deduced from instrumental data, and the plant measurements of this study furnish a means by which climatic efficiency as a whole may be directly compared for different periods and for different stations. The seasonal means derived from the plant data give relatively low efficiency values for the climatic complexes of the three western stations (Oakland, Chewsville and Monrovia), high values for the complexes of Baltimore and Darlington, and intermediate values for the complexes of the remaining stations (College, Coleman, Easton, and Princess Anne).

If indices for total seasonal climatic efficiency are derived by multiplying the seasonal average growth rate per day by the normal length (days) of the growing season for the station in question, these indices have the following values for the several stations: Oakland, 9009; Chersville, 12480; College, 16567; Easton, 17685; Princess Anne, 19005; Coleman, 21115; Darlington, 236S5; Baltimore, 25122. In considering these relative climatic indices it should be emphasized that the data of this study do not involve precipitation as an infuential climatic feature; the culture plants were automatically irrigated so that they never suffered from lack of soil moisture.

A study was made of the interrelations of the different kinds of plant measurements, dealing therefore with some aspects of growth correlation in soy-bean. It appears that the rate of stem elongation was greater than the rate of leaf expansion when both were relatively small, while the former rate was the smaller of the two when both were relatively large. The rate of production of dry weight appears to have been nearly proportional to the rate of increase of leaf surface; the relative values of these two growth criteria are generally about equal numerically.

The siatements just made apply to the data for plants quite openly exposed, but some observations on cultures somewhat protected above by glass were available, and also a set of observations on cultures in forest at Baltimore. These all indicate that the height rate was relatively greater than the rate of leaf expansion for these more or less shaded conditions, while the rate of dry-weight production was smaller than the corresponding rate of leaf expansion. The outcome of this part of the study may throw some light on the general problem as to what sort of plant measurements may be best suited to quantitative comparisons of the efficiencies of different climatic complexes. An interesting, and probably valuable result of this study is that the calculated leafproduct (length times breadth, which can be obtained without injury to the plants, if that is desirable) is generally proportional to the leaf area; of course for these soy-bean plants.

The climatic data themselves showed a pronounced general agreement between the graph for sunlight and the corresponding one for evaporation (standardized white cylindrical porous-cup atmometer), this being probably due to the relatively great importance of solar radiation in determining the evaporation rate. The climatic values indicate a general seasonal march, which is very evident for temperature, less so for sunlight and rather obscure for evaporation. For details regarding the climatic values, as well as for the plant values, reference must be made to the tables and graphs and to the text of the paper. 


\section{CONTENTS}

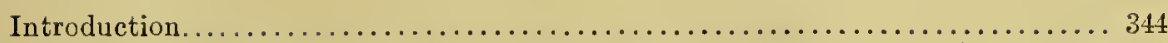

The observational data and the averages derived from them

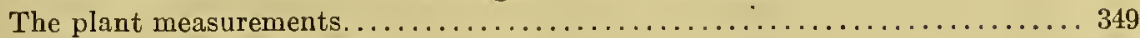

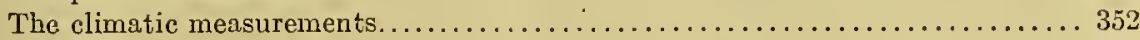

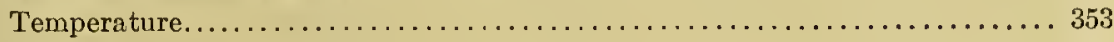

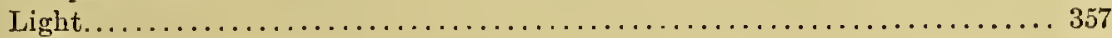

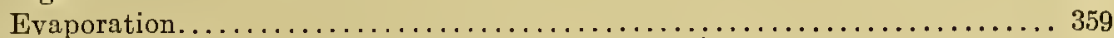

Results and discussion

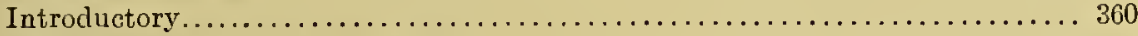

Results from stations in the open

The 2-rveek values

The 2-week plant data for stations in the open

Correlations between the 2 -week plant graphs................ 371

Trends of the 2-iveek plant values and their seasonal ranges for the sev-

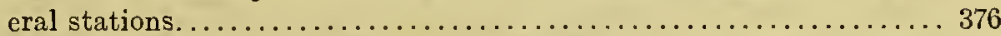

The 2-rveek climatic data for stations in the open ................. 377

The 2 -week temperature data................................. 378

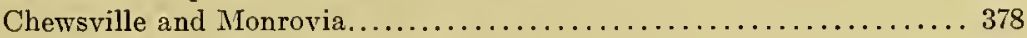

Baltimore, Darlington and Coleman........................... 379

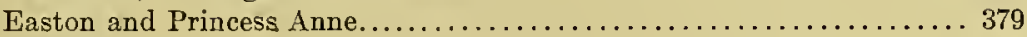

College................................................ 379

Oakland............................................... 379

The generalized graph.................................... 380

Light and the evaporating power of the air, 2-week data............. 380

Variability of temperature and evaporation values................. 382

Correlation of the 2 -week plant and climatic values................... 383

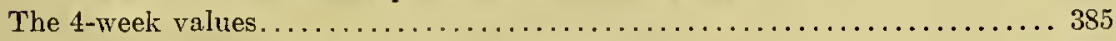

The 4 -week plant data for stations in the open .................. 386

The 4-week climatic data for stations in the open................. 390

Results for the three covered stations

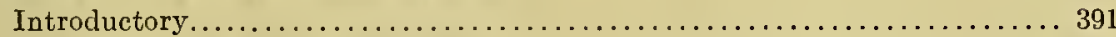

The plant data, covered stations.................................. 391

The Oakland covered station.............................. 393

The Baltimore covered station............................ 394

The Easton covered station................................ 394

The climatic conditions, covered stations....................... 394

Results for the Baltimore forest station.......................... 395

The plant data as measures of the climatic efficiency for growth of the standard plants

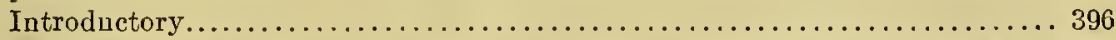

Seasonal averages of mean daily intensity values for the several stations.... 398

Total seasonal efficiencies for the several stations.................... 403

General conclusion........................................ 405 


\section{INTRODUCTION}

During the summer of 1914 an elaborate investigation was undertaken by the Maryland State Weather Service in cooperation with the Laboratory of Plant Phyrsiology of the Johns Hopkins University, with the object of aseertaining some of the relations between climatie eonditions and the growth of eertain plants exposed at different stations in Maryland. Detailed information as to the growth of the plants used is of eourse neeessary in sueh a study, as is also eorresponding knowledge of those environmental eonditions that are considered as climatic. The plant records were seeured in this ease by growing eultures of certain plants under the environmental eonditions to be studied, and noting the amount of growth accomplished during definite periods of time. In order that a corresponding series of measurements of some of the environmental conditions might be available for comparison with these growth measurements, the eultures were located at certain of the regular observation stations of the $\mathrm{U}$. S. Weather Bureau, at nine different places in the state. The general plan of the study and a detailed consideration of the methods used has already been published by MeLean, ${ }^{5}$ who did all of the ficld work personally. The original data dealt with in the present paper were secured from MeLeans' records, and it will be neeessary to give here only so much description of the ways in which these measurements were obtained as is needed to render their use in the present publication intelligible. The following deseription is taken mainly from MeLean's paper, which also deals with the growth of soy-bean plants, but for only two of the stations, Easton and Oakland. The present paper gives the main results for soy-bean plants for all of the nine stations, together with some attempts at interpretation.

This study has been carried out partly through financial aid furnished by the Maryland State Weather Service. It was suggested by Prof. B. E. Livingston and carried out under his direetion. The writer wishes to express his indebtedness to Prof. Livingston for much assistance in carrying out the study and for helpful eritieisn in the preparation of manuseript. The writer also wishes to thank Dr. H. E. Pulling for valuable suggestions made during the course of the study.

The stations employed were Oakland, Chewsville, Monrovia, College Park, Baltimore, Darlington, Coleman, Easton, and Princess Anne. One station, Oakland, is in the Allegheny plateau. Four stations are in the Piedmont plateau; one of these (Chewsville) being in the Hagerstown valley, two (Darlington and Monrovia) in the hilly eountry north and west of Baltimore, and one (Baltimore) at the lower edge of the plateau near Chesapeake bay. Four stations, College Park, Coleman, Easton and Princess Anne, are in the coastal

5 McLean, F. T. A Preliminary study of elimatic conditions in Maryland, as related to plant growth. Physiol. Res. 2: 129-208. 1917. 
plain. Coleman, Easton, and Princess Anne, are east of Chesapeake bay, while College Park is west of it and much farther inland, near the line of demarcation between the coastal plain and the Piedmont plateau. All of the stations except Oakland are at comparatively low elevations - less than 310 meters (1000 feet) above sea-level. Oakland has an elevation of 775 metcrs (2500 feet). The geographical distribution (see fig. 1) of these stations is such as to insure considerable differences in climatic conditions.

At each of the nine places referred to, a series of cultures was grown in the open with no covering other than a screen of large-meshed wire netting. These have been termed the exposed stations. Also, at Oakland, Baltimore, and Easton series of cultures were grown under glazed cold-frame sash supported horizontally 1 meter ( 3.3 feet) above the surface of the soil. These have been termed the covered stations. The plants were freely exposed at the sides, the sash being supported merely by corner posts. They were located within a very few meters of the enclosures containing the plants of the exposed stations and were subjected to the same climatic conditions as the exposed plants, except in so far as these conditions were modified by the glass covers. Furthermore, a series of cultures was exposed in the woods hear the Laboratory of Plant Physiology of the Johns Hopkins University at Baltimore. This has been termed the Baltimore forest station. As in the case of the exposed stations, these forest cultures were covered by a protective screen of wire netting. They were, of course, subjected to a complex of climatic conditions quite different from those of the exposed and covered stations at Baltimore. The forest station was distant about 150 meters $(490$ feet) from the exposed and covered stations, at Baltimore. There are thus plant data available from 13 series of cultures in all, each series having been exposed to a different set of environmental conditions throughout the season.

The cultures were so planned that the plants might be considered as standard plants for the comparative measurement of climatic conditions in accordance with a suggestion made by Livingston and McLean. ${ }^{6}$ Since the problem of expressing plant growth in terms of the intrumental measurements of the climatic conditions that control it is rendered exceedingly complex by the number of these conditions and by their continual variation, as well as by the changing internal conditions of the plant itself, a detailed analysis of the control of plant growth is very difficult. Livingston and McLean suggest that the rate of growth of any plant is itself an expression of the summation of all the effects of the external conditions acting during the growing period, and that a standard plant may be employed as an automatically weighting, integrating, and recording instrument for the comparative measurement of environmental conditions as these are effective in growth control. Thus several environments may be measured and compared in terms of their sev-

6 Livingston, B. E., and McLean, F. T. A living climatological instrument. Science 43: 362. 1916. 


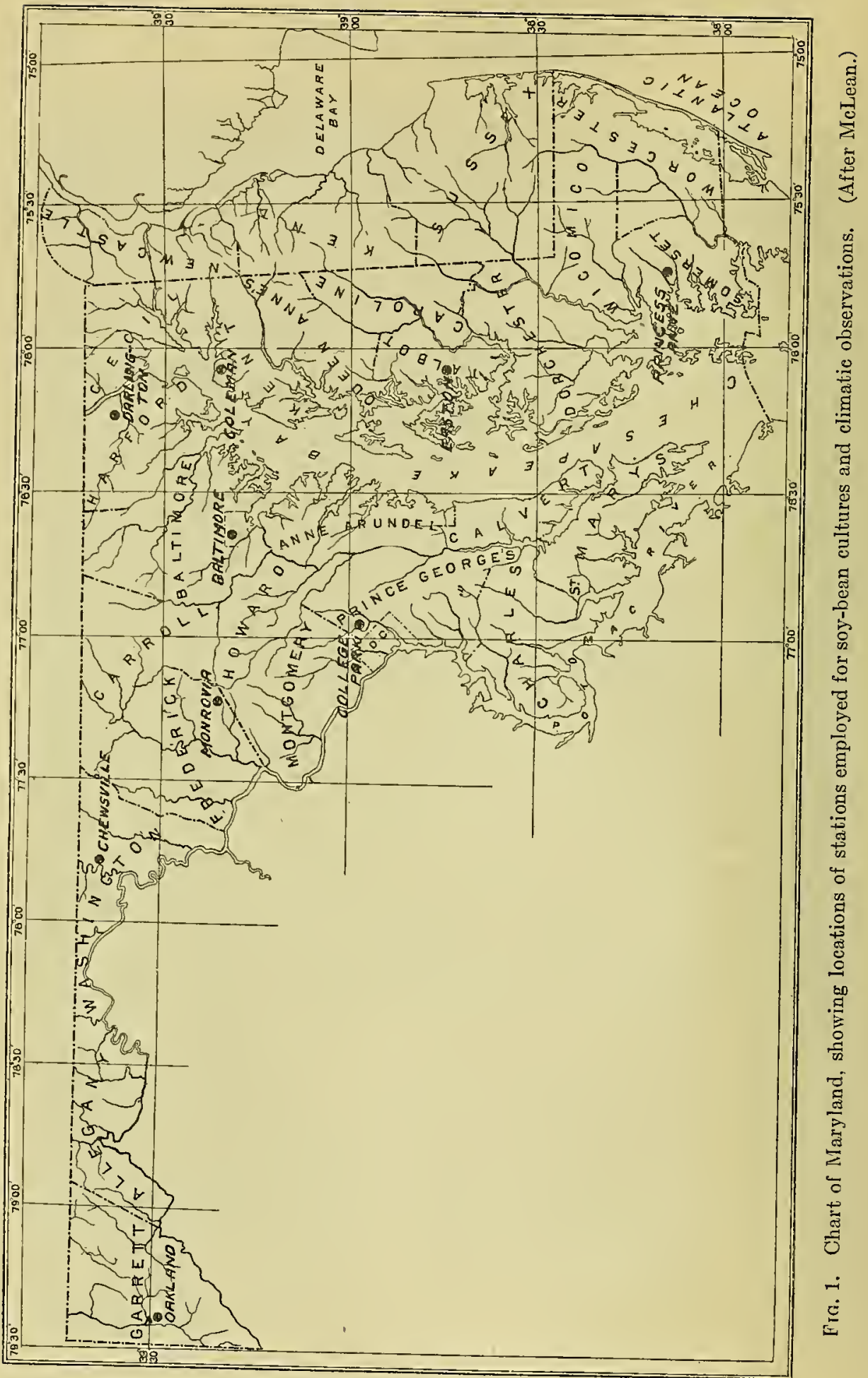


eral capacities for producing growth in the standard plant. This method of measuring the environmental complex in terms of plant growth can be applied, of course, only when it may be assumed that all the standard plants are alike at the beginnings of the several periods of exposure. In this study the requirement just stated was fulfilled by employing the seed as the starting point for the plants of the various cultures. It was apparent that if the cultures were always started from the seed, the plants might be considered as more mearly ahike at the beginning of the several culture periods than would have been the case if an attempt had been made to obtain like plants in any other phase of their development.

Growth rates were measured and compared in terms of size and weight of the plants. Each culture consisted of six plants grown for a period of four weeks from the seed. Cultures were started approximately every two weeks during the growing season, at each of the stations employed, and growth measurements were made after about two weeks and again after about a month. The plants were harvested at the end of the longer period.

As in other problems in which a number of conditions enter into the control of a process, the relations between conditions and process rate are more easily detected the smaller is the number of conditions involved, and conditions may be temporarily left out of consideration if they are the same in several experiments. Just as the internal conditions of the standard plant at the start of the experiment are left out of the argument by the simple device of having them all alike at the beginning of the exposure period (the instrument being thus set at the zero of its scale, in the words of Livingston and McLean), so selected conditions of the surroundings may be left out of consideration by having them alike throughout all of the periods. According to this principle, most of the environmental conditions that acted on the plants below the soil surface were kept nearly the same for all times and at all stations. Assuming that this artificial control of the subterranean environmental conditions kept them practically constant, the differences observed in the growth rates of the standard plants were taken to be related almost entirely to the aerial conditions of the surroundings. These are the ones referred to by McLean as climatic, and this term will be used with the same meaning in the present paper. To accomplish this control of the subterranean conditions, the soil was always the same at the beginning of all cultures and its moisture content was generally kept approximately the same throughout all culture periods, by means of the Livingston auto-irrigator. This arrangement and its operation have been described by McLean and will also receive some attention below.

While several clifferent plant species were employed throughout the experimental work, the present paper deals only with the data obtained from soybean. A variety of this plant called "Peking," was used. The seed was of pure strain obtained from the 1913 crop of the Maryland Agricultural Experi- 
ment Station. All the seeds were first treated with carbon bisulphide vapor for one week, to destroy insects, after which they were placed in paraffined paper cylinders with tight-fitting covers and stored until ready for use.

A rather light soil, of the type classified as Norfolk Sand by Bonsteel, ${ }^{7}$ obtained from an untilled field near College Park, Maryland, was used in all of the plant cultures. This soil was chosen for three reasons: first, its water-holding power is comparatively low, so there was little danger of longcontinued excessive water-logging after a rain; second, it was not a very fertile soil and yet was capable of giving good growth under favorable climatic conditions; and finally, it was conveniently obtained. The method of obtaining it was to remove the top soil to a depth of $15 \mathrm{~cm}$. from a small area of the field. This top soil was then thoroughly mixed, sifted, and placed in cloth sacks for shipment to the various stations where it was stored in air-dry condition in covered, water-tight, galvanized iron cans until needed for use in the cultures. The soil container's for the cultures were ordinary " 6 inch" porous clay flower-pots, in form like the frustruin of a cone, being smaller at the bottom, and of a cubic capacity of approximately $1980 \mathrm{cc}$.

In order to secure uniform soil conditions in the various cultures, it was necessary, not only that the soil should be of the same character in all of them, but also that it should be brought into the same physical condition for the beginning of all cultures. Furthermore, it was desirable that this physical condition be such that it might be retained with as little change as possible during the growth periods of the plant. To put the soil into a state of aggregation to be least altered by varying weather conditions (especially heavy rains which pack it more or less) it was saturated with water immediately after being put into pots. This was accomplished by plunging the filled pots into a bucket of water and allowing them to remain submerged until air bubbles ceased to rise. The pots were then drained and a two-week interval was allowed to intervene before the seeds were planted.

The soil moisture in the cultures was maintained always above a certain minimum by means of auto-irrigators. ${ }^{8}$ This device, as here used, consisted of two cylindrical porous clay cups (of the regular form supplied by the "Plant World") connected with each other and with a water reservoir by glass tubes each having the form of an inverted J. The cups were placed vertically in the pot, their rubber-stoppered tops level with the soil surface, and were so arranged as to supply water to the soil against a pressure of $35 \mathrm{~cm}$., or somewhat more, of a water column. The moisture content of the soil was thus maintained so that it was never less than about 10 or 11 per cent on the basis

\footnotetext{
${ }^{7}$ Bansteel, J. A. The Soils of Prince George's County [Maryland]. Maryland Geological Survey: Baltimore, 1911.

${ }^{8}$ Livingston, B. E. A method for controlling plant moisture. Plant World 11: 39-40. 1908. Livingston, B. E. Auto-irrigation of pots of soil for experimental cultures. Carnegie Inst. Washington Year Book 14: 76. 1916.
} 
of dry weight. With this water content this particular soil was rather too wet than too dry for the best growth of the plants.

After preparing the pots and arranging the watering devices the pots were allowed to remain fallow for about two weeks before planting, as has been mentioned. Thus the soil was fully drained after the preliminary saturation and had settled into a condition somewhat approaching that of structure equilibrium, before the seeds were planted. The seeds were placed $2.5 \mathrm{~cm}$. deep, six seeds in each pot. Care was taken to space them uniformly from each other, from the auto-irrigator cups and from the sides of the pots, so that all should have, as nearly as possible under the general conditions of the experiments, the same soil moisture conditions. When the plants were removed from a pot (about six weeks after that pot had been filled) the soil was discarded and fresh soil from the stored supply was used in refilling for the next following culture.

\section{THE OBSERVATIONAL DATA AND THE AVERAGES DERIVED FROM THEM}

\section{The Plant Measurements}

The first plant measurements were made after approximately two weeks of growth from the seed. At that time the length of each leaflet, from the tip to the junction of blade and petiole, was determined, as was also the greatest width of each leaflet, measured at right angles to the long axis. The height of each plant was also measured, from the soil surface to the base of the terminal bud. At the end of approximately four weeks of growth the height measurement was repeated, after which the plants were cut off at the soil surface and photographic prints were prepared of the fresh leaves. By means of these leaf-prints the leaf area (one side) was afterwards determined planimetrically, for each leaf and for each plant. Finally, the dry weight of tops for each culture was determined. All linear measurements were made to the nearest millimeter, areal measurement to the nearest $0.1 \mathrm{sq} . \mathrm{cm}$., and weight measurements to the nearest $0.01 \mathrm{~g}$.

For convenience, these five kinds of observational data on growth rates are summarized below.

After about 2 weeks of growth:-

(1) Stem, height, millimeters.

(2) Length and breadth of all leaflets, millimeters.

After about 4 weeks of growth:--

(1) Stem height, millimeters.

(2) Leaf area (one sicke), square millimeters.

(3) Dry weight (of tops), milligrams. 
Of course the growth data obtained by aetual observation require averaging in some way so as to represent the varions periods throughout the season. The ordinary method of averaging was applied in all eases, but the observational data for leaflet dimensions required speeial preliminary treatment. The two dimensions derived from the measurements were multiplied together for eaeh leaflet, giving the leaflet-produet and these produets were summed to give the total leaf-produet of eaeh plant. As McLean pointed out, the mean daily rate of inerease in total leaf-product for a period of 4 weeks is very nearly proportional to the eorresponding rate of inerease in aetual leaf area, and it seems safe to suppose, as McLean did, that the 2-week leaf-product values may be regarded as indices of inerease in the area of the leaves. These product values are therefore used, for the 2 -week periods of this study, as indieators of the rates of leaf expansion. Leaf areas were of course not determined for the 2 -week periods, although they are available for the 4 -week periods.

There were six plants started in eaeh eulture, but in many eases the number of plants from which records were aetually taken was less than six (it was never less than three and was usually four or five in such cases), on account of noticeable injury due to other eonditions than the ones here studied, such as insect attack, ete. All plant data have therefore been recluced to averages per plant. Also, in many eases the length of the period differed slightly from 14 days for the 2 -week periods, and from 28 days for the 4 -week periods, and the averages per plant have eonsequently been expressed as mean daily values for the respective periods. This method renclers the plant measurements for the different periods more strietly eomparable. It should be noted, however, that the growing periods were 14 and 28 days long in the majority of eases, and that variations in the length of the eulture period were slight. Considering the 2-week and 4-week plant values as measures of the results of plant proeesses acting through these periods, the mean daily values represent mean daily inerements or process rates, and they will be termed "daily inerements," for their respective periods, in the diseussion that follows. Thus, for a plant $10 \mathrm{~cm}$. high at the end of a 13-day period, $10 / 13$ (or 0.77 ) em. is regarded as the mean daily increment of inerease in height, for that period. Letting the word growth represent the particular process to which the given kind of measurement refers (as increase in height, increase in leaf area, etc.), these may be spoken as growth increments.

The mean daily growth inerements, and also the mean daily elimatic values, for the respective periods have been expressed in terms of the corresponding average of all the periods considered, for all exposed stations. This proeedure renders all the values direetly comparable. To obtain this unit for any lind of value, all of the eorresponding values (as all 2 -week daily mean inerements in height, for example, for all exposed stations) were summed and the sum was divided by the number of values summed. Then eaeh indi- 
vidual value was divided by the unit thus obtained. The data were expressed as these ratio values, which will be termed relative values in the following discussion. To avoid decimals, these relative values have all been multiplied by 100 , and are thus given in the tables and in the text of this paper. The absolute magnitude of the unit used for cxpressing each lind of value is of course not important; it is essential only that all comparative values be expressed in terms of the same unit. The unit here employed represents in every case simply the average of all similar quantities that are used in the present study. If another station had been employed, or if the season had been longer or shorter at any station, the values of these comparative units would have been different. The magnitudes of these units thus depend to some extent upon the climatic conclitions encountered at the various stations in the summer of 1914 , to some extent upon the number and location of the stations, to some extent upon the nature of the soil used in this investigation, and to some extent upon the physiological nature of the soy-bean plant. The actual values of the various growth units are given below.

For first 2 weeks of growth from seed

Average daily increment of stem height per plant, $3.56 \mathrm{~mm}$.

Average daily increment of leaf-product per plant, $112.0 \mathrm{sq} . \mathrm{mm}$.

For first 4 weels of growth from seed

Average daily increment of stem height per plant, $3.20 \mathrm{~mm}$.

Average daily increment of leaf area per plant, $122.0 \mathrm{sq} . \mathrm{mm}$.

Average daily increment of dry weight (of tops) per plant, $6.29 \mathrm{~g}$.

The use of the relative values described above simplifies the plotting of the graphs upon which interpretation of such a study as this so largely depends. It also renclers possible a direct comparison between the values for any two cultures irrespective of their dates or stations. Furthermore, it is possible to tell from the magnitude of the relative value for any culture the extent to which the plant, or climatic, measurement under consideration departs from the mean of that measurement for all the cultures of the study.

To obtain the original or absolute plant; or elimatic, value from a given relative value, it is necessary only to reverse the arithmetical procedure by which the relative value was derived. For example, suppose it is clesired to get the actual mean claily rate of increase in leaf-area per plant for the fourweek period ending September 2 , and for the station at Coleman. The relative value given in the table is 108 . The first operation is to divide by 100 , which gives 1.08 as the true relative value. The average daily increment in leaf area per plant, for the period and station in question, was therefore 1.08 times the value of the common unit employed for comparing the rates of increase in leaf area. Multiplying this unit value (122 sq. mm., as given above), by 1.08 gives $132.0 \mathrm{sq}$. mm. as the actual mean daily increment required. To obtain the average total leaf area per plant at the end of the period in question, we multiply $132.0 \mathrm{sq}$. mm. by the number of days in the period ( 28 in this 
case) and get $3698 \mathrm{sq} . \mathrm{mm}$. Since there were 5 plants measured in this culture, the total leaf area for the entire culture at the end of the period is obtained by multiplying $3698 \mathrm{sq}$. mm. by 5 , which gives $18490 \mathrm{sq}$. mm. or 184.9 sq. $\mathrm{cm}$., which is the actual areal value determined from the prints of these leaves. All of the original absolute values may be obtained from the relative ones in a similar manner. It is of course evident from the above description of the manner in which the relative values have been derived that they are proportional to the corresponding absolute values. In all subsequent discussion, when plant (and also climatic) values are referred to, it will be understood that these are the relative values rather than the absolute ones.

As in the case of the observational data, the five kinds of derived growth values used in this study are listed below, for convenience.

After about 2 weeks of growth from seed

(1) Relative mean daily increment of stem height per plant.

(2) Relative mean daily increment of total leaf-product per plant.

After about 4 weeks of growth from seed

(1) Relative mean daily increment of stem height per plant.

(2) Relative mean daily increment of total leaf area per plant.

(3) Relative mean daily increment of dry weight (tops) per plant.

\section{The Climatic Measurements}

The weather observations taken by the coöperative observers at the several stations here employed consisted of daily readings of maximum and minimum thermometers, daily ocular observations of cloudiness, daily measurements of rainfall, and general notes as to storms, wind, etc. The records of the Baltimore office of the Weather Bureau were used for the Baltimore stations. In addition to these records of the weather observers, evaporation was measured by means of Livingston standardized cylindrical porous cups with non-rain absorbing mountings. ${ }^{9}$ Of the five sets of climatic observations mentioned above, only three will be considered in this paper; namely those of temperature, light, and evaporation. As was pointed out by McLean, rainfall showed little or no relation to the growth of these plants, as was indeed to be expected, since the soil moisture of the cultures was always kept sufficiently high (by the auto-irrigators) for the needs of the plants. Also, the miscellaneous climatological observations reported by the weather observers will not be considered in this paper, since none of them have been found to bear any discoverable relation to the growth rates of these plants. The

\footnotetext{
- Livingston, B. E. A rain-correcting atmometer for ecological instrumentation. Plant World 13: 79-82. 1910.-Livingston, B. E., and Shive, J. W. The non-absorbing atmometer. Carnegie Inst. Washington Year Book 13: 93-94. 1915.-Shive, J. W. An improved non-absorbing porous cup atmometer. Plant World 18: 7-10. 1915,-Johnston, E. S. A simple non-absorbing atmometer mounting. Plant World 21: 257-260. 1918.-Livingston, B. E., and Thone, Frank. A simplified non-absorbing mounting for porous porcelain atmometers. Science 52: 85-87. 1920.
} 
observational data were obtained daily throughout the entire season. For convenience, these three kinds of observational data on climatic conditions are listed below.

(1) Temperature.

(2) Light.

Daily maximum and minimum air temperature (shade), degrees, Fahernheit.

Daily light condition, whether clear, partly cloudy, or cloudy.

(3) Evaporation.

Daily evaporation from standardized cylindrical porous-cup atmometer, cubic centimeters.

The climatic data, like the plant data, require special treatment before they can be used in such a study as this. How the mean values for the various periods were secured from the observational data will be described, for each of the three kinds of climatic measurements, in the following sections.

\section{TEMPERATURE}

It is clear that the readings of a thermometer do not express the effectiveness of various degrees of temperature to accelerate or retard plant growth, and it therefore becomes desirable to replace the actual thermometer readings by a scries of weighted values, more or less directly proportional to the temperature effect upon the growth of plants. Owing to lack of information of a quantitative nature as to the relation between plant growth and environmental temperature, this can be accomplished only in a tentative and approximate way at the present time.

The observational data for temperature were all obtained from maximum and minimum thermometers read daily at sunset, these data being taken from the published monthly reports of the U. S. Weather Bureau. ${ }^{10}$ The mean temperature for each day was determined by averaging the maximum and minimum for that day. McLean has discussed some of the ways in which daily maximum and minimum temperature data may be treated in order to obtain weighted values that may tentatively represent temperature effects upon plant growth rates. He emphasizes the fact that temperature values, as shown by a thermometer, do not show a linear proportionality to plant growth. If thermometer readings might be taken as expressing, even in an approximate way, the effectiveness of temperature to produce plant growth, such a relation could only be true up to the optimum temperature, since beyond this point increased temperature results in decreased growth. It would therefore be desirable to replace each thermometer reading by an index representing the effectiveness of that particular temperature for plant

\footnotetext{
10 Fassig, O. L. Climatological data, Maryland and Delaware Section. May to November, inclusive. U. S. Weather Bureau. 1914.
} 
growth. Three ways of doing this, all of which have been considered by MeLean, may reeeive brief mention here.

(1) One way of expressing temperature, which has been used in ecological studies, has been called the remainder-summation method. This is based on the supposition that the growth activities of most plants stop when the temperature falls below $40^{\circ} \mathrm{F}^{11}$ Above this temperature, growth increases with increased temperature, to an optimum. For eonvenience, the growth rate for $40^{\circ} \mathrm{F}$. may be considered as unity: then it should be 2 for $41^{\circ}, 5$ for $44^{\circ}, 20$ for $59^{\circ}$, etc. If we subtraet $39^{\circ}$ from any given temperature, the remainder will represent, according to this method, the efficiency of the given temperature for producing growth. A total efficieney value for any period of time, such as the 4 -week growth periods of these studies, may be obtained by subtraeting $39^{\circ}$ from each daily mean temperature and summing the remainders for the period, thus obtaining the remainder summation.

(2) Another method of weighting temperature values for the purpose before us, and one that apparently has a somewhat more rational basis, was suggested by Livingston and Livingston. ${ }^{12}$ They proposed a series of temperature-efficieney indices based on the van't Hoff-Arrhenius law, which states that the velocity of many ehemical reactions approximately doubles with a rise in the temperature of $10^{\circ} \mathrm{C}$. $\left(18^{\circ} \mathrm{F}\right.$.). If it is assumed that the growth rate for plants follows this law above $40^{\circ} \mathrm{F}$., at which temperature the rate is taken to be unity, a series of values representing temperature effieiencies for higher temperatures may be derived. When this scheme is used, the efficiency value for any temperature is represented by the value of the index that corresponds to the temperature value itself. Assuming the growth rate to be unity for a temperature of $40^{\circ} \mathrm{F}$., it should be 1.21 for a temperature of $45^{\circ}, 2.0$ for $58^{\circ}$, ete. These indices are ealled by Livingston and Livingston "exponential indices," and they have published a table of these values.

Since most of the temperatures with which we have to deal are below the optimum for plant growth, since temperature and the growth rate are related in an approximately linear manner between $40^{\circ} \mathrm{F}$. and the optimum (about $90^{\circ} \mathrm{F}$.), and siuce both the exponental and remainder series of index values increase in a nearly linear way throughout this range, both of the methods just considered give temperature efficieney numbers that are more or less approximately proportional to plant growth as it is influeneed by temperatures between these limits. It is obvious, however, that neither of these methods ean properly express efficiencies for temperatures above the optimum,

\footnotetext{
11 The temperature data of this paper are all expressed in terms of temperature degreeson the Fahrenheit scale, simply hecause the ohservational data had this old-fashioned form. By retaining the Fahrenheit values much lahor has been avoided, but it is not to be understood that the writer is really as conservative as this feature of the paper might seem to suggest.

12 Livingston, B. E, and Grace J. Livingston. Temperature coefficients in plant geography and climatology. Bot. Gaz. 55: 319-375. 1913.
} 
since they give numbers which continue to increase with increasing temperature, while growth increases with increasing temperature up to the optimum and then decreases with higher temperature. Also, both these methods give results that are approximately proportional to each other for ordinary summer temperatures. This fact has been noted by Livingston and Livingston and again by Stevens, ${ }^{13}$ and it is also obvious from the climatic data given by McLean. But it must be remembered that these methods cannot be satisfactory excepting when the temperatures dealt with lie mainly between $40^{\circ}$ and $90^{\circ} \mathrm{F}$.

When the exponential indices are employed each daily mean temperature for any period is replaced by its index and the series of indices thus obtained is summed for the period, giving the exponential summation.

(3) The third method of expressing temperature values as they affect plant growth has been more recently suggested by Livingston. ${ }^{14}$ It is based on the results of Lehenbauer's experiments with maize seedlings. From. Lehenbauer's data, Livingston derived a series of coefficients giving the efficiencies of various temperatures in terms of the growth of this plant.' He has called these "physiological temperature indices." The growth rates upon which the index values were based are those shown by Lehenbauer's seedlings when exposed for 12 hours to varions maintained temperatures, the other conditions of the experiment being approximately the same for all tests. Livingston suggests that the coefficients thus derived from the growth of maize under controlled conditions, with different maintained temperatures, may possibly express some approach toward a general relation between plant growth and temperature and may thus be applicable to plants growing under other conditions. The graph of these physiological indices exhibits the same direction of slope between a low temperature and the optimum as do the graphs of temperature efficiencies derived by the other two methods, but for this portion of the temperature range the slope of the graph of physiological indices is generally stceper than that of the graph of remainder indices, the latter graph itself having a much steeper slope than that of the exponential indices. This is shown by Livingston and also by Stevens, in the papers cited above. Since they are derived from the actual growth rates of a plant, the physiological temperature indices appear to have a more rational basis than either the remainder or the exponential indices. For this reason, and for others that will appear below, physiological indices bave been used in this study for expressing the temperature values as they are to be compared with the plant growth-rates.

13 Stevens, Neil E. Influence of temperature on the growth of Endothia parasitica. Amer. Jour. Bot. 4: 112-118. 1917.-Idem. Influence of certain climatic factors on the development of Endothia parasitica. Ibid. 4: 1-33. 1917.

14 Livingston, B. E. Physiological temperature indices for the study of plant growth in relation to climatic conditions. Physiol. Res. 1: 399-420. 1916.-Lehenbauer, P. A. Growth of maize seedlings in relation to temperature. Physiol. Res. 1: 247-288. 1914. 
In using the physiological temperature indices for the purposes of this study, the procedure has been as follows. Each daily mean temperature for any period has been replaced by its corresponding index (taken from Ijivingston's table,-1916) and then all the daily index values have been summed to give the physiological summation for the period. This summation value is finally divided by the number of days in the given period.

Two other series of temperature values are presented in the tables of this paper, but neither has been found to be as satisfactory for expressing this chimatic condition as are the physiological-summation indices. These are (a) the average daily mean temperature for each culture period (in degrees, Fahrenheit) and (b) the remainder-summation index for each period.

As has been stated, the physiulogical-summation indices for all periods have been represented as daily means, and these have been stated always as relative values, in terms of the general average for all periods and stations. The average value used as unity in expressing the relative index values for temperature is 56.39 .

The following considerations may be added to show the reason for using the physiological-summation indices in this study, secured as above described, rather than the remainder-summation or exponential-summation indices. It will be necessary to anticipate somewhat the discussion that is to follow this section. The three climatic conditions (temperature, evaporation and light) each show a definite seasonal march for each of the places employed in this study. The temperature rises from low values in the spring to a midsummer maximum, which is followed by a subsequent fall to low autumnal values. On the other hand, the values representing light and evaporation both decrease, in general, throughout the season. If, now, a generalized curve representing the growth of the plants be drawn, employing average values to represent all the stations together, and plotting them as ordinates with the dates of the middles of the periods as abscissas, such a growth curve follows the seasonal march of temperature and shows only secondary variations as related to the other two climatic indices. The growth of the plants is thus apparently determined mainly by temperature. Obviously, also, the seasonal march of the temperature values must show the same general form of curve no matter what scheme is used in expressing temperature efficiency. In view of these facts, and in consideration of the general comparative purpose of the present study, a method should be used, for expressing temperature efficiency, that gives a seasonal march of the efficiency values in accord with the corresponding march of generalized plant growth. Of the three methods mentioned, the physiological-summation index fulfills this requirement best, and this has accordingly been selected for use throughout the entire study, as has been said.

An examination of the plant and climatic graphs (to be considered later) shows that the plant values for most of the stations rise above the temperature 
efficiency values in the middle of the season, and fall below them, at its end. This is probably due in part to the effect of light and evaporation but it may also be related to an inadequacy of the temperature efficiency values to represent the actual effect of temperature on the growth of these plants. It appears to be at least suggested that the actual temperature efficiency values for these soy-bean plants increase more rapidly with increase in the temperature itself, for the range here encountered (between $40^{\circ}$ and $85^{\circ} \mathrm{F}$.), than to the physiological index values derived from Lehenbauer's study of maize seedlings. This whole question deserves much more experimental study. It is a surprising fact that we have available only a single thoroughgoing investigation (Lehenbauer's) of the relation of temperature to the growth of higher plants, in spite of the fact that the primary importance of the temperature control of growth is obvious to every observer and has long been qualitatively appreciated. A comparison, for any of the stations employed, of the range of growth values for the plants with the remainder-summation values for temperature (which are practically equivalent to the expouentialsummation values in this study) and with the physiological-summation indices will furnish evidence for the verification of these statements. The graphs of the physiological-summation indices of temperature efficiency show much steeper slopes than do the corresponding graphs derived from the other two kinds of temperature indices mentioned above, however, so that the physiological indices are evidently more suitable to represent temperature efficiencies than are either of the other two kinds of indices.

\section{LIGHT}

The only records of light conditions that were available for all of the stations of this study were the daily ocular estimates of cloudiness obtained by the weather observers, and these alone were used. To make use of these estimates it was, of course, first necessary to bring the daily percentages of clear'sky together for each culture period, so as to derive for each period a single value that might be taken to represent the intensity of the light condition for that period. The method employed to accomplish this is presented below. ${ }^{15}$

The total heat equivalent of the actual sunshine for any given period at a given station is primarily a function of three terms: (1) the maximum possible number of hours of sunshine (determined by latitude and season); (2) the mean daily intensity of full sunshine for the period and station, which may be expressed in terms of units of heat received per unit of a horizontal surface; (3) the condition of the sky, whether overcast, partly overcast or clear. The daily values for the first two of these terms vary in a regular manner

15 The presentation of this method is here practically the same as that previously published. See: Hildebrandt, F. II. A method for approximating sunshine intensity from ocular observations of cloudiness. Johns Hopkins Univ. Cire., March, 1917. 
throughout the year for any given place, and the ones for the third term are roughly stated in the observer's records, as just mentioned.

The first two terms are combined in the ordinates of the graph given by Kimball ${ }^{16}$ for the maximum possible total radiation received per day at Mount Weather, Virginia. Since this station is at about the same latitude as the stations here dealt with, the ordinates from Kimball's graph may be taken as approximate measures of the total maximum possible light intensities for the corresponding dates for all of the Maryland stations. These values represent the total amount of heat received from the sun and sky on clear days at Mount Weather, in gram-calories per square centimer of a horizontally exposed surface. The method of using this graph along with the weather observer's reports, for estimating sunshine intensity for any station and period, will be best shown by an example. Suppose it is desired to estimate the average daily sunshine intensity for some station in the general region of Mount Weather, for the first week of August. The average ordinate value for this week is first obtained from Kimball's graph. For periods as short as a week or two this may be done by averaging the values for the first and last days of the period, since the curve may be taken as a straight line for such short intervals. The ordinate values for August 1 and August 7 are - - and - _ and their average is ——. From the report of the weather observer at the place in question, the number of clear, partly cloudy, and cloudy days is next determined for the days August 1 to August 7 , inclusive, and some arbitrary weighting is given to each kind of day. This was done in the present instance by regarding days reported "clear" as days of full sunshine, those reported "partly cloudy" as half days of sunshine, and those reported "cloudy" as without any sunshine. The same scheme of weighting must of course be adhered to in all the estimates used for comparative purposes in any discussion. Suppose there were 2 clear days, 3 halfcloudy days and 2 cloudy days. By summing these values as 2, 1.5 and 0 , we obtain 3.5, representing the equivalent number of wholly clear days for the period considered. Now, 3.5 is 0.5 of the total number of days in the week period, and the latter value may be termed "the coefficient of clear weather." By multiplying the average daily intensity value for clear days, - - (obtained by the use of Kimball's graph) by this coefficient of clear weather (0.5) we obtain — g.-cal. as a rough approximation of the average daily sunshine index for the week.

While it is certain that solar radiation affects plants in other ways than through its heating effect, it is no less certain that by far the greater part of the energy of sunshine absorbed by plants is converted into heat (largely as latent heat of vaporization of water), and it seems probable that the other effects produced upon the plant may be more or less proportional to the total

1 ${ }^{16}$ Kimball, Herbert $H$. The total radiation received on a horizontal surface from the sun and sky at Mount Weather. Monthly Weather Rev. 42: 474-487, 1914. (See especially fig. 8, p. 484.) 
energy equivalent of sunshine. This method of deriving sunshine indices is, however, to be taken only as a rough approximation.

For each 2-week and for each 4 -week period of this study an index of sunshine intensity was secured in the manner just described, and each of these sunshine values was expressed in terms of the average of all values in the series. The relative values thus obtained are quite parallel with the other relative values already referred to. They are given in the tables of data and the actual values may be obtained from them in a manner like that described for the plant values. The general unit used in expressing these relative light values (the average daily sunshine intensity for all stations and for all periods) is 442 gram-calories per square centimeter of horizontal surface.

\section{EVAPORATION}

The evaporating power of the air was measured as has been said, by means of standardized cylindrical porous-cup atmometers, located so as to have about the same exposure as the plant cultures. The instruments were read at intervals of about two weeks, the dates of reading being the same as those on which observations were made on the plants. After every reading each atmometer cup was removed and replaced by another that had just been standardized. The used cup was subsequently restandardized so as to detect any change in the coefficient of the cup consequent upon its exposure. When the restandardization showed a change in the coefficient, the mean of the original coefficient and the coefficient found upon restandardization was employed to reduce the reading to the Livingston cylindrical standard. The evaporation readings should therefore be directly comparable to other measurements related to the same standard,

As has been pointed out by Livingston, ${ }^{17}$ the porous-cup atmometer is somewhat similar to plant foliage in the way in which its evaporating surface is exposed to the surroundings. It may therefore be supposed that the transpiration from the plants for any period should be approximately proportional to the evaporation from the atmometer, except in so far as the transpiration rates may be influenced by conditions within the plant. The work of Briggs and Shantz indicates that evaporation from small open pans or porous cups is influenced by the same external conditions, and in about the same way, as is plant transpiration, if the comparison is made for periods of a day or more. Of course the two rates do not vary proportionally within the day period, since the internal conditions of the plant exhibit a peculiar daily march, but with such details this study does not need to deal. It has becn supposed, therefore, that the effectiveness of the external conditions to influence the transpiration rates of the plants of this study was approxi-

17 Livingston, B. E. The relation of desert plants to soil moisture and to evaporation. Carnegie Inst. Wash. Pub. 50. 1906. 
mately measured by the corresponding correeted evaporation rates from the atmometer. The atmometer readings have been reduced, in every case, to mean daily rates for the 2 -week and 4 -week periods, and these iates have been taken as indices of the evaporating power of the air as it affected transpiration from the plants. Finally, all atmometrie values have been expressed relatively, in terms of the general average for all stations and for all periods, as in the case of the other data. The general average used as unity for these relative atmometric values is 16.2 cc. per day.

The three derived climatic values in this study may be brought together here, for convenience. The list applies to the 2 -week as well as to the 3 -week series of data.

(1) Temperature. Relative daily mean of the physiological-summation indices for the period.

(2) Light. Relative daily mean of calculated light-intensity values for the period, gram-calories per square centimeter of horizontal surface.

(3) Evaporation. Relative daily mean of atmometric indices for the period, cubic centimeter's of loss from the Livingston standard cylindrieal porous cup.

\section{RESULTS AND DISCUSSION}

\section{INTRODUCTORY}

The discussion of the data obtained in this study will be devoted in part to descriptions of the growth changes observed in the plants at the various stations, and for the various periods at each station, and in part to corresponcling descriptions of the elimatic values. Owing to the complexity of the problem and to the number and variety of the data to be dealt with, it has been found necessary to depart frequently from a general logical order and to treat matters that seem to be of seondary importance at greater length than might appear necessary from a more restricted point of view. Such physiological interpretations as are attempted in the course of the presentation of the data are of interest partly for their own sake, but more particularly because of the bearing they may have on the general problem of the use of standard plants for the comparative integration of effective climatic complexes. The work here reported was planned primarily to make a first trial in the use of standard plants in this way. The discussion of the data will be presented more in the form of a running narrative, with digressions at many points, than is ideally desirable, but the newness of this lind of study and the fact that the fundamental prineiples and even the terms to be employed have yet to be developed, make anything approaehing a true logical sequence quite impossible now.

The various kinds of data to be considered will be brought forward in groups corresponding to their sources. The 2-week plant data and the 2-week cli- 
matic data for the stations in the open will first be presented, followed by a presentation of the 4 -week plant and climatic data for these stations. Subsequently, a special discussion of the data for the covered stations and a similar treatment of the data for the forest station at Baltimore will be given.

The relative numbers, or indices, derived as described above, are given in tables I to VIII, together with the dates of the first and last days of each culture period and other information, including the length of each period. the number of plants in each culture, etc. Also, a set of figures is presented showing graphically certain parts of the information given in the tables. Tables I to VIII give twenty-six sets of data. Nine of these sets (tables IIII) contain the plant and elimatic measurements for the 2-week culture periods for the exposed stations, nine others (tables IV-VI) give the data for the four-week culture periods for the exposed stations, six others (tables VIIVIII) give the data for the 2- and 4-week culture periods for the covered stations at Oakland, Baltimore and Easton, and the two remaining (table VIII) give the data for the 2- and 4-week culture periods for the Baltimore forest station.

In each of the eight tables just mentioned, the first line gives the name of the place referred to, the kind of culture period (whether 2- or 4-week), the character of the exposure of the plants (whether the station is exposed, covered, or forest, and the dates of the beginning and end of each culture period. The second line of each table gives the serial culture numbers. These numbers being assigned to the various cultures for convenience of reference. When several kinds of stations occur at one place, cultures of the same number cover approximately the same time period. For instance, for Baltimore there is an exposed station, a covered station, and a forest station, and there is a 2-week culture " 8 " for each of these three stations, the dates for each of these being August 20 and September 3 . In some cases, culture periods of the same number for the exposed and covered stations show a difference of a day in the lengths of their respective periods owing to the fact that it was impossible to take measurements on both the exposed and covered plants on the same day. The third line of each table gives the length of each culture period, in days. The fourth line gives the number of plants actually used in obtaining the plant measurements. A dash appearing in place of a relative value indicates that the data necessary for calculating this value are lacking. An asterisk placed opposite a.climatic index value shows that this particular value was not plotted in the graphs (to be described later). (Points are omitted from the climatic graphs in the case of most cultures where no plant data are available for comparison with the climatic values.) The remainder of the table presents the relative plant and climatic values, the derivation of which has already been made clear. The last column of each of the tables gives the seasonal averages for the station considered. 
TABLE I

T'wo-week data for exposed stations, Oakland, Chewsville and Monrovia

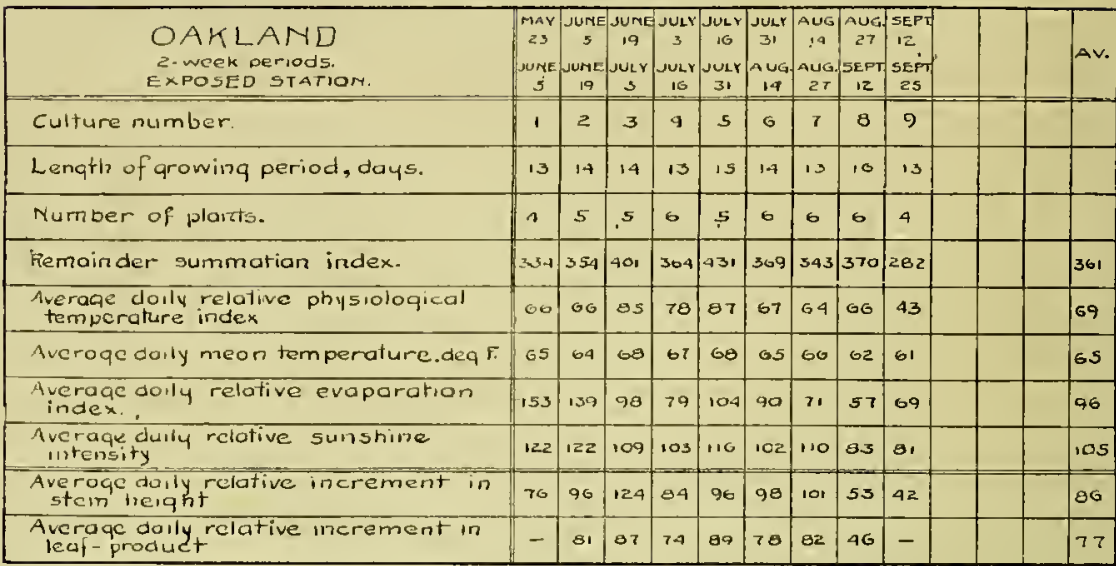

\begin{tabular}{|c|c|c|c|c|c|c|c|c|c|c|c|c|}
\hline $\begin{array}{l}\text { CHE WSVILLE } \\
\text { 2-ween periodS. } \\
\text { EXPOSED STATION }\end{array}$ & $\begin{array}{c}\text { MAY } \\
19 \\
\text { JUNE. } \\
2\end{array}$ & $\begin{array}{c}\text { JUNE } \\
2 \\
\text { JUEE } \\
16\end{array}$ & $\begin{array}{l}\text { JUME } \\
16 \\
\text { JUME } \\
30\end{array}$ & $\begin{array}{l}\text { Jume } \\
30 \\
30 \mathrm{~L} \\
14\end{array}$ & $\begin{array}{c}J U L Y \\
14 \\
\text { JULY } \\
28\end{array}$ & $\begin{array}{c}\text { JULY } \\
29 \\
\text { AUG. } \\
11\end{array}$ & $\begin{array}{c}\text { AUG. } \\
\text { iI } \\
\text { AUG. } \\
25\end{array}$ & $\begin{array}{c}A \cup G . \\
25 \\
5 E P C \\
0\end{array}$ & $\begin{array}{c}\text { SEPT } \\
9 \\
5 E P T \\
Z 2\end{array}$ & $\begin{array}{l}\text { SEPT } \\
22 \\
\text { OCT } \\
\end{array}$ & $\begin{array}{c}\text { OCT. } \\
7 \\
\text { OCT. } \\
20\end{array}$ & Av \\
\hline Culture number: & 1 & ᄅ & 3 & 4 & 5 & 0 & 7 & $\theta$ & 9 & 10 & 11 & \\
\hline Length of grownig period, duys & 14 & 14 & 14 & 14 & 14 & 14 & 14 & 14 & 14 & 15 & 13 & \\
\hline Number of plants & 6 & o & $\rightarrow$ & 6 & 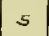 & 4 & 3 & $s$ & 6 & 6 & $\Theta$ & \\
\hline Femainder summation index. & 416 & +43 & 472 & 4.53 & $5 \geq 3$ & 450 & 517 & 436 & 302 & 328 & 301 & 422 \\
\hline $\begin{array}{l}\text { Average doily rclative physiological } \\
\text { temperature index. }\end{array}$ & 92 & 106 & 119 & $\| 12$ & 149 & $\because 2$ & 195 & 103 & 48 & 51 & 53 & 98 \\
\hline Averaqe doily mean temperature, deq F & 6.9 & 71 & 73 & 71 & 76 & 7 & 76 & 70 & 61 & GI & 02 & 69 \\
\hline $\begin{array}{l}\text { Averaqc doily relative evoparation } \\
\text { index. }\end{array}$ & 110 & 115 & 107 & 75 & 108 & 87 & 105 & 80 & 79 & 73 & GA & 91 \\
\hline $\begin{array}{l}\text { Averauc daily relative sunshine } \\
\text { intensity. }\end{array}$ & 121 & 129 & 116 & 106 & 121 & 94 & 98 & 67 & 104 & 73 & 44 & 98 \\
\hline $\begin{array}{l}\text { Averacje doily relative increment in } \\
\text { stem height. }\end{array}$ & 93 & 93 & 149 & 112 & 126 & 98 & 98 & 76 & $4 \theta$ & 37 & 37 & 87 \\
\hline $\begin{array}{l}\text { Averaqe daily relative increment in } \\
\text { leat-product. }\end{array}$ & 104 & 110 & 137 & 90 & 139 & 127 & 100 & 52 & 32 & 20 & 4 & $B A$ \\
\hline
\end{tabular}

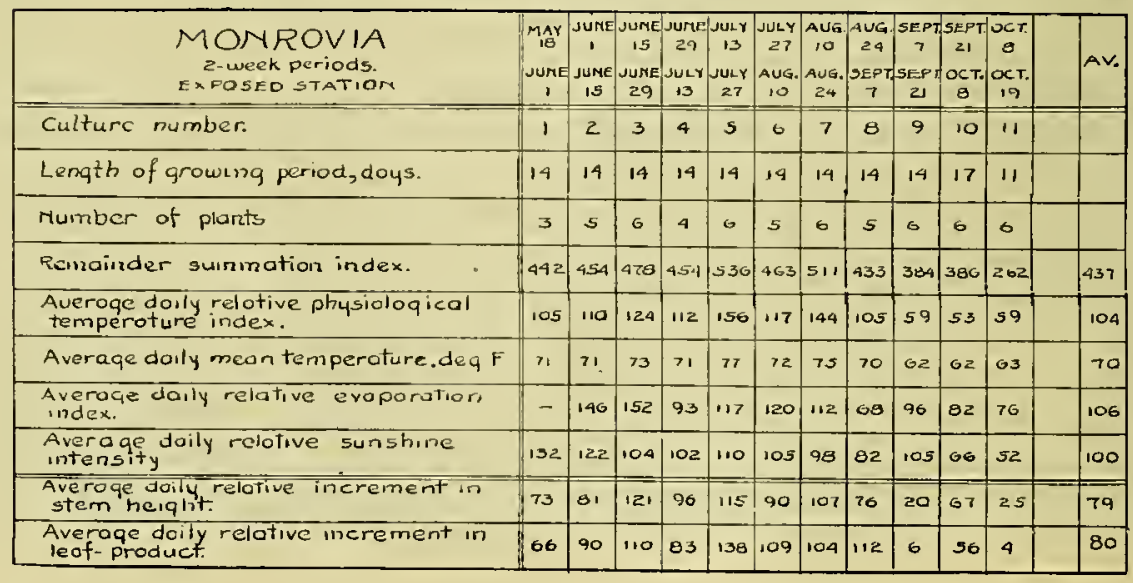


TABLE II

Two-week data for exposed stations, College, Baltimore and Darlington

\begin{tabular}{|c|c|c|c|c|c|c|c|c|c|c|c|c|}
\hline $\begin{array}{l}\text { COLLEGE } \\
\text { E-ween periods } \\
\text { EXPOSED STATION. }\end{array}$ & $\begin{array}{c}-110 \\
33 \\
\text { Jung } \\
6\end{array}$ & $\begin{array}{c}\text { JUME. } \\
0 \\
\text { JUNE } \\
17\end{array}$ & $\begin{array}{c}\text { JUnr } \\
14 \\
\text { JULY } \\
3\end{array}$ & $\left|\begin{array}{c}3441 \\
3 \\
\text { uLr } \\
17\end{array}\right|$ & $\begin{array}{c}\text { JULY } \\
17 \\
\text { JULY } \\
31\end{array}$ & $\begin{array}{c}\text { JULY } \\
31 \\
\text { AUG. } \\
\text { IA }\end{array}$ & $\begin{array}{c}\text { Aug } \\
1 \cdot 1 \\
\text { AuG. } \\
27 \\
27\end{array}$ & $\begin{array}{c}\text { AUG } \\
27 \\
3256 \\
10 \\
\end{array}$ & $\mid \begin{array}{c}35 \\
356 t \\
101 \\
34,1\end{array}$ & 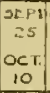 & $\mid \begin{array}{c}00 \pi \\
10 \\
00 \pi \\
2.1\end{array}$ & AV. \\
\hline culture number. & 2 & 3 & 4 & 5 & 6 & 7 & 3 & 9 & 10 & 11 & 12 & \\
\hline Length of qrowing period. days. & 19 & is & 14 & 14 & 19 & 14 & 13 & 19 & 15 & 15 & 14 & \\
\hline Numiber of ploits. & 6 & 5 & 5 & 6 & 4 & 4 & 5 & 6 & - & 6 & $\Leftrightarrow$ & \\
\hline Renzeinder sunzmzotion index. & 546 & .101 & 326 & 444 & 520 & 194 & $128 \mid$ & १49 & 376 & $3 \leq 5$ & 327 & 450 \\
\hline $\begin{array}{l}\text { Average daily relotive physioloqieal } \\
\text { temperature index. }\end{array}$ & 100 & 103 & 157 & 134 & 148 & 133 & 143 & 115 & 67 & so & 53 & 108 \\
\hline Averaqe daly mean temperatune, deq. & וד & 70 & 76 & 14 & 76 & 74 & T6 & TI & 84 & Gi & .2 & 70 \\
\hline $\begin{array}{l}\text { Averaqe daily relative evaparution } \\
\text { inden. }\end{array}$ & 160 & 154 & 123 & 90 & 1.73 & 147 & 105 & 107 & 78 & 34 & ez & 119 \\
\hline $\begin{array}{l}\text { Average daily relative sunshine } \\
\text { intensity. }\end{array}$ & - & - & - & - & - & - & $n$ & - & - & . & - & \\
\hline $\begin{array}{l}\text { Averagc auily relalive increment in } \\
\text { stem heiqht. }\end{array}$ & 93 & 132 & 119 & 118 & 124 & 118 & 90 & 76 & - & 48 & 33 & 95 \\
\hline $\begin{array}{l}\text { Averaqe daily relative increment in } \\
\text { leof-product. }\end{array}$ & 96 & 123 & 81 & 152 & 203 & 1.50 & 117 & 62 & $\rightarrow$ & 13 & 10 & 101 \\
\hline
\end{tabular}

\begin{tabular}{|c|c|c|c|c|c|c|c|c|c|c|c|c|}
\hline $\begin{array}{l}\text { BALTIMORE } \\
\text { Z-wCE PERIOAS. } \\
\text { EPOSED STATION. }\end{array}$ & $\mid \begin{array}{c}\operatorname{mar} \\
14 \\
\operatorname{mar} \\
29\end{array}$ & $\begin{array}{c}\text { MAY } \\
29 \\
\text { VUNE } \\
10 \\
\end{array}$ & $=\mid \begin{array}{c}\text { UUNE } \\
10 \\
\text { JUNE } \\
\text { ZS }\end{array}$ & $\begin{array}{c}\text { UUNF } \\
\text { 2S } \\
\text { JULY } \\
9\end{array}$ & \begin{tabular}{|c|}
$\mathrm{JULY}$ \\
9 \\
$\mathrm{JULY}$ \\
23
\end{tabular} & \begin{tabular}{|c|} 
JULY \\
23 \\
AUG \\
6
\end{tabular} & $\begin{array}{c}\text { AUG } \\
G \\
\text { AUG. } \\
20\end{array}$ & $\begin{array}{c}\text { Aug } \\
20 \\
\text { SEPT } \\
3\end{array}$ & {$\left[\begin{array}{c}\text { SEPT } \\
3 \\
\text { SEFT } \\
\text { 19 }\end{array}\right.$} & $\begin{array}{c}\text { SEPT } \\
19 \\
\text { OCT. }\end{array}$ & $\begin{array}{c}0, T \\
1 \\
0 \in T \\
1-1\end{array}$ & Av. \\
\hline Culture number. & 1 & 2 & 3 & 4 & 5 & $G$ & 7 & $B$ & c) & 10 & 11 & \\
\hline Lenuth of yrowizg period, days & is & 12 & 15 & 19 & 14 & 14 & 14 & 14 & 10 & 12 & 13 & \\
\hline Number of piuizts. & 5 & - & 5 & 6 & 6 & 4 & 5 & $s$ & 0 & 5 & $s$ & \\
\hline Remainder summation index. & $15 i$ & 370 & $50 B$ & 489 & 540 & 500 & 5as & 502 & 545 & 300 & 37.7 & 448 \\
\hline $\begin{array}{l}\text { Average daily relotive plyssiolouicol } \\
\text { temperature mdex. }\end{array}$ & 91 & 49 & 123 & $12 s$ & 162 & 190 & 160 & 139 & 62 & 67 & $\left\{\begin{array}{lll}0 \\
03\end{array}\right.$ & 116 \\
\hline Average dolly mean temperuture, deq f: & 69 & 70 & 73 & 7.3 & 70 & 75 & 70 & 75 & 64 & 64 & 04 & 72 \\
\hline $\begin{array}{l}\text { Averaqe daily relutive evaporution } \\
\text { intex. }\end{array}$ & 127 & 102 & 115 & ea & 92 & 112 & 110 & a, & 50 & 58 & G.4 & 93 \\
\hline $\begin{array}{l}\text { Averaqu duily relotive sunshim } \\
\text { intensity. }\end{array}$ & 137 & 87 & 108 & 60 & ay & 72 & 79 . & -14 & $\theta \geq$ & 89 & 54 & 90 \\
\hline $\begin{array}{l}\text { Avcragc duily relative } 117 \text { ercment in } \\
\text { stem height. }\end{array}$ & 93 & - & 196 & 152 & 183 & 152 & 152 & 149 & 73 & 56 & 90 & 125 \\
\hline $\begin{array}{l}\text { Averuqe daily relative increinent in } \\
\text { teot-product. }\end{array}$ & 100 & - & 125 & 163 & 194 & 110 & 233 & 130 & 54 & 22 & 49 & 119 \\
\hline
\end{tabular}

\begin{tabular}{|c|c|c|c|c|c|c|c|c|c|c|c|c|}
\hline $\begin{array}{l}\text { DARLINGTON } \\
\text { E-weEh pariads. } \\
\text { EXPOSED STATION }\end{array}$ & $\begin{array}{c}\text { MAY } \\
15 \\
\text { MAY } \\
30\end{array}$ & $\begin{array}{c}\text { MAY } \\
\text { 3O } \\
\text { JUNE } \\
13 \\
\end{array}$ & $\begin{array}{c}\text { HUNE } \\
13 \\
\text { JUNE } \\
26 \\
\end{array}$ & $\begin{array}{c}\text { JUME } \\
20 \\
\text { JULY } \\
10 \\
\end{array}$ & $\begin{array}{c}j u L r \\
10 \\
\text { JuLr } \\
24 \\
\end{array}$ & $\begin{array}{c}\text { JULY } \\
24 \\
\text { AUG } \\
7 \\
\end{array}$ & $\begin{array}{c}\text { AUE } \\
7 \\
\text { AUG } \\
21\end{array}$ & $\begin{array}{c}\text { AUG } \\
21 \\
\text { SEPT: } \\
-7\end{array}$ & $\begin{array}{c}\text { SEP } \\
4 \\
\text { SFPT } \\
18\end{array}$ & $\begin{array}{c}5 E \mathrm{TT} \\
19 \\
\mathrm{OCT} \\
2 \\
\end{array}$ & $\begin{array}{c}20 \mathrm{TC} \\
\mathrm{OCT} \\
10\end{array}$ & Av. \\
\hline Culture number. & 1 & 2 & 3 & 4 & 5 & 0 & r & 9 & 9 & 10 & 11 & \\
\hline Lenath of growna period, days. & 15 & 14 & 13 & 14 & $1-7$ & 19 & 19 & 14 & 14 & 14 & 14 & \\
\hline Number of plants. & 6 & 5 & 6 & 4 & 5 & 5 & - & 5 & 5 & 5 & 4 & \\
\hline Renzinder sumurzotionz irzdex. & 430 & 432 & 392 & 432 & 512 & nst & 500 & 472 & 309 & 315 & 338 & 416 \\
\hline $\begin{array}{l}\text { Averaqe doily relative physioloqicol } \\
\text { temperature index. }\end{array}$ & a & 99 & 94 & 99 & 149 & 113 & 196 & 123 & 45 & 59 & 5.7 & 97 \\
\hline Averaqe daily meon temperature, deq. $F$ & 60 & 70 & 39 & 70 & 26 & 72 & 70 & 73 & 61 & Ge & 03 & 64 \\
\hline $\begin{array}{l}\text { Averoge daily relative evoporation } \\
\text { index. }\end{array}$ & 130 & 125 & 90 & 62 & 74 & 77 & 79 & 6.7 & $a z$ & 89 & 37 & E 7 \\
\hline $\begin{array}{l}\text { Average daily relative sunskine } \\
\text { intensity. }\end{array}$ & 154 & 129 & 92 & 77 & 111 & $\cdots$ & 110 & $7 \theta$ & 98 & 96 & 43 & 100 \\
\hline $\begin{array}{l}\text { Average daily relative increment in } \\
\text { stem heiqh? }\end{array}$ & ina & 104 & 1.96 & 1.71 & 229 & 196 & - & 107 & +12 & -18. & 54 & 113 \\
\hline $\begin{array}{l}\text { Average doily relotive increment in } \\
\text { leaf-praduct. }\end{array}$ & 135 & 129 & iss & 115 & 29.5 & 1.48 & - & 108 & 29 & $7 s$ & $\because$ & ine \\
\hline
\end{tabular}




\section{TABLE III}

Two-week data for exposed stations, Coleman, Easton and Princess Anne

\begin{tabular}{|c|c|c|c|c|c|c|c|c|c|c|c|c|c|}
\hline $\begin{array}{l}\text { COLEMAN } \\
\text { 2-Week pOriodS. } \\
\text { EXFOSED STATIOM. }\end{array}$ & $\begin{array}{c}\text { MAY } \\
13 \\
\text { MAY } \\
28 \\
\end{array}$ & $\begin{array}{c}\text { MAV } \\
29 \\
\text { JUNE } \\
11 \\
\end{array}$ & $=\mid \begin{array}{c}\text { JUME } \\
11 \\
\text { JuRE } \\
24\end{array}$ & $\begin{array}{c}\text { JUNE } \\
24 \\
\text { JULY } \\
\mathbf{a} \\
\end{array}$ & $\begin{array}{c}5.5 \\
\text { Jutit } \\
\\
\text { Juit }\end{array}$ & $\begin{array}{c}\text { JULY } \\
22 \\
\text { AUG. } \\
5\end{array}$ & $\begin{array}{c}A \mathrm{Ka} \\
5 \\
\text { A UG } \\
19\end{array}$ & $\begin{array}{c}\text { AUG } \\
19 \\
\text { SEPT } \\
\end{array}$ & $\begin{array}{c}\text { SEPT } \\
2 \\
\operatorname{sePT} \\
16\end{array}$ & $\mid \begin{array}{c}\text { SEPT: } \\
16 \\
\text { SEPT } \\
30\end{array}$ & $\begin{array}{c}35 \mathrm{FT} \\
30 \\
0<\mathrm{T} \\
13\end{array}$ & $\mid \begin{array}{c}0, \pi \\
13 \\
0<\pi \\
2 \theta\end{array}$ & Av. \\
\hline culture number. & 1 & 2 & 3 & 4 & 5 & 0 & 7 & $\theta$ & 9 & 10 & 11 & 12 & \\
\hline Leizgth of grawing peric & 15 & 14 & 13 & 14 & 14 & 19 & 19 & 14 & 14 & 14 & 13 & 15 & \\
\hline Mumberc of plunts. & 6 & 6. & 4 & 4 & 0 & 6 & 5 & 0 & 4 & 4 & 4 & 6 & \\
\hline Renainder sunmation index. & 412 & 406 & 433 & $48 B$ & 560 & 5,7 & 530 & $52 a$ & 390 & 599 & - & - & 472 \\
\hline $\begin{array}{l}\text { Average daily relative physioloqicol } \\
\text { temperature index. }\end{array}$ & B1 & 113 & 118 & 130 & 170 & 145 & 158 & 198 & 84 & 85 & - & - & 123 \\
\hline Averaqe daily mean temperature, deq. F. & 60 & 72 & 67 & 74 & 79 & 76 & 77 & 70 & 67 & 67 & - & - & 72 \\
\hline $\begin{array}{l}\text { Average daily relative evaporation } \\
\text { 112dex. }\end{array}$ & 139 & 1.52 & 137 & $1 \geq 0$ & 193 & 155 & 119 & 96 & 132 & 135 & 27 & 93 & 127 \\
\hline $\begin{array}{l}\text { Average daily relative sunshine } \\
\text { liztensity. }\end{array}$ & 142 & 150 & 125 & 61 & 141 & 124 & 118 & 85 & - & - & - & - & $12 a$ \\
\hline $\begin{array}{l}\text { Averuge da!ly relative increment in } \\
\text { stem? height. }\end{array}$ & 79 & BT & 107 & 135 & 149 & 157 & 121 & 107 & 62 & 53 & 67 & $2 \theta$ & 96 \\
\hline $\begin{array}{l}\text { Averoge daily relative incroment in } \\
\text { leaf-product. }\end{array}$ & 100. & 111 & 97 & 172 & 211 & 198 & 138 & 110 & 38 & 53 & 38 & 4 & 107 \\
\hline
\end{tabular}

\begin{tabular}{|c|c|c|c|c|c|c|c|c|c|c|c|c|c|}
\hline $\begin{array}{l}\text { EASTON } \\
\text { 2-week periods. } \\
\text { EXPOSED STATIOM }\end{array}$ & $\begin{array}{c}\operatorname{MAR} \\
8 \\
\operatorname{Mar} \\
25 \\
\end{array}$ & $\begin{array}{c}\text { MAY } \\
\text { ES } \\
\text { JUNE } \\
8\end{array}$ & $\begin{array}{c}\text { JUNE } \\
\text { a } \\
\text { JUNE } \\
22 \\
\end{array}$ & $\begin{array}{c}\text { Jure } \\
2 Z \\
\text { JuLY } \\
6 \\
\end{array}$ & $\begin{array}{c}\text { JuLr } \\
\text { G } \\
\text { JuLr } \\
3 a\end{array}$ & $\begin{array}{c}\text { JWLY } \\
20 \\
\text { AUG } \\
3\end{array}$ & \begin{tabular}{|c|} 
AUG \\
3 \\
AUG \\
17 \\
\end{tabular} & $\begin{array}{c}\text { AuG } \\
17 \\
\text { Aug } \\
31\end{array}$ & $\begin{array}{c}\text { AUG } \\
31 \\
\text { SEPT } \\
14 \\
\end{array}$ & \begin{tabular}{|c|} 
SEPT \\
14 \\
SEPT \\
28 \\
\end{tabular} & $\begin{array}{c}\text { SEPT } \\
26 \\
\text { OCT } \\
11 \\
\end{array}$ & $\mid \begin{array}{c}O C T \\
11 \\
O C r \\
20\end{array}$ & Av. \\
\hline Eulture number & 1 & 2 & 3 & 4 & 5 & 6 & 7 & 8 & 9 & 10 & 11 & 12 & \\
\hline Lengtliz of growing periad, tays. & 17 & 14 & 14 & 14 & 14 & $1-7$ & 14 & 14 & 14 & 14 & 13 & 15 & \\
\hline Number of plarts. & 6 & 4 & $s$ & $G$ & 4 & 5 & 5 & $s$ & 5 & 6 & $\mathbf{G}$ & 3 & \\
\hline Remoincler sunzmition undex. & 430 & 453. & $4 S r$ & 492 & 532 & 495 & 513 & 519 & 392 & 381 & 326 & 347 & 495 \\
\hline $\begin{array}{l}\text { Average daily relative physialayieal } \\
\text { temperature index }\end{array}$ & 07 & 112 & 160 & 131 & 154 & 133 & 144 & 146 & 87 & 70 & 04 & 40 & 106 \\
\hline Averaqe daly mean temperature, deg. F & 6.5 & 71 & 71 & 74 & 77 & 74 & 76 & 70 & 07 & 66 & 54 & 62 & 71 \\
\hline $\begin{array}{l}\text { Averuge duily relative evaporation } \\
\text { index. }\end{array}$ & 95 & 130 & 133 & 91 & BO & 133 & 128 & 113 & 111 & 104 & $8 \theta$ & $\theta 2$ & 108 \\
\hline $\begin{array}{l}\text { Averciqu daily relative sunsmine } \\
\text { inteirsity. }\end{array}$ & 145 & 172 & 141 & 120 & 124 & 108 & 117 & 99 & 97 & 95 & $\forall 4$ & 52 & 111 \\
\hline $\begin{array}{l}\text { Averuae daily relative increment in } \\
\text { stem heiqht. }\end{array}$ & 43 & B? & 112 & 132 & 1.40 & $1-40$ & 132 & we & $\theta_{1}$ & 45 & 65 & 34 & 95 \\
\hline $\begin{array}{l}\text { Averaye daily relative increment in } \\
\text { leaf-product. }\end{array}$ & 71 & 97 & 112 & 99 & 152 & 130 & 163 & 129 & 64 & 35 & - & - & 195 \\
\hline
\end{tabular}

\begin{tabular}{|c|c|c|c|c|c|c|c|c|c|c|c|c|c|}
\hline $\begin{array}{l}\text { PRIMCESS ANIYE } \\
\text { 2-WEen PERIOAS } \\
\text { EXPOSED STATIUM }\end{array}$ & {$\left[\begin{array}{c}\max \\
11 \\
\max \\
25\end{array}\right.$} & $\begin{array}{c}\operatorname{mar} \\
20 \\
\text { JUNE } \\
0\end{array}$ & $\begin{array}{c}\text { JuTn: } \\
\\
\text { JuME } \\
23\end{array}$ & $\begin{array}{l}\text { JUME } \\
23 \\
\text { JULY } \\
7\end{array}$ & $\begin{array}{c}\mathrm{JULT} \\
7 \\
\mathrm{JULY} \\
\mathrm{LL}_{1}\end{array}$ & $\begin{array}{c}\text { JULY } \\
21 \\
\text { AUG. } \\
4\end{array}$ & $\begin{array}{c}\text { AUG } \\
4 \\
\text { A } \\
10\end{array}$ & {$\left[\begin{array}{c}\text { AUG } \\
10 \\
\text { SEPT } \\
1\end{array}\right.$} & $\left\{\begin{array}{c}1 \\
\text { SEPT } \\
15\end{array}\right.$ & $\begin{array}{c}\text { SEFT } \\
15 \\
\text { SEPT } \\
29 \\
\end{array}$ & $\begin{array}{c}3 E P \\
29 \\
0 \subset T \\
12\end{array}$ & $\begin{array}{c}\infty \pi \\
12 \\
00 T \\
27\end{array}$ & Av. \\
\hline Culture number. & 1 & 2 & 3 & 4 & 5 & $G$ & 7 & $\theta$ & 9 & 10 & 11 & 12 & \\
\hline Length of growring period, days. & 15 & 13 & 15 & 19 & 14 & 19 & it & 14 & 14 & 17 & 13 & is & \\
\hline Number of plants. & 6 & 5 & $\infty$ & 6 & 6 & 0 & 3 & 6 & 6 & 5 & 5 & 4 & \\
\hline Romainter Summation irzdex. & 358 & 405 & 504 & 493 & 514 & 483 & 5,3 & 520 & 387 & 363 & 315 & 328 & 432 \\
\hline $\begin{array}{l}\text { Average daily relotive physiological } \\
\text { temporature index. }\end{array}$ & 59 & 103 & 101 & 132 & 1.94 & 120 & 194 & 146 & 94 & 71 & 60 & +5 & (a) \\
\hline Average daily incan temperuture, deq.F. & $\omega$ & 70 & 75 & 74 & 70 & 74 & 70 & ing & 07 & 65 & 63 & 61 & 70 \\
\hline $\begin{array}{l}\text { Averaqe duily relative evaporation, } \\
\text { index }\end{array}$ & 117 & 134 & - & - & .03 & Bs & 101 & 79 & 73 & 79 & 70 & 39 & 84 \\
\hline $\begin{array}{l}\text { Averaye daily relative sunshine } \\
\text { intensity. }\end{array}$ & 107 & 118 & 103 & $\theta 5$ & $S B$ & 90 & 75 & 80 & 79 & $\varkappa$ & 57 & 42 & 86 \\
\hline $\begin{array}{l}\text { Average daily relative increment in } \\
\text { stem height: }\end{array}$ & $C 2$ & 110 & 107 & 124 & 197 & $|43|$ & 155 & 121 & 79 & $65^{\circ}$ & 53 & 45 & 106 \\
\hline $\begin{array}{l}\text { Average doily relotive increment in } \\
\text { leaf-product. }\end{array}$ & 90 & 116 & 104 & 115 & 163 & .102 & .77 & 138 & 82 & 34 & 18 & 6 & 96 \\
\hline
\end{tabular}


TABLE IV

Four-week data for exposed stations, Oakland, Chewsville and Monrovia

\begin{tabular}{|c|c|c|c|c|c|c|c|c|c|c|c|c|}
\hline $\begin{array}{l}\text { OAKLAND } \\
\text { 4-week periods } \\
\text { EXPOSED STATION }\end{array}$ & $\begin{array}{c}\text { Mar } \\
23 \\
\text { jured } \\
19\end{array}$ & $\begin{array}{c}\text { June } \\
5 \\
\text { suLr } \\
3\end{array}$ & $=\begin{array}{c}3 U T E \\
19 \\
\text { JULr } \\
16\end{array}$ & $\begin{array}{c}\text { JULY } \\
3 \\
3 \\
31\end{array}$ & $\begin{array}{c}\text { JuLY } \\
16 \\
\text { Aug } \\
14\end{array}$ & $\left\{\begin{array}{c}J U L Y \\
31 \\
A \cup G \\
27\end{array}\right.$ & $\mid \begin{array}{c}\text { Aug } \\
\text { SEP } \\
12\end{array}$ & $\mid \begin{array}{c}A \cup G \\
27 \\
S E P T \\
25\end{array}$ & & & & Av- \\
\hline culture number. & 1 & $z$ & 3 & 4 & 5 & 0 & 7 & 8 & & & & \\
\hline Length of qrowirg period, days. & 27 & 28 & 27 & $2 \theta$ & 29 & 27 & 29 & 29 & & & & \\
\hline Nuniber of plonts. & 4 & 5 & 5 & 6 & 5 & 6 & 6 & 6 & & & & \\
\hline Remoinder summation index. & Ga3 & 755 & 765 & 795 & 800 & 713 & 714 & 652 & & & & 73.5 \\
\hline $\begin{array}{l}\text { Ave, age daily relative physiologicol } \\
\text { tcmperature index. }\end{array}$ & 66 & 76 & $a z$ & 83 & 77 & 66 & os & $5 s$ & & & & 71 \\
\hline Average daily mean temperature.uleq.F & 63 & 60 & 61 & 67. & क7 & 65 & 64 & 62 & & & & 65 \\
\hline $\begin{array}{l}\text { Average duily relative evaporalion } \\
\text { index. }\end{array}$ & 196 & 119 & 89 & 92 & 97 & ei & G4 & 63 & & & & 94 \\
\hline $\begin{array}{l}\text { Averuqc daily relative sunshine } \\
\text { intensity. }\end{array}$ & $1 \geq 2$ & 116 & 10 & 110 & 109 & 100 & 97 & 82 & & & & 106 \\
\hline $\begin{array}{l}\text { Average doily relative inciement in } \\
\text { stem heiqht. }\end{array}$ & 66 & 78 & 94 & 69 & 72 & 81 & 63 & 47 & & & & $x_{1}$ \\
\hline $\begin{array}{l}\text { Average daily relative increment in } \\
\text { leaf area. }\end{array}$ & 41 & 67 & 91 & 75 & eo & 90 & 72 & 52 & & & & 71 \\
\hline $\begin{array}{l}\text { Average daily relative lizerement in } \\
\text { dry weight. }\end{array}$ & 51 & 97 & 103 & 63 & 86 & 83 & 70 & 46 & & & & 79 \\
\hline $\begin{array}{l}\text { CMEWSVILLE } \\
\text { A-WEeK periods. } \\
\text { EXPOSED STATION. }\end{array}$ & $\begin{array}{c}\text { MAY } \\
19 \\
\text { JUTE } \\
16 \\
\end{array}$ & $\begin{array}{c}\text { JUNE } \\
2 \\
\text { JURE } \\
30 \\
\end{array}$ & $\begin{array}{c}\text { JuME } \\
16 \\
\text { juir } \\
14 \\
\end{array}$ & $\begin{array}{c}\text { JuNE } \\
30 \\
\text { JuLY } \\
28 \\
\end{array}$ & \begin{tabular}{|c|}
$3 U 1 Y$ \\
14 \\
AUS \\
11 \\
\end{tabular} & $\begin{array}{r}\text { JULY } \\
28 \\
\text { AUG } \\
2.5 \\
\end{array}$ & $\begin{array}{c}A \cup G \\
11 \\
S E P C \\
0\end{array}$ & $\begin{array}{c}A U G \\
25 \\
\text { SEP } \\
22\end{array}$ & $\begin{array}{c}\text { SEP } \\
8 \\
\text { OCT } \\
7 \\
\end{array}$ & $\mid \begin{array}{c}\text { SEPT } \\
22 \\
\text { OCT } \\
20 \\
\end{array}$ & $\begin{array}{c}\text { oct } \\
7 \\
\text { nov } \\
3 \\
\end{array}$ & Av. \\
\hline Culture number. & 1 & 2 & 3 & 4 & 5 & 6 & 7 & 8 & 9 & 10 & 11 & \\
\hline Length of qrowing period, days. & 28 & $2 \theta$ & 20 & $2 \theta$ & 28 & 20 & 20 & 20 & 29 & 20 & 27 & \\
\hline Number of ploizts. & 6 & 6 & $A$ & 6 & 5 & 4 & 3 & 5 & 6 & $G$ & 6 & \\
\hline Remainder swmmotion index & es? & 915 & 925 & 976 & $\mid 973$ & 967 & 753 & 730 & 650 & 629 & 490 & 023 \\
\hline $\begin{array}{l}\text { Average daily relative physioloqioal } \\
\text { Temperature index. }\end{array}$ & 99 & 113 & 116 & 131 & 131 & 129 & 129 & $76 \mid$ & 50 & 52 & 37 & 96 \\
\hline Averaqe dolly meon tenperature, deq. F & 70 & 72 & 72 & 74 & 74 & 74 & 73 & 00 & Gi & 62 & $s \theta$ & 69 \\
\hline $\begin{array}{l}\text { Average daily relative evaporation } \\
\text { index. }\end{array}$ & 113 & 111 & 91 & 92 & 90 & 96 & 93 & Eo & 76 & 69. & 71 & 90 \\
\hline $\begin{array}{l}\text { Average daily relative suizshine } \\
\text { intensity. }\end{array}$ & 125 & 123 & $\because 11$ & 119 & 108 & 96 & 83 & 86 & 89 & 59 & 56 & 9.5 \\
\hline $\begin{array}{l}\text { Averoge doily relative increment in } \\
\text { stem height. }\end{array}$ & 75 & 103 & 122 & 97 & 91 & 84 & 84 & so & 47 & 41 & 31 & 75 \\
\hline $\begin{array}{l}\text { Averoge daily relative increment in } \\
\text { leat area. }\end{array}$ & 73 & 9 & 132 & 03 & 89 & 94 & 99 & 5T & 49 & 45 & 12 & 74 \\
\hline $\begin{array}{l}\text { Averoue dally relative increment in } \\
\text { dry weiglat: }\end{array}$ & 78 & 102 & 142 & eT & 92 & 86 & 86 & $6 z$ & si & $3 \theta$ & 24 & 76 \\
\hline
\end{tabular}

\begin{tabular}{|c|c|c|c|c|c|c|c|c|c|c|c|c|}
\hline $\begin{array}{l}\text { MONROVIA } \\
\text { A wEeM pERIOdS: } \\
\text { EXFOSED STATIOM }\end{array}$ & $\begin{array}{l}\text { MAY } \\
10 \\
\text { une } \\
15\end{array}$ & $\begin{array}{c}\text { JUME } \\
1 \\
\text { JUME } \\
29\end{array}$ & $\begin{array}{c}\text { JUME } \\
1.5 \\
\text { JuLr } \\
13\end{array}$ & $\begin{array}{c}\text { JURE } \\
29 \\
\text { JULY } \\
27\end{array}$ & $\begin{array}{c}J U L Y \\
13 \\
A \cup G \\
10\end{array}$ & $\begin{array}{c}\text { JULY } \\
\cdot 27 \\
\text { AUG } \\
Q 4\end{array}$ & \begin{tabular}{|c|} 
AUG \\
10 \\
SEPT \\
7
\end{tabular} & \begin{tabular}{|c|}
$A \cup G$ \\
$Z 4$ \\
$S E P D$ \\
21
\end{tabular} & $\begin{array}{c}\text { SEPT } \\
7 \\
O C T \\
\theta\end{array}$ & $\begin{array}{c}\text { SEPY } \\
21 \\
\text { OCV } \\
19\end{array}$ & $\begin{array}{c}\text { OCT } \\
0 \\
\text { nor } \\
2\end{array}$ & AV. \\
\hline Culture number & , & $z$ & 3 & 4 & 5 & 6 & 7 & $\theta$ & 9 & 10 & " & \\
\hline Lenath of growing period, days & 28 & $e \theta$ & $\varepsilon B$ & 20 & 28 & 28 & 28 & $2 a$ & 31 & 28 & 25 & \\
\hline Number of plants. & 3 & 5 & G & 4 & 6 & $s$ & 6 & 5 & $G$ & 6 & 0 & \\
\hline Relwander sumnzotion index. & 390 & 232 & 932 & 290 & 997 & 374 & 944 & 8,7 & 270 & 648 & 403 & 651 \\
\hline $\begin{array}{l}\text { Averaqe doily relative physiolagical } \\
\text { temperature index }\end{array}$ & 108 & 117 & ile & 134 & 132 & 131 & 125 & $B 2$ & 56 & 56 & 53 & 102 \\
\hline Averoge dolly meon temperature, degf & 71 & 72 & 72 & 74 & 75 & 74 & 73 & 66 & 62 & 63 & se & 69 \\
\hline $\begin{array}{l}\text { Average dolly relotive evaporation } \\
\text { index }\end{array}$ & - & 149 & 123 & 105 & 119 & 116 & 9० & 82 & 89 & 79 & Q1 & 103 \\
\hline $\begin{array}{l}\text { Averoge daly relotive sunshine } \\
\text { intensity }\end{array}$ & 137 & 113 & 103 & 106 & 100 & 102 & 90 & 94 & 80 & 59 & 58 & 96 \\
\hline $\begin{array}{l}\text { Averaqe daly redative increment in } \\
\text { stem heiqht }\end{array}$ & 63 & 78 & 84 & 84 & 70 & 91 & 84 & 56 & 44 & 41 & $2 \theta$ & 66 \\
\hline $\begin{array}{l}\text { Average dolly relative wenement in } \\
\text { leaf area. }\end{array}$ & 71 & $10 B$ & $8 B$ & 99 & 71 & 104 & 75 & 70 & 39 & 48 & 12 & 71 \\
\hline $\begin{array}{l}\text { Aucroqe daily relative increment in } \\
\text { dry weight? }\end{array}$ & 70 & 119 & .08 & 99 & eq & 105 & 81 & e7 & 41 & 48 & 24 & 79 \\
\hline
\end{tabular}


TABLE V

Four-week data for exposed stations, College, Baltimore and Darlington

\begin{tabular}{|c|c|c|c|c|c|c|c|c|c|c|c|c|}
\hline $\begin{array}{r}\text { COLLEGE } \\
\text { A-week } \\
\text { EXPOSERTIOU. } \\
\end{array}$ & $\mid \begin{array}{c}\operatorname{maY} \\
9 \\
\text { JUME } \\
6\end{array}$ & $=\mid \begin{array}{c}\operatorname{mar} \\
23 \\
\text { Jume } \\
19\end{array}$ & $\mid \begin{array}{c}\text { JURE } \\
6 \\
\text { JULY } \\
3\end{array}$ & $\mid \begin{array}{c}\text { Jure } \\
19 \\
\text { suty } \\
17 \\
\end{array}$ & {$\left[\begin{array}{c}\text { JULY } \\
3 \\
\text { JULY } \\
3\end{array}\right.$} & $\begin{array}{c}\text { JuLr } \\
17 \\
\text { AuG. } \\
19\end{array}$ & $\begin{array}{c}U L Y \\
31 \\
\text { AUG } \\
2 T \\
\end{array}$ & $\begin{array}{c}A U G \\
14 \\
5 E F \\
10 \\
\end{array}$ & $\mid \begin{array}{c}A L G \\
22 \\
\text { SEPT: } \\
25 \\
\end{array}$ & $\begin{array}{c}\text { SEPT } \\
10 \\
\text { OCT } \\
10\end{array}$ & $\mid \begin{array}{c}T E P T \\
25 \\
24 \\
\end{array}$ & Av. \\
\hline Culture number. & 1 & 2 & 3 & 4 & 5 & 6 & 7 & 8 & 9 & 10 & 11 & \\
\hline Length of qrowing period, doys. & $2 \theta$ & 27 & $2 r$ & 20 & $2 \theta$ & 20 & 27 & 27 & 29 & 30 & 29 & \\
\hline Number of plants. & 6 & 6 & 5 & 5 & $\sigma$ & 4 & 4 & $G$ & $G$ & - & 6 & \\
\hline $\begin{array}{l}\text { Remainder summation index. } \\
\text { Average daily relative }\end{array}$ & $\infty 08$ & 950 & asa & 102011 & 1014 & $|1004|$ & 1072 & marit & Bat & 713 & 662 & 902 \\
\hline $\begin{array}{l}\text { Average daily relative physiologicul } \\
\text { tempcrature indax. }\end{array}$ & 88 & 110 & 121 & 137 & 191 & 141 & 130 & 129 & 91 & $59^{*}$ & 52 & 110 \\
\hline $\begin{array}{l}\text { Average doily meun kemperoture, deq. F. } \\
\text { Average dolly relotive evoprotigu }\end{array}$ & G? & 71 & 73 & $7 s$ & 75 & 75 & 75 & 74 & 68 & 63 & 62 & 71 \\
\hline $\begin{array}{l}\text { Averaqe dolly relotive evaporation } \\
\text { index. } \\
\text { Average doily relutive } 34 \text { nstring }\end{array}$ & 169 & 157 & 139 & 110 & 120 & 145 & 141 & 121 & 93 & $8 i^{*}$ & 93 & .124 \\
\hline $\begin{array}{l}\text { Average doily relutive sunstzine } \\
\text { intensity. } \\
\text { Average daily relative }\end{array}$ & - & - & - & - & - & - & - & - & - & - & - & \\
\hline $\begin{array}{l}\text { Average daily relative izerement in } \\
\text { stum heiglat. } \\
\text { Averaqe daily relutive inerement in } \\
\text { leaf area. }\end{array}$ & $4 T$ & 75 & 100 & ופ & 91 & 97 & 103 & 72 & 63 & - & 56 & 80 \\
\hline $\begin{array}{l}\text { Average daily relutive inerement in } \\
\text { leaf arca. } \\
\text { Averaqe dally relutive inerement in } \\
\text { dry weight. }\end{array}$ & 70 & 92 & 125 & $7 \theta$ & 98 & 173 & 209 & 126 & 06 & - & 46 & 110 \\
\hline $\begin{array}{l}\text { Average daly relutive increment in } \\
\text { ury weight. }\end{array}$ & 86 & 110 & 140 & 95 & 119 & 172 & 199 & 132 & 84 & - & si & 119 \\
\hline
\end{tabular}

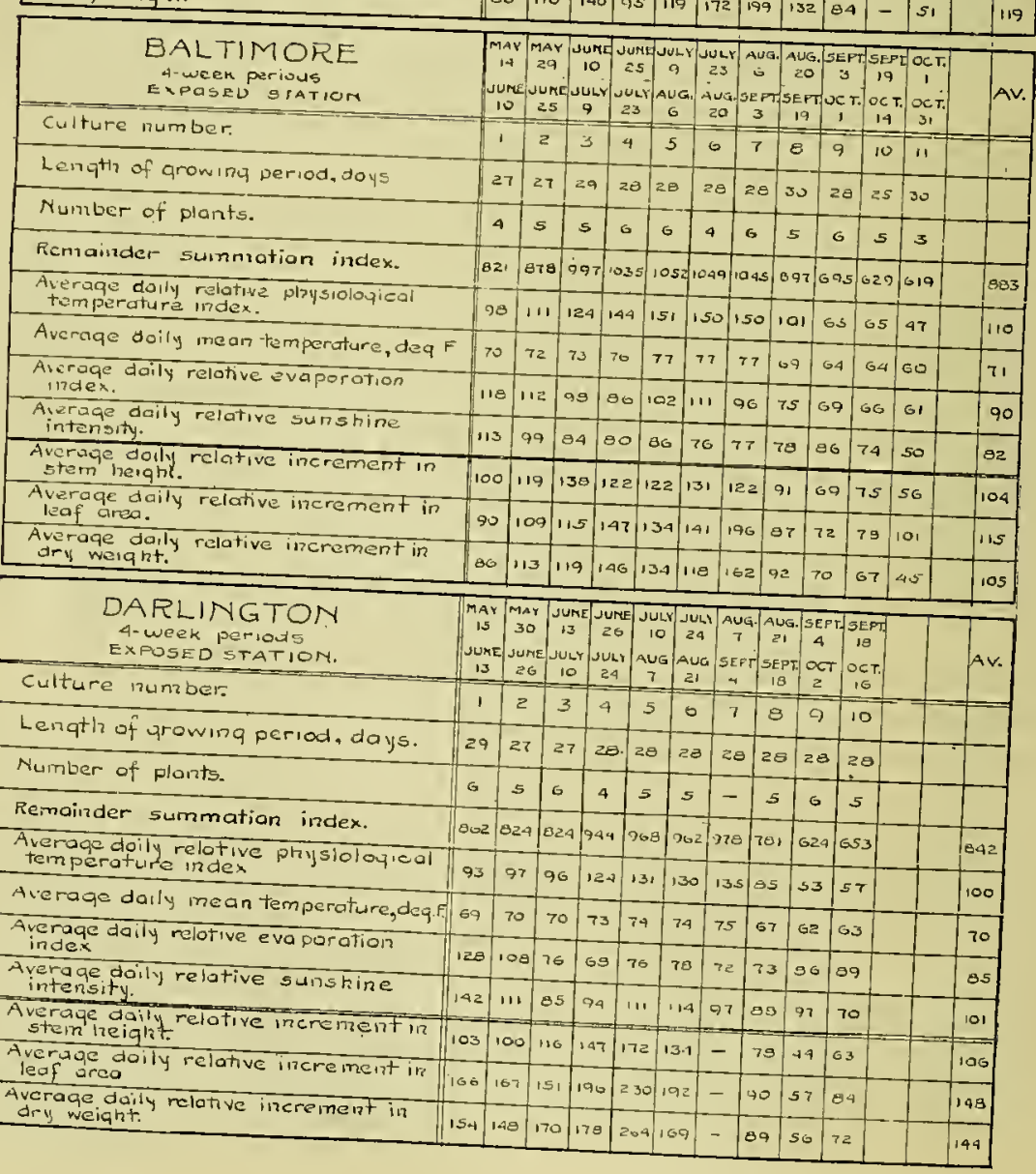


TABLE VI

Four-wcek data for exposed stations, Coleman, Easton and Princess Anne

\begin{tabular}{|c|c|c|c|c|c|c|c|c|c|c|c|c|}
\hline $\begin{array}{l}\text { COLEMAN } \\
\text { 4-Week periods. } \\
\text { EXPOSED STATION. }\end{array}$ & $\begin{array}{c}\text { minr } \\
\text { junc } \\
11 \\
\end{array}$ & $\begin{array}{c}\text { May } \\
28 \\
\text { unt } \\
\text { e. }\end{array}$ & $\begin{array}{c}\text { Junt } \\
11 \\
\text { JuLr } \\
8 \\
\end{array}$ & $\begin{array}{c}\text { SUME } \\
24 \\
\text { JuLY } \\
22\end{array}$ & $\begin{array}{c}\text { JULY } \\
6 \\
\text { AUG } \\
5 \\
\end{array}$ & $\begin{array}{c}2 u 4 r \\
22 \\
\text { Aua } \\
19\end{array}$ & $\begin{array}{c}\text { AUG } \\
5 \\
\text { SEPh } \\
2\end{array}$ & $\begin{array}{l}\text { Aug } \\
19 \\
5 E P \\
16\end{array}$ & $\begin{array}{c}\text { SEPT } \\
2 \\
\text { SEPT } \\
30 \\
\end{array}$ & $\begin{array}{c}\operatorname{seg} \\
16 \\
\alpha \\
13\end{array}$ & $\mid \begin{array}{c}\operatorname{sen} \\
30 \\
\text { oct } \\
20\end{array}$ & $A v$. \\
\hline Culture inumber. & 1 & と & 3 & $A$ & 5 & 6 & 7 & 8 & 9 & 10 & 11 & \\
\hline Length of growing period, days. & 29 & 21 & 27 & 28 & $2 \theta$ & 28 & $2 \theta$ & 20 & za & 27 & 28 & \\
\hline Number of plonts. & G & 6 & 4 & 4 & 6 & $G$ & 5 & S & 5 & 4 & 5 & \\
\hline Remainder summation index. & 078 & $\Delta x$ & 921 & 1048 & 1078 & 1055 & 1058 & 913 & 709 & - & - & 959 \\
\hline $\begin{array}{l}\text { Average daily ralative pizysiological } \\
\text { tempenature index. }\end{array}$ & 97 & 116 & 124 & 150 & 158 & 152 & 1.53 & 116 & 8.5 & - & - & 120 \\
\hline Averoge daily mean temperature, deq. F. & 69 & 70 & 71 & ד ד & 78 & 77 & 77 & 72 & 67 & - & - & 73 \\
\hline $\begin{array}{l}\text { Average daily relotive evoparation } \\
\text { madex. }\end{array}$ & 196 & 1.45 & 129 & 132 & 149 & 137 & 100 & 119 & 13.0 & 116 & 45 & 128 \\
\hline $\begin{array}{l}\text { Average doily relotive subshine } \\
\text { inzteasity. }\end{array}$ & 151 & 143 & 93 & 101 & 133 & 121 & 102 & - & - & - & - & 121 \\
\hline $\begin{array}{l}\text { Averaqc doily relative increnzent in } \\
\text { stew! liziglat. }\end{array}$ & 69 & 01 & 94 & 106 & 100 & 109 & $8-4$ & 72 & 53 & 50 & 53 & 80 \\
\hline $\begin{array}{l}\text { Avenuge daily relative inerciment in } \\
\text { leaf arca. }\end{array}$ & 116 & 150 & 107 & 144 & 135 & 195 & 100 & 89 & 71 & - & 47 & 117 \\
\hline $\begin{array}{l}\text { Average daily relative increment in } \\
\text { ory nalut. }\end{array}$ & 126 & 153 & 159 & 143 & 134 & 148 & 83 & 113 & GT & 25 & 43 & 113 \\
\hline
\end{tabular}

\begin{tabular}{|c|c|c|c|c|c|c|c|c|c|c|c|c|c|}
\hline $\begin{array}{l}\text { EASTON } \\
\text { A-weeh periods. } \\
\text { EApOSEU stATION. }\end{array}$ & {$\left[\begin{array}{c}\text { MAY } \\
8 \\
\text { JNEE } \\
8\end{array}\right]$} & $\begin{array}{c}\text { MAY } \\
25 \\
\text { MNE } \\
22\end{array}$ & $=\begin{array}{c}\text { Junt } \\
8 \\
\text { outr } \\
0\end{array}$ & \begin{tabular}{|c|} 
JUNE \\
$2 Z$ \\
JULY \\
20 \\
\end{tabular} & \begin{tabular}{|c|}
$J U L Y$ \\
6 \\
AUG. \\
3
\end{tabular} & $\begin{array}{c}\text { JULY } \\
20 \\
A U G \\
17\end{array}$ & \begin{tabular}{|c|} 
AuG \\
3 \\
AuG \\
31 \\
\end{tabular} & \begin{tabular}{|c|} 
AUG \\
17 \\
AUG. \\
14
\end{tabular} & \begin{tabular}{|c|}
$A U G$ \\
31 \\
JEPR \\
20 \\
\end{tabular} & $\begin{array}{c}\text { ERT } \\
19 \\
\infty \sigma_{1} \\
11\end{array}$ & $\begin{array}{c}\text { SEP } \\
2 \theta \\
O C r \\
20 \\
\end{array}$ & $\begin{array}{c}a c t \\
11 \\
\text { nov. } \\
6\end{array}$ & Av. \\
\hline Culture number & 1 & 2 & 3 & 4 & 5 & 6 & 7 & 8 & 9 & 10 & 11 & 12 & \\
\hline Length of qrowurg period, doys & 31 & 20 & 28 & 28 & 28 & 28 & $2 \theta$ & $2 \theta$ & 28 & 27 & 20 & 26 & \\
\hline Numiver of plants. & 6 & 4 & 5 & $G$ & 4 & 5 & 5 & $s$ & 5 & 6 & 6 & 3 & \\
\hline Remainder suinmalion index. & $\operatorname{exg}$ & 904 & 943 & 1024 & 1027 & 1008 & 1032 & 911 & 173 & 207 & 673 & $4 m$ & 866 \\
\hline $\begin{array}{l}\text { Average daily relative ploysioloqicol } \\
\text { Temperature index. }\end{array}$ & 90 & 111 & 121 & 143 & 194 & 139 & 145 & 117 & $a_{2}$ & 70 & 56 & 30 & 105 \\
\hline Averaqe daily mean temperature, deq $F$ & 68 & 71 & 73 & 70 & 76 & 75 & 70 & 72 & aर & G5 & 63 & 53 & 10 \\
\hline $\begin{array}{l}\text { Averaqc daily relative evaporation } \\
\text { index. }\end{array}$ & 113 & 132 & na & 80 & 110 & 131 & $|2|$ & 112 & 103 & 90 & as. & 98 & 109 \\
\hline $\begin{array}{l}\text { Averaqc duily relotive sunshine } \\
\text { intensity }\end{array}$ & 159 & 157 & 131 & 122 & 116 & 113 & 108 & 98 & 96 & 80 & so & Go & 100 \\
\hline $\begin{array}{l}\text { Aver uye daily relative increnient in } \\
\text { stem heiqh. }\end{array}$ & 47 & 72 & 91 & 103 & 103 & 1,3 & 103 & 81 & 50 & 50 & 50 & 30 & 75 \\
\hline $\begin{array}{l}\text { Average duily relative increment in } \\
\text { leof area. }\end{array}$ & 74 & 70 & , & 90 & 101 & 121 & 121 & 95 & GG & 64 & 58 & 8 & az \\
\hline $\begin{array}{l}\text { Averaje daily relative increment it } \\
\text { Ary weight. }\end{array}$ & 80 & ar & 119 & 91 & 113 & 121 & 121 & 81 & .72 & +13 & 52 & 22 & 83 \\
\hline
\end{tabular}

\begin{tabular}{|c|c|c|c|c|c|c|c|c|c|c|c|c|}
\hline $\begin{array}{c}\text { PRINCESS ANIYE } \\
\text { A-week periods } \\
\text { EXHOSEOSTATION }\end{array}$ & $\left\{\begin{array}{c}\text { mar } \\
11 \\
\text { rums } \\
y\end{array}\right.$ & 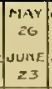 & $=\begin{array}{c}\text { JuNe } \\
8 \\
\text { JuL } \\
7\end{array}$ & $\begin{array}{c}\text { JUNE } \\
23 \\
\text { JULX } \\
21\end{array}$ & $\begin{array}{c}\text { JUL: } \\
7 \\
\text { AuG } \\
\rightarrow\end{array}$ & $\left\{\begin{array}{c}\text { JuLr } \\
21 \\
\text { Aug } \\
18\end{array}\right.$ & $\mid \begin{array}{c}4 \\
4 \\
s e+r \\
1\end{array}$ & $\begin{array}{l}\text { Aust } \\
18 \\
\text { SErt } \\
\text { is } \\
\end{array}$ & $\begin{array}{c}\text { SEP } \\
1 \\
5 E F T \\
20\end{array}$ & $\begin{array}{c}\text { SEPT } \\
15 \\
\alpha C T \\
+2\end{array}$ & $\begin{array}{c}\text { SEFT } \\
29 \\
\text { OCT } \\
2 T\end{array}$ & AV. \\
\hline Culture rimben & 1 & 2 & 3 & 4 & 5 & 0 & 7 & $\theta$ & 9 & 10 & 11 & \\
\hline Length of growniz period. days. & $\angle \theta$ & 28 & 29 & 28 & 20 & as & $\approx \theta$ & 28 & 28 & 27 & $2 \theta$ & \\
\hline Number of plonts. & 6 & 5 & 5 & b & 6 & 0 & 3 & 6 & 6 & 5 & G & \\
\hline Remaincler sumination indax. & $17 \in 3$ & 709 & 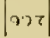 & 1007 & 97 & 900 & 1033 & $70 x$ & 750 & 678 & 643 & 880 \\
\hline $\begin{array}{l}\text { Average daily relative physiologieal } \\
\text { tenigerutine index. }\end{array}$ & 81 & 102 & 117 & 130 & 130 & 130 & 145 & 110 & 78 & 00 & 52 & 106 \\
\hline Averaqe daily mean tem perature, deq. $F$ & 67 & 73 & 75 & 75 & 7.5 & 75 & 76 & 72 & $\infty 0$ & 04 & 62 & 71 \\
\hline $\begin{array}{l}\text { Average dally relotive evaporalion } \\
\text { index. }\end{array}$ & 120 & - & - & - & 73 & 92 & 90 & $7 B$ & $7 \theta$ & 74 & 55 & 83 \\
\hline $\begin{array}{l}\text { Averoge daily relotive sunshine } \\
\text { intensity }\end{array}$ & 113 & III & 94 & 8.7 & 92 & 80 & 01 & 0.3 & Bi & $7 s$ & s5 & 67 \\
\hline $\begin{array}{l}\text { Averuge daily relative incroinent in } \\
\text { stem heiqlit. }\end{array}$ & 63 & 180 & 103 & 100 & 138 & $1 \geq 5$ & 138 & 64 & 63 & 56 & 49 & 92 \\
\hline $\begin{array}{l}\text { Averoqe doily relotive increment in } \\
\text { leuf ured. }\end{array}$ & 125 & 155 & 116 & - & 127 & 132 & 206 & 102 & 90 & 72 & 30 & T11 \\
\hline $\begin{array}{l}\text { Avcraqe daily relative irrerement it? } \\
\text { dry weight: }\end{array}$ & 132 & 150 & 137 & 118 & 137 & 135 & 1,71 & $\rightarrow 1$ & 39 & b7 & 36 & 116 \\
\hline
\end{tabular}




\section{TABLE VII}

Data for covered stations, Oakland and Baltimore

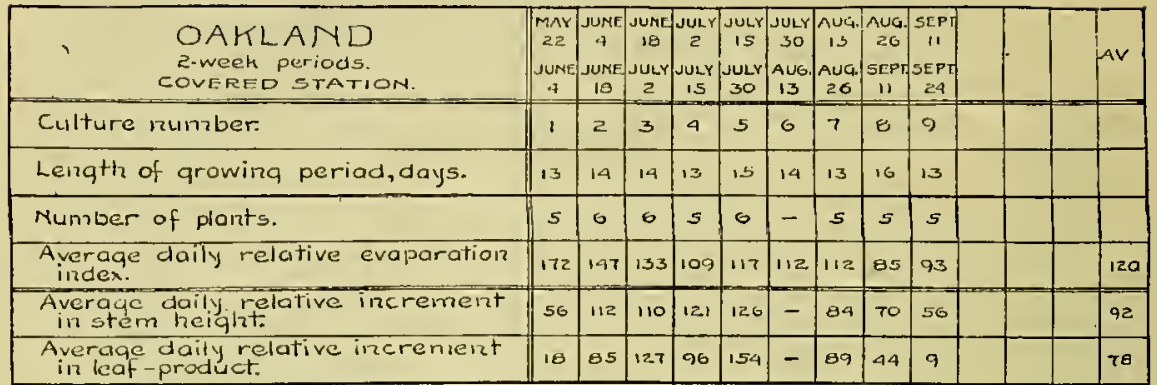

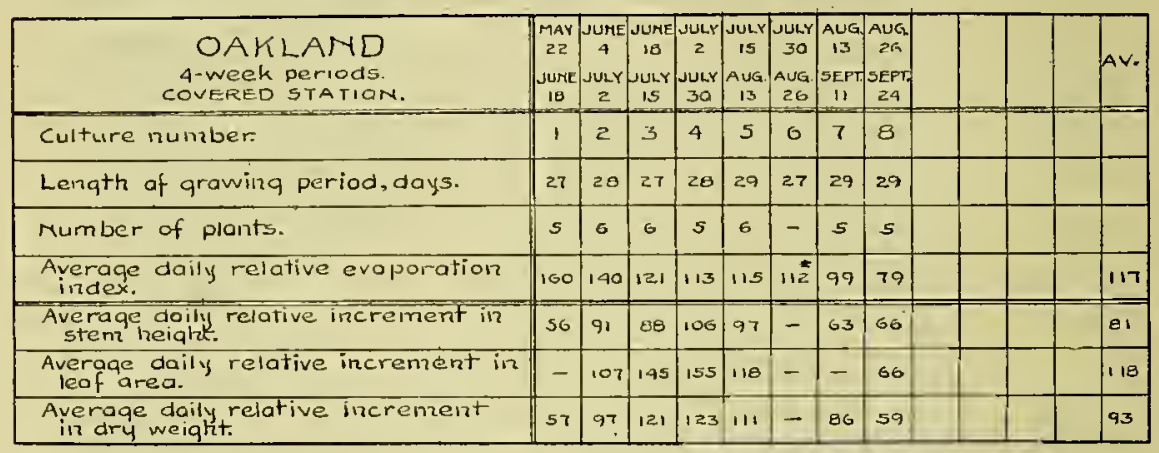

\begin{tabular}{|c|c|c|c|c|c|c|c|c|c|c|}
\hline $\begin{array}{l}\text { BALTIMORE } \\
\text { z-WEeK perIOAS. } \\
\text { COVEREO STATIOH. }\end{array}$ & \begin{tabular}{|c|} 
JUME \\
10 \\
JUNE \\
25 \\
\end{tabular} & $\begin{array}{c}\text { JUME } \\
25 \\
\text { JULY } \\
.9 \\
\end{array}$ & \begin{tabular}{|c|}
$J U L Y$ \\
9 \\
$J U L Y$ \\
23 \\
\end{tabular} & $\mid \begin{array}{c}J U L Y \\
23 \\
\text { AUG } \\
G\end{array}$ & $\begin{array}{c}\text { AUG } \\
6 \\
\text { AUG } \\
20\end{array}$ & $\mid \begin{array}{c}\text { AUC } \\
2 a \\
\text { SEPT } \\
3\end{array}$ & \begin{tabular}{|c|} 
SEPT \\
3 \\
SEPT \\
19 \\
\end{tabular} & $\begin{array}{c}\text { SEFT } \\
19 \\
O C T \\
1 \\
\end{array}$ & $\begin{array}{c}a c t \\
1 \\
O C T \\
14\end{array}$ & AV. \\
\hline Culture number: & 3 & 4 & $s$ & B & 7 & 8 & 9 & 10 & 11 & \\
\hline Length of arowing periad, doys. & 15 & 14 & 14 & 14 & $14^{\circ}$ & 14 & 16 & 12 & 13 & \\
\hline Number of plonts. & 6 & 6 & 4 & 6 & 5 & 5 & 3 & 5 & 4 & 1. \\
\hline $\begin{array}{l}\text { Average daily relative evopatation } \\
\text { index. }\end{array}$ & 119 & 95 & 112 & 109 & 117 & 8T & 81 & 77 & 73 & 97 \\
\hline $\begin{array}{l}\text { Ayerage doily reigtive increment } \\
\text { in stem height. }\end{array}$ & 157 & 160 & 326 & 233 & 197 & 191 & 56 & סד & 155 & 172 \\
\hline $\begin{array}{l}\text { Averaqe doily relative incrementilz } \\
\text { leaf-product. }\end{array}$ & 111 & 150 & 262 & 147 & 180 & 163 & 51 & 21 & 43 & 125 \\
\hline
\end{tabular}

\begin{tabular}{|c|c|c|c|c|c|c|c|c|c|c|c|}
\hline $\begin{array}{l}\text { BALTIMORE } \\
\text { A-week periods. } \\
\text { CaVERED STATION. }\end{array}$ & \begin{tabular}{|c|} 
MAY \\
29 \\
JUNE \\
25 \\
\end{tabular} & \begin{tabular}{|c|} 
JUMEF \\
10 \\
SULY \\
9 \\
\end{tabular} & \begin{tabular}{|c|} 
JUREF \\
25 \\
JULY \\
23 \\
\end{tabular} & $\begin{array}{c}\text { JuLY } \\
9 \\
\text { Aug. } \\
6 \\
\end{array}$ & $\begin{array}{c}\text { JUL.Y } \\
23 \\
\text { AuG. } \\
20\end{array}$ & $\left|\begin{array}{c}\text { AuG } \\
6 \\
\text { Sepr } \\
3\end{array}\right|$ & $\begin{array}{c}\text { AuG } \\
20 \\
\text { SEPr } \\
19\end{array}$ & $\begin{array}{c}\text { SEPT } \\
3 \\
0 \mathrm{CT} \\
1 \\
\end{array}$ & \begin{tabular}{|c|} 
SEP \\
19 \\
OCT \\
19 \\
\end{tabular} & $\mid \begin{array}{c}a c t \\
1 \\
\text { oct } \\
31\end{array}$ & Av. \\
\hline Culture number & 2 & 3 & 4 & 5 & 6 & 7 & 8 & 9 & 10 & 11 & \\
\hline Leizatiz of growirg period, days. & 27 & 29 & 28 & 28 & 28 & 20 & 30 & 28 & $2 s$ & 30 & \\
\hline Number of plants. & 5 & 6 & 6 & 4 & 6 & 5 & 5 & 3 & 5 & 4 & \\
\hline $\begin{array}{l}\text { Average daily relative evaporation } \\
\text { index. }\end{array}$ & 119 & 107 & 107 & $\cdots$ & 113 & 102 & 84 & 79 & 75 & 20 & 97 \\
\hline $\begin{array}{l}\text { Average daily relative increment } \\
\text { in stent lelght. }\end{array}$ & 156 & 128 & 134 & 231 & 169 & 1.53 & 131 & 72 & 103 & 78 & 136 \\
\hline $\begin{array}{l}\text { Average daily relative increment } \\
\text { in leaf ared. }\end{array}$ & - & - & 168 & 230 & 137 & 17.4 & 154 & 74 & 101 & - & 154 \\
\hline $\begin{array}{l}\text { Average doily relative inciement } \\
117 \text { dry weiglat. }\end{array}$ & 134 & 54 & 110 & 108 & 103 & 135 & 1114 & 64 & 60 & 32 & 95 \\
\hline
\end{tabular}


TABLE VIII

Data for covered station at Easton and for forest station at Baltimore

\begin{tabular}{|c|c|c|c|c|c|c|c|c|c|c|c|}
\hline $\begin{array}{l}\text { EASTON } \\
\text { Z-week pEIIOAS. } \\
\text { COVERED STATIOH. }\end{array}$ & $\begin{array}{c}\text { MAY } \\
25 \\
\text { JUME } \\
\theta\end{array}$ & $\begin{array}{l}\text { JUNE } \\
\text { B } \\
\text { JUNT } \\
22\end{array}$ & $\begin{array}{c}\text { JUNE } \\
22 \\
\text { JULY } \\
6\end{array}$ & $\begin{array}{c}\text { JULY } \\
6 \\
\text { JULY } \\
20\end{array}$ & $\begin{array}{c}\text { JULY } \\
20 \\
\text { AUG } \\
3\end{array}$ & $\begin{array}{c}\text { AUG } \\
3 \\
\text { AUG } \\
17\end{array}$ & $\mid \begin{array}{c}\text { AUG } \\
17 \\
\text { AUG } \\
31\end{array}$ & $\begin{array}{c}\text { AUG } \\
31 \\
\text { SEPT } \\
1.4\end{array}$ & $\begin{array}{l}\text { SEPT } \\
11 \\
\text { SEPT } \\
\text { 2E }\end{array}$ & $\begin{array}{c}s e p t \\
2 \theta \\
\infty C t \\
11\end{array}$ & Av. \\
\hline Culture number & 2 & 3 & 4 & 5 & 6 & 7 & $\theta$ & 9 & 10 & 11 & \\
\hline Lengtiz of growing period, days. & 14 & 14 & 14 & 14 & 19 & 19 & 19 & 14 & 1.3 & 14 & \\
\hline Nunzber of plants. & 4 & 6 & 4 & 3 & $\mathbf{G}$ & 6 & 5 & 6 & $\mathbf{u}$ & 6 & \\
\hline $\begin{array}{l}\text { Averaqe daily relative evaporation } \\
\text { index. }\end{array}$ & 100 & 135 & 80 & 112 & 144 & 129 & 131 & 131 & 104 & 100 & 124 \\
\hline $\begin{array}{l}\text { Average daily relative increment } 11 \\
\text { stem height. }\end{array}$ & 129 & 110 & 155 & 172 & 177 & 177 & 185 & 30 & 90 & - & 145 \\
\hline $\begin{array}{l}\text { Averaqe daily relative inci-enent } \\
\text { in leaf-product. }\end{array}$ & 122 & 112 & 89 & 180 & 162 & 210 & 225 & 125 & 55 & - & 142 \\
\hline
\end{tabular}

\begin{tabular}{|c|c|c|c|c|c|c|c|c|c|c|c|c|}
\hline $\begin{array}{c}\text { EASTON } \\
\text { A-week periads. } \\
\text { cOVERED STATIOM. }\end{array}$ & $\begin{array}{c}\text { MAY } \\
25 \\
\text { JUNE } \\
22\end{array}$ & $\begin{array}{c}\text { JUME } \\
\text { JULY } \\
0\end{array}$ & $\begin{array}{c}\text { JUME } \\
22 \\
\text { JuLY } \\
20\end{array}$ & $\begin{array}{c}J U L Y \\
6 \\
A \cup G \\
3\end{array}$ & $\begin{array}{c}\text { JULY } \\
20 \\
\text { AUG } \\
17\end{array}$ & $\begin{array}{c}\text { AUG } \\
3 \\
\text { AUG } \\
31\end{array}$ & $\begin{array}{c}\text { AUG } \\
17 \\
\text { SEFL } \\
14\end{array}$ & $\begin{array}{c}\text { AUG. } \\
31 \\
\text { SEPT } \\
\text { EQ }\end{array}$ & $\begin{array}{l}\text { SEPT } \\
14 \\
\text { OCT } \\
11\end{array}$ & $\begin{array}{c}5 E P T \\
28 \\
\text { OCT } \\
26\end{array}$ & $\begin{array}{c}\text { OCT } \\
11 \\
\text { rov } \\
6\end{array}$ & Av. \\
\hline Cultul-c rumber. & $z$ & 3 & 4 & 5 & 6 & 7 & 8 & 9 & 10 & 11 & 12 & \\
\hline Length of qrowing period, doys. & $2 \theta$ & $2 \theta$ & 28 & 28 & $2 \theta$ & 28 & 28 & $2 B$ & 27 & $2 \theta$ & 26 & \\
\hline Number of plants & 4 & 6 & 6 & - & 6 & 6 & 5 & 6 & 6 & - & - & \\
\hline $\begin{array}{l}\text { Average dally relative evaporatian } \\
\text { index. }\end{array}$ & 151 & 100 & 96 & $12 \%$ & 137 & 130 & 131 & 118 & .06 & 104 & $116^{*}$ & 120 \\
\hline $\begin{array}{l}\text { Average daily felative increment } \\
\text { in stem lieight. }\end{array}$ & 103 & 128 & 125 & - & 134 & 156 & 125 & 75 & BI & - & - & 116 \\
\hline $\begin{array}{l}\text { Average daily relative lincirement } \\
\text { in leaf area. }\end{array}$ & 117 & 191 & 90 & - & 130 & 202 & 159 & 104 & a.5 & - & - & 137 \\
\hline $\begin{array}{l}\text { Averaqe claily relative inci-ement } \\
\text { in di-y weight. }\end{array}$ & 108 & 144 & 86 & - & 107 & 180 & 129 & 105 & 56 & - & - & 109 \\
\hline
\end{tabular}

\begin{tabular}{|c|c|c|c|c|c|c|c|c|c|}
\hline $\begin{array}{l}\text { BALTIMORE } \\
\text { z-week periods. } \\
\text { FAREST STATIOM. }\end{array}$ & $\begin{array}{c}\text { JUNE } \\
Z i \\
\text { JULY } \\
9\end{array}$ & $\mid \begin{array}{c}\text { JULY } \\
9 \\
\text { JULY } \\
23\end{array}$ & $\begin{array}{c}J U L Y \\
23 \\
\text { AUG } \\
6\end{array}$ & $\begin{array}{c}\text { AUG } \\
\text { G } \\
\text { RUG } \\
20\end{array}$ & $\begin{array}{c}\text { AUG } \\
20 \\
\text { SEPT } \\
\end{array}$ & $\begin{array}{c}\text { SEPT } \\
3 \\
\text { SEFT } \\
19\end{array}$ & $\begin{array}{c}\text { SEFT } \\
19 \\
\text { OCT }\end{array}$ & $\begin{array}{c}\text { OCT. } \\
1 \\
\text { OCT. } \\
14\end{array}$ & Ar. \\
\hline culture number & 4 & 5 & 6 & 7 & $B$ & 9 & 10 & 11 & \\
\hline Length of growing period, doys. & 18 & 14 & 14 & 19 & 14 & 16 & 12 & 13 & \\
\hline Number of plants & 6 & 5 & - & 4 & 5 & 4 & 0 & 3 & \\
\hline $\begin{array}{l}\text { Average daily relative evaparation } \\
\text { index. }\end{array}$ & - & 75 & $82^{*}$ & 67 & 72 & 64 & 57 & 52 & 67 \\
\hline $\begin{array}{l}\text { Average daily relative increment } \\
\text { in stem height. }\end{array}$ & $2 G 1$ & 458 & - & 396 & 284 & 171 & 121 & 208 & 271 \\
\hline $\begin{array}{l}\text { Average daily relative increnzent in } \\
\text { leof-product. }\end{array}$ & 94 & 104 & - & 136 & 59 & 13 & 6 & 21 & 62 \\
\hline
\end{tabular}

\begin{tabular}{|c|c|c|c|c|c|c|c|c|c|}
\hline $\begin{array}{l}\text { BALTIMORE } \\
\text { 4-wCEK periOdS. } \\
\text { FOREST STATIOM }\end{array}$ & $\begin{array}{c}\text { JUHE } \\
21 \\
\text { JULY } \\
23\end{array}$ & $\begin{array}{c}\text { JuLr } \\
9 \\
\text { AuG. } \\
6\end{array}$ & $\begin{array}{c}\text { JULY } \\
23 \\
\text { AUG. } \\
20\end{array}$ & $\begin{array}{c}\text { AUG } \\
6 \\
\text { SEPT } \\
3\end{array}$ & $\begin{array}{c}\text { AUG } \\
20 \\
\text { SEPT } \\
19\end{array}$ & {$\left[\begin{array}{c}\text { SEPT } \\
3 \\
\text { OCT. } \\
1\end{array}\right.$} & $\begin{array}{c}\text { SEPT. } \\
19 \\
\text { OCT. } \\
19\end{array}$ & $\left|\begin{array}{c}O C_{T} \\
1 \\
O C T_{T} \\
31\end{array}\right|$ & Av. \\
\hline Culture rumber. & 9 & 5 & 6 & 7 & 8 & 9 & 10 & 11 & \\
\hline Length of qrowing period, doys. & 32. & 20 & $2 \theta$ & 28 & 30 & 28 & 25 & 30 & \\
\hline Nuinzber of plaizts. & 6 & 5 & - & 4 & 5 & 5 & 6 & 3 & \\
\hline $\begin{array}{l}\text { Aycruge daily relative evaporotion } \\
\text { index. }\end{array}$ & - & 79 & $75^{* 1}$ & 70 & 68 & 61 & 55 & 35 & 65 \\
\hline $\begin{array}{l}\text { Averaqe doily relative increnzent in } \\
\text { stem heiqlat. }\end{array}$ & 300 & 449 & - & 310 & 213 & 200 & 200 & 125 & 256 \\
\hline $\begin{array}{l}\text { Average daily relative increnient } \\
\text { in leaf area. }\end{array}$ & 104 & 104 & - & 9.5 & 73 & 40 & 38 & 32 & 69 \\
\hline $\begin{array}{l}\text { Averoge daily relative increment } \\
\text { il dry weight. }\end{array}$ & 52 & 62 & - & 46 & 37 & 30 & 33 & 2.7 & 41 \\
\hline
\end{tabular}


The 2-week tables for the exposed stations (tables I-III) show in line 5 the remainder-summation temperature index for each culture period, this being obtained by subtracting $39^{\circ}$ from each daily mean and then summing the remainders for the period. Line 6 gives the average daily relative physiological index for each period. Line 7 gives the average daily mean temperatures for each period, line 8 the average daily relative evaporation index, and line 9, the average daily relative sunshine-intensity value Line 10 shows the values of the average daily relative increment of stem height, and line 11 the values of the average daily relative increment of leaf-product. The two-week tables for the covered stations correspond to the two-week tables for the exposed stations, except that no temperature or sunshine data are here available and the tables thus contain only the relative evaporation indices and the two plant values. This is also true for the Baltimore forest station.

The 4-week tables correspond, line for line, with the 2-week ones, except that the 4 -week tables show the average daily relative increment of leaf area (instead of the average daily relative increment of leaf-product) and a line is added to the 4 -week tables giving the average daily relative increment of dry weight. Each 4-week value of the relative daily physiological temperature index, the relative daily evaporation index, and the relative daily sunshine intensity, was obtained by averaging the relative values of these climatic factors for the 2 -week periods in question. The 4 -week value of the remainder-summation index for each period was obtained by adding the values of this index for the two 2 -week periods that make up the 4-week period under consideration. The average daily mean temperature for the longer periods was obtained by taking the mean of the two average daily means for the two 2-week periods involved.

It will be noted that the plant values are uniformly given at the bottom of the table, with a double rule separating them from what precedes.

Figures 2-6 present graphically certain of the data given in tables I-VIII. Graphs for plant values are denoted by black lines and those for climatic values are shown in red. In all of these graphs the ordinates represent magnitudes of the plant and climatic relative values and the abscissas represent the time of the year. The ordinate scale is given at the left of each set of graphs, for convenience of reference, and the dates of the beginnings of successive culture periods are shown on the base line. Thus, for the first 2-week period at Oakland, the ordinates show the average daily relative values of the plant and climatic measurements for the 2 -week period beginning May 23. The 100-line of the ordinate scale represents the average seasonal value for all stations (as previously noted), this being the unit used in expressing the corresponding relative values. Full black lines (appearing only on 4-week graphs) represent dry weight. Dash black lines represent height. Dotted black lines (only on 4-week graphs) represent leaf area. 
Dash-and-dot lines (only on 2-week graphs) represent leaf-product. Full red lines represent temperature. Dash red lines represent cvaporation. Dotted red lines represent light.

The results obtained will now be brought forward, with some discussion, which is to be read with reference to tables I-VIII and figures 2-6.

\section{Results for Stations in the Open}

The data for the stations in the open will be considered as of two main groups, the 2-week data and the 4-week data.

\section{THE 2-WEEK VALUES}

The 2-week plant data for stations in the open (see figs. 2 and 3, black lines)

As has been stated, the plant measurements here in question were taken about two weeks after planting and included stem height and leaflet dimensions. From these have been derived (1) the relative mean daily rate of increase in stem height per plant and (2) the relative mean daily rate of increase in total leaf-product per plant, both for each 2-week period.

Therefore, one of these 2-week plant values represents the stem-producing power of the plant and the other stands for its leaf-producing power, under the given set of external conditions acting during that period. Since the plants are taken to be alike at the start, (seeds) these two derived plant values should be the same for all individuals if all were subjected to the same effective environmental conditions throughout the period, and when the various plants are exposed to different environments the values just mentioned become criteria by which the effectiveness of one environment may be compared with that of another, with reference, of course, to the particular set of internal conditions represented by the plants at the beginning of the tests. The two plant values just mentioned may thus be regarded as relative measures of the effectiveness or efficiency of the environmental complex for the 2-week period considered, as it acted to produce stem elongation and leafproduct increase, upon the soy-bean plants employed in this investigation. For convenience, the following discussion will refer to the graphs (figs. 2 and 3) rather than to the tables, but tables and graphs both present the same data in every case. This discussion will be given under two headings: (1) Correlations between the two plant graphs and (2) Trend of the plant values and their seasonal averages for the various stations.

Correlations between the two 2-week plant graphs.-It is readily seen that the two graphs showing relative rates of increase in stem height and in leafproduct agree in their general direction of slopefrom period to period, throughout the season and for all stations. In many cases the two plant graphs not only slope in the same general direction (upward or downward) but their 


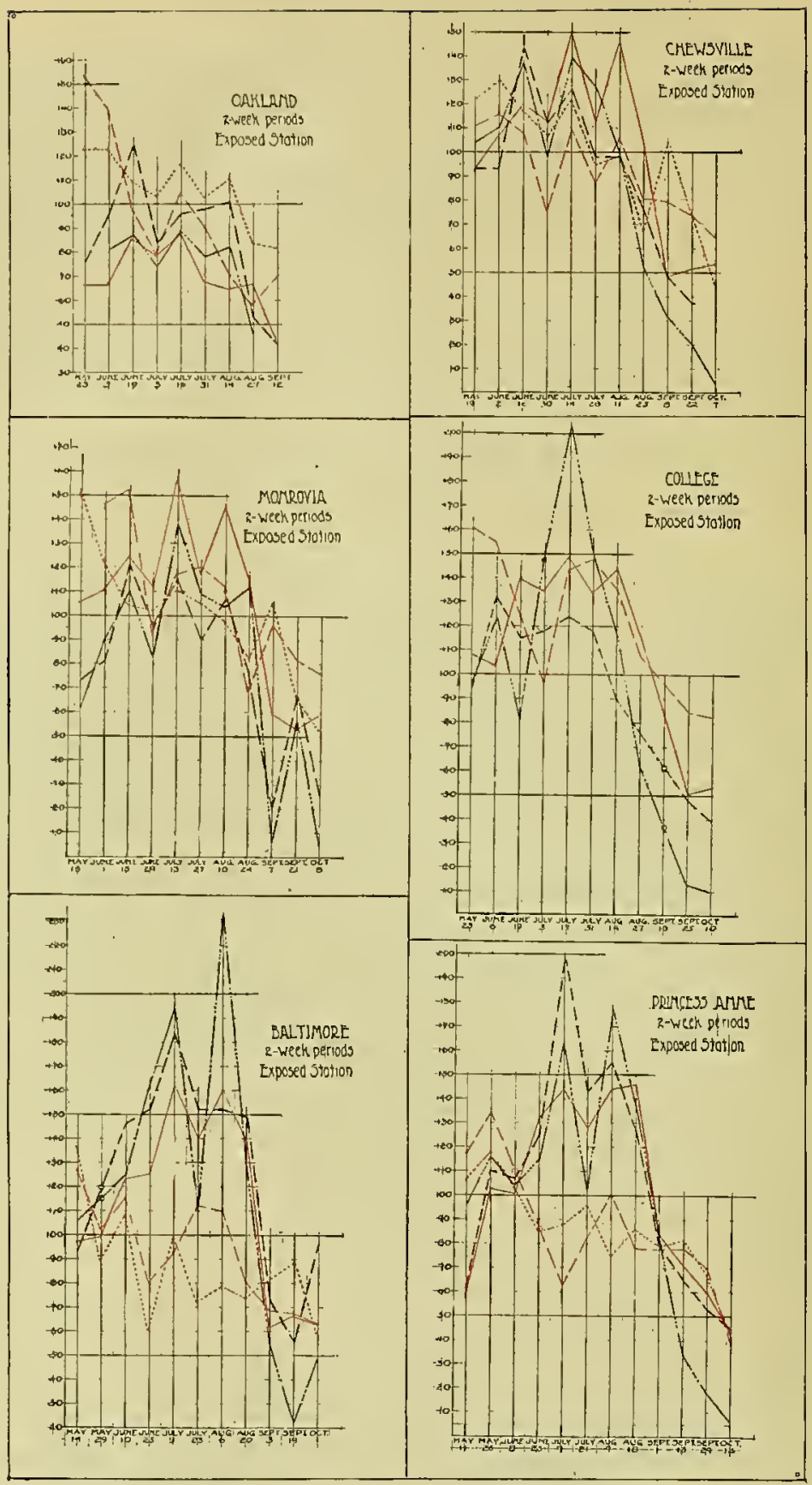

FIG. 2. Graphs of 2-week data for exposed stations, as named.

Black: Height, $-\ldots \ldots-$; Leaf product, $-\ldots \ldots$

Red: Temperature index, index,..... 


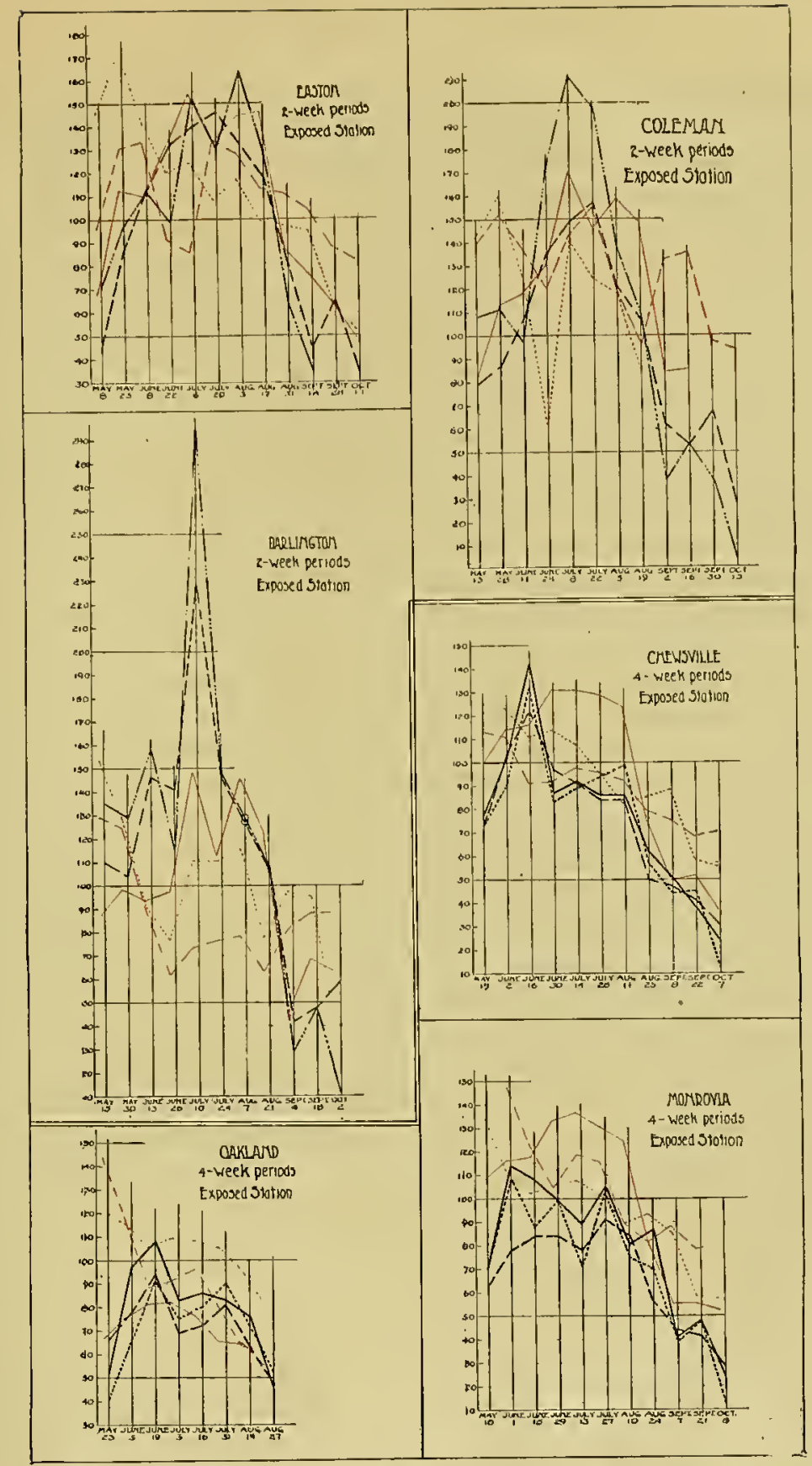

Fig. 3. Graphs of 2-week data for exposed stations, as named (continued). (Lines as in fig. 2.) - Graphs of 4-week data for exposed stations, as named. Black: Dry weight, ; Height, - - - - Leaf area; $\cdots . . . \cdots$ Red, as in fig. 2. 
corresponding angles of slope are nearly the same and their corresponding ordinates are about equal, so that they nearly coincide for considerable portions of their length. In other words, there appears to have been a pronounced general agrement between the effectiveness of the environment to produce stem elongation and its effectiveness to increase the magnitude of the leafproduct, as shown by these cultures. If this agreement were perfect it would mean, of course, that the environment exerted the same influence upon the process of leaf-surface increase (as measured by leaf-product) and upon the process of stem elongation, and either of these two criteria would be a measure of the other. But the coincidence of the two graphs is not by any means perfect and it becomes a matter of interest to study their differences, as shown by the corresponding relative values of their ordinates.

Inspection of the graphs shows that, leaving those for Oakland out of account, the index for stem height increase is frequently greater than the other plant index for the early and late portions of the frostless season, and that this relation generally is reversed for the middle portion. In other terms, the graph for stem elongation generally lies below the other graph for the middle of the season and above it for the beginning and end of the season. In still nther words, the seasonal maxima of leaf-product values are generally relatively higher than those of stem elongation, while the seasonal minima of the former are lower than those of the latter. It may be stated, as an approximation, that when these two plant values are both about 100 (as the data are presented in this paper) the leaf-product value is generally the higher of the two, while when both are below 100 the elongation value is usually the higher. In the case of Oakland, both values are comparatively very low throughout the season and, while the index of stem elongation reaches somewhat above. 100 for two periods, this index is never surpassed in magnitude by the index of leaf-product increase.

The generalization just stated indicating a relation between the rates of two plant processes, seems to be a physiological one, dependent upon the nature of the soy-bean plant and hence largely predetermined by the internal conditions of the seed. Within the range of environmental conditions encountered in this study it appears that the taller and more leafy the plant becomes in the first two weeks of growth, the lower is the value of the ratio of final height to final foliar expanse. The two growth processes here considered are, therefore, clearly interrelated and neither one alone is to be regarded as a criterion of plant growth in general. The average of these two indices may be considered as a tentative index of the general growth of the plants during the first two weeks from the seed. Inspection of the 2-wcek graphs leads to the impression that this mean of the two values offers perhaps the mosi promising way to obtain from them a single index of plant growth. The two are always so nearly parallel throughout the season (nearly coinciding for many periods, as has been stated) that the charts have not been further 
complicated by introducing the graph for the average, but the form of this graph is readily appreciated from the two graphs that are given.

The general relation between the two plant values that has just been emphasized does not always hold, and the more detailed discussion of the plant graphs for individual stations, given in the next following paragraph, is of value in showing the main exceptions.

For Oakland the height value lies above that for leaf-product throughout the season. The two graphs have the same general direction of slope except for the period beginning July 16. For Chewsville the height graph exhibits the same general direction of slope as does the leaf-product graph, from period to period, throughout the season, with the former well above the latter for the last four periods (beginning August 25, September 8, September 22 and October 27). For the periods beginning June 16 and June 30 the latter relation also holds, although the index values are large, especially in the case of the first of these two periods. For Monrovia the two plant graphs follow each other very closely throughout the entire season. The graphs for College for the periods beginning July 3 , July 17 and July 31 , illustrated the tendency of the height values to decrease relatively to those of leaf-product when both values are large. For the periods beginning September 10, September 25 and October 10 for this station, both values are small and, as would be expected, stem height is relatively greater than leaf product. For the period beginning June 19 the expected relation between the two graphs does not obtain. For Baltimore the periods beginning June 10, July 23 and August 20 are exceptions to the proposition that the height graph should lie below the graph of leaf-product when both plant values are large. The generalization is true, however, for the remaining periods of the Balitimore season. For Darlington the two plant graphs agree closely in value throughout the season. For Coleman stem height and leaf-product show the expected relation. For Easton the generalization holds, with three exceptions: the height index is lower than the other for the period beginning May 8, although both indices have low values, and this relation is reversed for the periods beginning June 22 and July 20 , in spite of the fact that both values are large in these cases. For Princess Anne the graphs show values of the height index higher than those of the other index for the periods beginning June 23 , July 7 and July 21 , although both indices are large for all three periods. Otherwise these grapls agree with the generalization.

The fact that the generalization given above holds in the great majority of the cases here studied renders the exceptions of special interest. Assuming that the seeds were all alike at the beginning of all cultures and that no disturbing influence was introduced by soil conditions, it may be supposed that the periods characterized by exceptions to this generalization should also be characterized by some sort of corresponding peculiarities in the aerial environmental complexes. Now, a study of the charts for the exposed sta- 
tions brings out the following fact: most of the 2-week periods for which both plant values are large and yet the index of stem elongation is greater than that of leaf-product increase, are characterized by low indices of sunshine intensity. This suggests that the plants of these cultures experienced an acceleration in their rates of stem elongation due to low light intensity, in short that they exhibited some of the effects of incipient etiolation. They seem to show a somewhat increased rate of stem elongation and a somewhat decreased rate of leaf expansion, as compared with plants receiving more radiation. This interpretation is not to be regarded as at all well established, but it is at least a suggestion of one way in which the external condition of light intensity and duration may be registered in such plants as were here employed.

Trends of the 2-week plant values and their seasonal ranges for the several stations. The following consideration of the seasonal marches of the 2 -week plant values for the various stations will be limited in extent, since most of the facts and deductions that seem to be of importance in this connection can be better brought out later. Attention will here be called only to two characteristics of the plant.graphs: (1) They begin with values of about 100 rise to high midsummer values and then fall to low values at the end of the season. (2) Differences in the magnitude of the midsummer maxima constitute the chief differences between the graphs for the various stations.

Oakland shows lower values for stem height and leaf-product than does any other station, due largely to the low temperatures prevailing at this station throughout the season. The data of this study indicate that the climate of Oakland, so far as it affects the plants, is very unlike that of any of the other stations employed. Both plant graphs for this station show the typical low values at the beginning and end of the season, however, with midsummer maxima of 124 for stem height and 89 for leaf-product. Chewsville shows typical graphs, the highest value reached by stem height being 143 while the leaf-product maximum is 139 . The end of the season at this station is characterized by very low leaf-product values. The graphs for Monrovia are also typical, with low values of both indices for the period beginning May 18 and low values at the end of the season, after midsummer maxima of 121 (stem height) and 138 (leaf-product). An explanation of the low values shown for the Monrovia periods beginning September 7 and October 8 may lie in the fact that a minimum temperature only several degrees above freezing was reached during each of these periods. For both Chewsville and Monrovia the plant values are, for the most part, lower than 100 , with relatively low midsummer maxima of 132 and 203, for stem height and leaf-product, respectively. The Baltimore plant graphs begin with high values and reach maxima of 183 and 233, for stem height and leaf-product respectively. For Darlington the main distinguishing features are the very high maxima of 228 for stem height and 295 for leaf-product, for the period 
beginning July 10 , and the relatively high values shown by the graphs for the beginning of the season. The midsummer maxima for Coleman are 157 (stem height) and 211 (leaf product). The plant graphs for Easton show relatively low values of the midsummer maxima, 146 being the highest value reached for stem height and 163 for leaf-product. Also, the plant values are low for the beginning of the season for this station. The midsummer maximum for stem height for Princess Anne is 197 and the corresponding maximum for leaf-product is 163 .

The plant graphs, as may be seen from the above outline of their main features, fall into three groups: (1) The Oakland graphs, which show values of the leaf-product index below 100 for all periods and similar low values of the stem-height index for all periods except those beginning June 14 and August 14, while the maxima of these graphs are relatively low. (2) The graphs for Chewsville, Monrovia, Princess Anne and Easton, showing higher midsummer values of the plant growth-rates than do the Oakland graphs, the maxima being about one and one-half times the seasonal average.

The graphs for College, Baltimore, Darlington and Coleman which are distinguished by high relative values of their maxima. This classification serves to summarize such characteristics of the graphs as are of present interest.

The 2-week climatic data for stations in the open (see figs. 2 and 3 , red lines)

The 2-week climatic data consist of the average daily relative values of the indices for temperature, evaporation, and light for each of a series of consecutive periods extending through practically the entire growing season, each period being about 14 days long. These values therefore furnish a continuous record of the growing season at each station. The 4-week periods, however, overlap, each one including the last two weeks of the preceding and the firsi two weeks of the following 4 -week period, so that the climatic averages based on the 4-week data form a smoother curve than do the 2-week values in every case, small variations in the conditions being to a great extent obscured by, averaging the overlapping periods. This series of 2-week values therefore exhibits the mareh of the climatic conditions at each of the various stations in somewhat greater detail than do the corresponding series of 4-week values. The former will therefore be made the basis for a somewhat detailed and comparative discussion of the climatic conditions at the various stations, temperature receiving attention first and light and evaporation being afterwards considered together. In each case, the general characteristics (common to most or all of the stations) of the seasonal march of the condition considered will be brought out, after which attention will be given to peculiarities of the values for individual stations. 
The 2-week temperature data

The most obvious general characteristic of the physiological temperature index is that its value is high for mid-summer and low for the beginning and end of the season, for all stations. Graphs of similar form are obtained when daily means and remainder summations are correspondingly plotted, but the midsummer rise is much mole pronounced in the graph of physiological index values (here employed) than in either of the others. The second general characteristic of all the graphs of the physiological index of temperature is that each graph possesses two maxima, both of which have about the same magnitude. The first occurs for the last two weeks of July and the second for the last two weeks of August, this statement being true for all the stations considered except Oakland, for which station they both occur relatively early in the season, in the last two weeks in June and July respectively. A third feature which is common to most (though not all) of these graphs is that the upward slope is more gradual before the occurrence of the high midsummer maxima than is the downward slope after their occurrence. A generalized temperature-efficiency graph, representing averages of the corresponding values for all of the stations, is not symmetrical about the ordinate for its highest midsummer value; it slopes upward less rapidly than downward. A fourth general characteristic of these graphs lies in the fact that the final low index values of the frostless season are not very different for the various stations. The following consideration of the graphs for some of the individual stations will serve to bring out the points mentioned above and will give opportunity to note exceptions to the general statements just made.

With regard to the forms and other characteristics of the 2-week temperature-efficiency graphs, the nine stations studied may be placed in five groups: (1) Chewsville and Monrovia, (2) Baltimore, Darlington and Coleman, (3) Easton and Princess Anne, (4) College, and (5) Oakland. These five groups are discussed in order below. It will be noted that groups 1,2 and 3 are composed of stations that are located near each other, and this probably accounts for the grouping.

Chewsville and Monrovia. The graph of physiological temperature indices for Chewsville shows all the characteristics mentioned as general throughout the series of stations. It rises gradually during the first three periods, (period beginning May 19 to period beginning June 16), then drops slightly during the fourth period (beginning June 30 ) after which it rises for the period beginning July 14 to a primary maximum of 149 . The value for the 6 th period (beginning July 28) is relatively low (112), after which a secondary maximum (145) occurs for the period beginning August 11. The index value in question then decreases rapidly during the next two periods attaining a magnitude of 48 for the 9 th period (beginning September 8 ) and remaining low until the end of the frostless season. Monrovia has the same sort of graph as Chews- 
ville, the maxima coming in the periods beginning July 13 and Lugust 10. The minimum relative value of the temperature index is 53 for the period beginning September 21.

Baltimore, Darlington and Coleman. For Baltimore, the physiological temperature values increase gradually to a primary maximum of 162 for the period beginning July 29. The sccondary maximum oceurs in the period beginning August 6, after which there is a relatively rapid decline of the index values, to 62 for the period beginning September 3. The Darlington graph has its first maximum in the first two weeks of July and its second in the 2-week period beginning August 7, and then falls off rapidly to a minimum of 46 for the first period in September. The graph for Colcman shows a gradual rise, two maxima for the periods béginning July 8 and August 5, and a rapid fall. The temperature record is incomplete at this station and the low values for the end of the season are not available.

Easton and Princess Anne. For Easton there is a gradual risc to a maximum of 154, for the first period in July, the second maximum coming in the period beginning August 17 . The curve then falls to a minimum of 48 , for the last period of the season. The Princess Anne curve shows the two typical maxima in the periods beginning July 9 and August 18, with a minimum of 43 for the last period of the season.

College. The College graph of physiological indices is unusual in showing a marked rise for the period beginning June 19, thus giving the graph three maxima (129, 148 and 143, for the periods beginning June 19, July 17 and August 14, respectively). The graph descends rapidly to a value of 50 , for the period beginning September 25 .

Oakland. The temperaturc-index values for Oakland are all relatively low, being always considerably less than the seasonal average for all periods and stations. This graph shows two maxima, one for the latter half of June and the other for the latter half of July. Each of these maxima occurs about a month earlier than do the corresponding ones for the other stations herc studied. The Oakland graph is also unlike those for the other stations in that its downward slope is more gradual. Its final relative value is 43 , for the 2 -week period beginning September 12, which was the last full period for this station before the occurrence of a killing frost. The most outstanding characteristics of the Oakland season, in respect to this temperature-efficiency graph, as compared with the seasons at the other stations, are: (1) general low values of the physiological temperature-index. (2) short duration, owing to the occurrence of late spring and early fall frosts, and (3) early occurrence of the maxima. These marked differences between the Oakland graph and those for the other stations here dealt with are no doubt largely due to the relatively high altitude of Oakland as compared with the others as has been mentioned by McLean in his comparative study of the Easton and Oakland seasons based on these same data. 
The generalized graph. Leaving the graph for Oakland out of account, those for the other stations may be described as a single generalized graph, in the following general terms. Beginning with a relative index-value of about 80 (for the first part of May) the graph rises to a maximum (about 150) for the first part of July, falls slightly and rises again to a second maximum of about the same value as the first, for the first part of August, and finally falls to a minimum value of about 50 for the last period of the frostless season. That the initial values are not lower is no doubt due to the fact that the cultures were not started until somewhat after the beginning of the frostless season. (See McLean's paper, already cited.) This generalization of the temperature values for the various stations is not, of course, to be considered otherwise than as a statement of what occurred in the particular season during which this investigation was carried out.

\section{Light and the evaporating power of the air, 2-week data}

The 2-week graphs of the index values for light and atmospheric evaporating power will be treated together since che seasonal marches of these two climatic conditions generally exhibit the same main characteristics. Three points may be noted in regard to them. (1) Both graphs have, in general, a downward slope from the beginning to the end of the season. (2) In the majority of cases they agree with each other in direction of slope, from period to period, throughout the season. (3) They agree in having a primary maximum with a very high value, for an early period of the season and one or more secondary maxima with lower values, for periods that occur later. The secondary maxima of the graphs for light and evaporation sometimes (but not always) coincide, as to time of occurrence, with a corresponding maximum of the graph for temperature efficiency. The following consideration of the individual station graphs for the two conditions may serve to bring out these points.

For Oakland, the primary maximum in the graph of atmospheric evaporating power (153) occurs in the first period (beginning May 23). The value of the evaporation index then decreases steadily to a relative magnitude of 79 , for the first two weeks in July, after which it increases to (104), which corresponds in time of occurrence (period beginning July 6) to the secondary maximum of the graph of temperature efficiency for this station. After passing through this high value the evaporation graph descends again, to the low values 57 and 69 for the last two periods (beginning August 27 and September 12). The sunshine-intensity index for Oakland varies from an initial value of 122 to a final value of 81 , with maxima for the periods beginning July 16 and August 14. Inspection of these two graphs for Oakland shows that the direction of slope is the same, from period to period, for the greater part of the season. 
For Chewsville, the two graphs agree in direction of slope throughout the entire season, except between the periods beginning August 25 and September 8. Both are approximately parallel to the temperature-efficiency graph for this station, from the period beginning July 14 to the period beginning August 25 and both have a downward slope, in general, from the beginning to the end of the season. Moreover, they agree in direction of slope from the period beginning June 15 to that beginning October 8 .

For College, the evaporation maximum for the period beginning July 27 corresponds to a secondary minimum in temperature efficiency. The graph of the evaporating power of the air for College has a primary maximum for the second period (beginning May 28) and a well-marked secondary maximum for the period beginning July 22. No sunshine data are available for this station.

For Baltimore, the two graphs in question agree in direction of slope up to the period beginning July 9 after which evaporation passes through a secondary maximum which corresponds, in a very rough way, to the double maximum of temperature efficiency.

The Darlington light and evaporation graphs show the general characteristies mentioned at the beginning of this discussion, for the greater part of the season. The atmometric values for this station are relatively very low, all but two of them being less than the seasonal average for all periods and stations.

For Coleman, the sunshine record is incomplete, but the two graphs generally agree in direction of slope, so far as comparison is possible, excepting between the periods beginning July 17 and July 31 .

For Easton and Princess Anne, the graphs are typical. For the latter station, evaporation data are lacking for the periods beginning June 8 and June 23.

The comparatively close agreement between the graphs for sunshine and evaporation, for all the stations employed in this study, together with the fact that evaporation exhibits no well-defined relation to temperature effciency, appears to indicate that the rate at which water evaporated from the white cylindrical cups employed as atmometers in this investigation was determined to a considerable extent by the amount of radiant energy absorbed by the cups, and that air temperature played a secondary part in the determination of this rate. The fact that the physiological temperature index is here used for expressing temperature values does not militate against this conclusion, since, as has been previously stated other methods of expressing the temperature values give graphs which slope for the most part, in the same direction as does the graph of physiological temperature indices. A large effect of sunshine on evaporation, the sunshine intensity being measured by a black-bulb sunshine recorder, has been found by Briggs and Shantz. ${ }^{18}$

${ }_{18}$ Briggs, L. J., and Shantz, H. L. Hourly transpiration rate on clear days as determined by cyclic environmental factors. Jour. Agric. Res. 5: 583-650. 1916. 
These authors were able to calculate approximately the amount of evaporation from a shallow blackened tank using a formula which involved sunshine intensity and the saturation deficit of the air, sunshine intensity having a preponderating influence. They also state that while the cups and the tank respond in different ways to the daily cycle of changes in the evaporating power of the air, a certain average ratio exists between the evaporation from the tank and that from the cups. It is therefore to be expected from their work that the rate of evaporation from Livingston porous cups is largely influenced by sunshine intensity, and that air temperature exerts a secondary influence on evaporation as measured by these instruments. It must be remembered, also, that the evaporation measurements of this study were made in the plant enclosures, while air temperature was measured by thermometers located in a shelter about 1.5 meters ( 5 feet) above the ground and often 4 or 5 meters (15 feet) from the plant enclosures. This may account in some measure for the apparent absence of any marked effect of air temperature on the evaporating power of the air as measured by porous-cup atmometers. As Livingston has remarked, the porous cups are exposed in snmewhat the same way as are plant leaves, and the foliage of McLean's plants was freely exposed to sunshine, as were his atmometers also. Air temperature is always obtained from shaded instruments.

\section{Variability of temperature and evaporation values}

It may be noted that the temperature-efficiency values for the stations here considered, exclusive of Oakland, are much more nearly alike for any given 2 -week period than are the sunshine and evaporation values. The values of these three climatic indices for the first 2 weeks of June and for the first 2 weeks of August, for the eight stations, are given in table IX. Since the dates of observation were not the same for all stations, these values have been approximated from the graphs, but they may be considered as suffciently accurate to illustrate the manner in which the data at hand support the conclusion just stated.

If the highest value given for each of the three indices and for each of the two periods be divided by its lowest value, the ratios presented in the next to the last line of the table are obtained. Each ratio represents the magnitude of the range of variation of the climatic index that it represents, for the eight stations in question. The average value for these periods is given in the last line. It thus appears that the variation of the temperature-efficiency index due to difference in location of the stations is markedly less than is the corresponding variation in the index of sunshine or that of evaporation. This relation holds generally throughout the season. In short, the temperatureefficiency values exhibit a smaller degree of geographical or local variation than is exhibited by the index for sunshine or for the evaporating power of the air. 
TABLE IX

Values of the three elimatic indices for the first 2 weeks in June and the first 2 weels in August, with ratio of highest to lowest value for each index, for all stations excepting Oakland.

\begin{tabular}{|c|c|c|c|c|c|c|}
\hline \multirow{2}{*}{ STATION } & \multicolumn{2}{|c|}{ ETAPORATION } & \multicolumn{2}{|c|}{ SUNSHINE } & \multicolumn{2}{|c|}{$\begin{array}{l}\text { TEMPERATURE } \\
\text { EFFICIENCY } \\
\text { (PH YAIOLOGICAL } \\
\text { INOEX) }\end{array}$} \\
\hline & $\begin{array}{l}\text { 1st } 2 \\
\text { weeks of } \\
\text { June }\end{array}$ & $\begin{array}{l}\text { 1st } 2 \\
\text { weeks of } \\
\text { August }\end{array}$ & $\begin{array}{l}\text { 1st } 2 \\
\text { weeks of } \\
\text { June }\end{array}$ & $\begin{array}{c}\text { 1st } 2 \\
\text { weeks of } \\
\text { August }\end{array}$ & $\begin{array}{l}\text { 1st } 2 \\
\text { weeks of } \\
\text { June }\end{array}$ & $\begin{array}{l}\text { lst } 2 \\
\text { weeks of } \\
\text { August }\end{array}$ \\
\hline Chewsville. . & 115 & 90 & 130 & 95 & 105 & 120 \\
\hline Monrovia... & 146 & 115 & 122 & 103 & 110 & 125 \\
\hline College.... & 156 & 147 & - & - & 103 & 133 \\
\hline Baltimore.. & 109 & 110 & 92 & 77 & 102 & 152 \\
\hline Darlington. & 115 & 78 & 115 & 112 & 98 & 125 \\
\hline Coleman.... & 145 & 135 & 145 & 120 & 115 & 152 \\
\hline Easton........... & 132 & 135 & 165 & 115 & 112 & 140 \\
\hline Princess Anne....... & 125 & 95 & 110 & 75 & 102 & 135 \\
\hline $\begin{array}{l}\text { Ratio of highest to lowest value } \\
\text { in above series................ }\end{array}$ & 1.5 & 1.9 & 1.8 & 1.6 & 1.2 & 1.3 \\
\hline Average for the 2 periods. & \multicolumn{2}{|c|}{1.70} & \multicolumn{2}{|c|}{1.70} & \multicolumn{2}{|c|}{1.25} \\
\hline
\end{tabular}

\section{Correlation of the 2-week plant and the climatic values}

During the course of this study a number of attempts were made to correlate the climatic measurements with those representing the growth rates of the plants, but these were unsuccessful and no scheme applicable in a quantitative way to this problem has yet been formulated. For example, one of the simpler correlation schemes to be tried was based on the assumption that the growth of the plants was directly proportional to the index values for temperature and light and inversely proportional to those for evaporation. Stated as an equation, this assumption takes the form:

$$
G=\frac{K T L}{E}
$$

in which $G$ represents the plant growth rate and $T, L$, and $E$ represent the indices of temperature, light and evaporation, respectively, while $K$ is a constant of proportionality. Values were obtained for the right-hand member of this equation for the successive 2 -week periods for all stations and these values were compared with the corresponding growth-rate indices derived from the plant measurements. No close correspondence was generally to be detected. The equation is given as an illustration of the kind of methods by which the discovery of correlations between the plants and their climatic environment was attempted. Many combinations of the three climatic 
conditions were made and compared with the plant growth rates but, as noted above, without satisfactory results.

It seems probable that the difficulty experienced by every student who has thus far attempted this sort of correlation may arise partly from the fact that the environmental conditions have not been measured in the right way, and partly from the use of inadequate methods for the integration of the quantitative data that are obtained. It is hardly to be expected that either of the growth criteria here used should be as simple a function of the climatic conditions as the formula given above might suggest. Just as soon as facilities become available for actual experiments in this field,-experiments in which all the influential conditions may be controlled and analytically understood,-- the problem here brought forward prematurely may be seriously attacked. Until such experiments may be begun, all discussion regarding the relations between plant growth rates and environmental conditions must remain vague and unsatisfactory.

There is no doubt that the distribution of high and low values of any one of the climatic conditions, during the growtl period of the plants, is an important factor in determining the degree of their development. To take an extreme case as an example, a few days with a very low sunshine intensity would have no direct influence on plants not yet above ground, but such an occurrence would exert a very marked influence on plants with a considerable leaf area. Obviously, two periods showing similar average values of any climatic condition may have a widely differing distribution of high and low values of this condition. In the present study, while the distribution of high and low temperature and light values is known, the corresponding stages of the development of the plants are not, and it is thus practically impossible to take account of this distribution factor. The difficulty of correlating growth rates and climatic conditions is further increased by the fact that, in measuring dry weight, stem height, etc., we are not measuring single processes in the plants, but rather the combined effects of a number of processes taken together.

It is of interest to call attention at this point to certain features of the growth of the soy-bean plants of this study whose causes can only be surmised. These features may be of significance, however, since they show a departure from what may be termed the "normal" for plant behavior. In the first place, although all of the temperature graphs show two maxima, the plants, except in the case of Oakland, failed to respond to the second temperature maximum by a correspondingly high rate of growth. For Chewsville, as an example, in the period beginning August 11, we have a low value for the leaf-product with a high temperature index and the other conditions at about the seasonal average. For Monrovia in the period beginning August 10 , with a high temperature value and with sunshine intensity at about the seasonal average, the plants show a relatively low value of the leaf-product. 
This may be contrasted with the period beginning June 15 for this same station, which, with a leaf-product about the same as that of the first-mentioned period, seems to show less favorable growing conditions-namely, a much lower relative temperature index, a very high evaporation rate and a sunshine value only a little higher than the corresponding value for the period beginning August 10. For College, the periods beginning July 17, July 31 and August 14, with about the same values for temperature and evaporation, show magnitudes of 152, 204 and 150 respectively for the leaf-product. This variation may possibly be related to differences in the value of sunshine intensity for these periods, but sunshine data are lacking for this station. For Baltimore, the periods beginning July 23, August 6 and August 20 show large differences in the leaf-product with comparatively slight differences in the climatic conditions. Evaporation was slightly less rapid for the period beginning July 23 than for the period beginning August 8, and considerably less for the period beginning August 20, but this seems to have occurred without the expected effect on the plants. For Coleman the plant graph slopes upward to a value of over 200 for the period beginning July 8, while for the period beginning August 5, which has climatic conditions apparently as favorable, the relative value of the leaf-product is only 138. For Easton the leaf-product is lower than would be expected for the period beginning August 17, and for Princess Anne the plant values for the period beginning August 8 are much lower than for the period beginning July 7 , which had approximately the same climatic conditions as the first-mentioned period.

A second feature of the plant graphs, and one that cannot be correlated with the climatic data, is that the rate of stem elongation reaches its highest value for the season before the occurrence of the maximum leaf-product, for all stations except Darlington and Coleman. For Darlington, the highest value for stem height and leaf-product both occur for the period beginning July 10 and for Coleman the maximum value for stem height occurs for the period beginning July 22, while the leaf-product reaches its highest value for the season at this station in the preceding period. For the remaining stations, the highest value for stem height occurs two weeks or a month earlier than does the highest value for leaf-product.

\section{THE 4-WeEk VALUES}

The 4-iveek plant and climatic data derived from the exposed stations are presented in the tables and graphs already explained, and the following consideration of these values will refer to the graphs, as in the case of the 2 -week values. 
For the 4-week data, the rate of stem elongation may be compared with the rate of leaf expansion as determined from actual measurements of leaf area. This comparison shows the same general relations as appeared to exist between stem height and leaf-product for the 2-week growth periods. Owing to the fact that the 4 -week plants were grown for a longer time, however, the 4 -week clata show fewer cases with the rate of stem elongation greater than the rate of leaf expansion. In most cases the rate of stem elongation is considerably smaller than the rate of leaf expansion. This illustrates the tendency of the soy-beans to show a low rate of height growth relative to the rate of leaf expansion when both rates are large.

Fol. Oakland, the stem-height graph is above the leaf area graph for the first three periods of the season and below it for the other five periods. For Chewsville the three plant graphs follow each other very closely and the differences in their relative positions are probably due, for the most part, to individual variations in the plants of the separate cultures. The Monrovia graphs also support the assumption that stem height shows a well-defined tendency to remain below leaf area during the first part of the season. For College, the stem-height graph is below that for leaf area for the entire season, except for the two periods beginning June 19 and September 25. The Baltimore graphs show stem-height values higher than the corresponding leafarea values for the periods beginning May 14, May 29, June 10 and August 20 , due possibly to low light intensities. The Darlington cultures show very high values of both growth rates, with stem height below leaf area for the entire season. For Coleman, the stem-height graph remains below the leafarea graph for all the periods except the last, in which case it rises very slightly above the leaf-area graph. For Easton, the two growth rates are about alike, showing nearly the same relative values for each culture period. For Princess Anne, the stem-height and leaf-area graphs show a departure from the usual behavior during the first three periods of the season. For these periods, the leaf-area values are relatively large and those for stem height are relatively low, for some reason not apparent from the climatic conditions.

A very striking relation is shown between the 4 -week values for leaf area and for dry weight. For most of the cultures these two kinds of growth rates have practically the same relative numerical values for any given period. The Oakland graphs show this for all periods except the one beginning June 5 , for which dry weight is markedly larger than leaf area. For Chewsville, the general relation just mentioned shows very well throughout the season. For Monrovia, the leaf-area value shows a rather large deviation from the dryweight value for the periods beginning June 16, June 30 and Aug. 25, but otherwise the two growth rates correspond in their relative values during the 


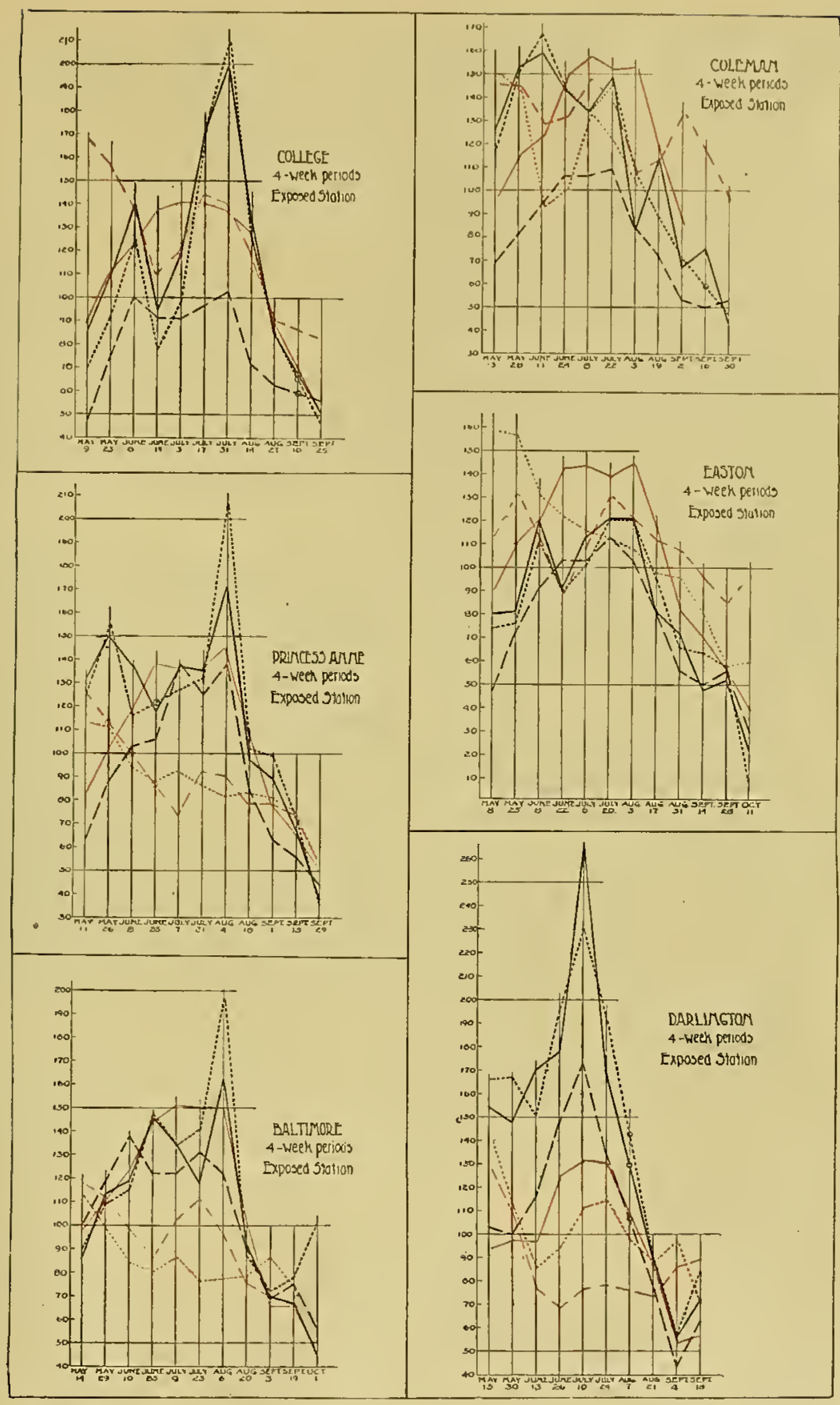

Fig. 4. Graphs of 4-week data for exposed stations as named (continued). (Lines as in 4 -week graphs of fig. 3.) 
entire season. The College graphs show close agreement, with dry weight above leaf area during the first part of the season. For Baltimore, the relative leaf-area value differs considerably from the value for relative dry weight for the periods beginning August 6 and October 1, but the remaining periods show close agreement. The two Darlington graphs show close agreement for all periods. For Coleman, dry weight and leaf area agree well for all periods, except those beginning August 5 and August 19. For Easton, no large differences between these two rates occur for any of the cultures. For Princess Anne, the period beginning August 4 is the only one showing a difference of considerable magnitude between the relative leaf-area value and the dry-weight value.

This property or characteristic of soy-bean renders possible the use of the leaf area of the plant as an index of the dry weight of the tops, and appears to render soy-bean particularly promising as a standard plant for climatic investigations, as has been pointed out in a previous paper, ${ }^{19}$ from which the following paragraph is taken.

"If the method proposed by Livingston and MeLean (1916), of employing the growth rates of standard plants as indices for the comparison of different climates as these influence plant growth in general, is to be of value, it is of course necessary that suitable plant characteristics be chosen for measurement in determining the growth rates, and it is desirable that the measurements be such as may be made from time to time without injury to the plants. The unost generally accepted criterion of plant growth, dry weight of tops, can be obtained but once for any individual plant, since the plant is destroyed during the determination. Also, the accurate determination of leaf area is very difficult unless the plants are destroyed. On the other hand, as MeLean has emphasized, leaf dimensions may be obtained repeatedly during the development of the plant, without serious danger of inflicting injury. It may therefore be of consiclerable importance if leaf area, and even dry weight can be satisfactorily estimated for soy-bean by the employment of the leaf-product as an index."

Dry weight and actual leaf area were both determined only for the 4 -week periods, the plants being then destroyed, but the lengths and breadths of all leaflets were obtained for both the 2 -week and the 4 -week periods. Consequently, to study the correlation between total leaf area and total leafproduct per plant, only the 4 -week data are available and these are the ones here considered.

Since soy-bean leaflets are approximately elliptical in form and since the area of an ellipse is proportional to the product of its axes, the leaflet-product (length times breadth) of any leaflet should be nearly proportional to the area of that leaflet. Whecher this relation may hold during the growth of

\footnotetext{
19 Hildehrandt, F. M. Leaf product as an index of growth in soy-bean. Johns Hopkins Univ. Circ., Mlarch, 1917. P. 202-205.
} 
the leaflet under different sets of climatic conditions depends upon how nearly the elliptical form is retained. The sum of the individual leaflet-products of any plant, which is the total leaf-product for that plant, should be approximately proportional to the lotal leaf area of the plant, if the relation given above holds. In the discussion that follows it will be shown that such an approximate proportionality does exist in the case of the 4-week soy-bean plants.

In order to find out whether the actual areas of the leaves in these cultures were proportional to the corresponding leaf-products, the ratio of the two quantities was worked out for a number of the stations. It was found that the leaf-product divided by the leaf area gives a number that varies only slightly from the value 1.28. In other words, if we measure the two diameters of the leaflets of a 4-week soy-bean plant, multiply these two numbers for each leaflet, and add the products, a number is obtained which, when divided by 1.28 , closely approximates the actual leaf area of that plant. Instead of using the sum of the products of length and breadth as an index of the area per plant we may use the sum of the squares of the lengths of the leaflets or the sum of the squares of the breadths of the leaflets. The numbers thus secured do not, however, bear as nearly constant a ratio to the actual leaf area as does the total leaf-product, and hence neither is as satisfactory an index of the area as is the leaf-product itself.

One of the most interesting properties of the 4 -week soy bean plant is that the dry weight of stem and leaves is approximately proportional to the total leaf area. Having, therefore, a means by which the leaf area may be conveniently estimated, it is possible to calculate the dry weight of the plant approximately, by multiplying the leaf-area by the proper constant. The proportionality between the weight of the plant and its leaf area is not quite so consiant as that between leaf area and leaf-product, but in the great majority of cases the variation in the ratio of dry weight to leaf area, from a constant value, is less than 10 per cent. The relations given hold over a very wide range of climatic conditions and for plants varying in height from 2 or $3 \mathrm{~cm}$. to 18 or $20 \mathrm{~cm}$. Since none of the plants in these experiments were grown to maturity, it is impossible to say whether this relation holds up to that time.

From the foregoing facts it may be concluded that the dry weight and leaf area of soy-beans 4 weeks old from the seed can be determined approximately from their leaflet dimensions. Soy-bean should therefore be very suitable for use as a standard plant for the measurement of climate in the manner suggested by Livingston and McLean, since the rate of its growth can be approximately determined from easily obtained leaf measurements. Also, the properties of soy-bean given above should make it a useful plant for any piece of physiological research in which it is desired to know approximately the dry weight of the plant used, at various stages of its development. 
The 4-week climatic data for stations in the open (see fig. 4, red lines)

It will be remembered that the cultures were started every two weeks and that each grew for a period of four weeks. The 4 -week periods thus overlap, and attention has been called to the fact that averages of the climatic factors for these over-lapping periods form a smoother graph than averages for the 2-week periods. The 4-week graphs, therefore, show the general seasonal march of the index values for various stations better than do the 2-weck ones, while the latter show the details of the seasonal march better than the former. This fact will be brought out by a brief reference to the graphs at this point.

The values of the physiological temperature indices for the 4-week periods show the scasonal marches of this condition for the various stations, from low values in May to high midsummer values, and then to low values again in the last part of the season. The graphs for all of the stations except Oakland show a steeper slope after the midsummer maximum has been passed than for the periods during which the temperature was rising to this maximum. The two maxima that were present in most of the 2 -week graphs are eliminated in the 4 -week averages and the graphs of temperature values show instead a period of about 6 weeks during which this condition remains approximately constant.

The 4-rveek evaporation and light data show the general characteristics of the seasonal marches of these conditions previously noted as exhibited by the 2 -reek data. It will be seen, in the first place, that both graphs exhibit a downward slope from the beginning to the end of the season; and, in the second place, that both graphs show, in addition to their high primary maximum in the early part of the season, one or more secondary maxima later. In some cases the secondary maxima of the evaporation graphs coincide, as to time of occurrence, with temperature maxima. Both of these general characteristics shown in the 4 -week graphs of evaporation and light are shown by the 2 -week graphs but since small variations are eliminated by averaging the over-lapping periods, there are fewer secondary maxima in the 4-week graphs. In the case of evaporation, there is usually one secondary maximum occurring in or near the 4 -week period including the last 2 weeks of July and the first 2 weeks of August. In the case of all stations this is one of the three 4 -week periods showing high temperature values. The 4 -week climatic graphs need not be discussed further here. The method by which the 4-week data were derived from the 2 -week data amounts to the same thing as smoothing the 2-reek graphs and only the more pronounced characteristics of the graphs remain after averaging. Interest in the 4 -week climatie data thus lies mainly in their relation to the plant growth rates. 


\section{Results for the Tilee Covered Stations}

\section{INTRODUCTORY}

All of the data discussed up to this point wore obtained for the open, with no covering other than a screen of wire netting of large mesh, to protect the plants from injury. At three of the stations, Oakland, Baltimore and Easton, as has been noted, a series of cultures was also grown under glazed cold-frame sash, supported three feet above the ground, these cultures being designated as the Oakland, Baltimore and Easton covered stations. 'The behavior of the plants grown under glass was very different from the behavior of those grown in the open, and the results for the covered stations will be considered in this section.

The covered cultures were placed near the exposed cultures at each of the three places mentioned, so that the climatic conditions for the two would be practically the same, except as modified by the glass.

\section{THE PLANT DATA, COVERED STATIONS}

\section{(See figs. 5 and 6, black lines)}

The effect of the glass cover was shown by the plants in two ways: (1) growth was always greater for the covered stations than for the exposed, and (2) the plants of the covered stations showed a marked difference in manner of growth from the plants of the exposed stations. The greater growth of the covered plants was shown in some cases by one, in some cases by two, or even by all three of the growth measurements taken. Not only did the plants show greater growth, but the maxima in the graphs of the various growth measurements for the covered plants do not usually occur at the same times as do the maxima in the corresponding graphs for the plants grown in the open. The principal effect of the covering on the way in which the plants grew is shown by a disturbance of the relation between dry weight and leaf area. In previous discussion of this relation for the exposed plants it was noted that the relative dry-weight and leaf-area values are approximately the same for the 4-week plants. In the case of the covered stations, on the other hand, every culture shows relative leaf area as higher (usually very much higher) than relative dry weight. Stem height for the covered cultures usually shows high, values as compared to the corresponding exposed cultures. The tendency noted in previous discussion for this growth rate to fall off relatively, as the plants become larger, seems to be only slightly in evidence here. The following consideration of the covered cultures in detail will bring out these features. It should be noted that the culture periods for the covered stations each agree in length, to within a day or two, with those for the corresponding exposed stations. Such slight differences as exist in 


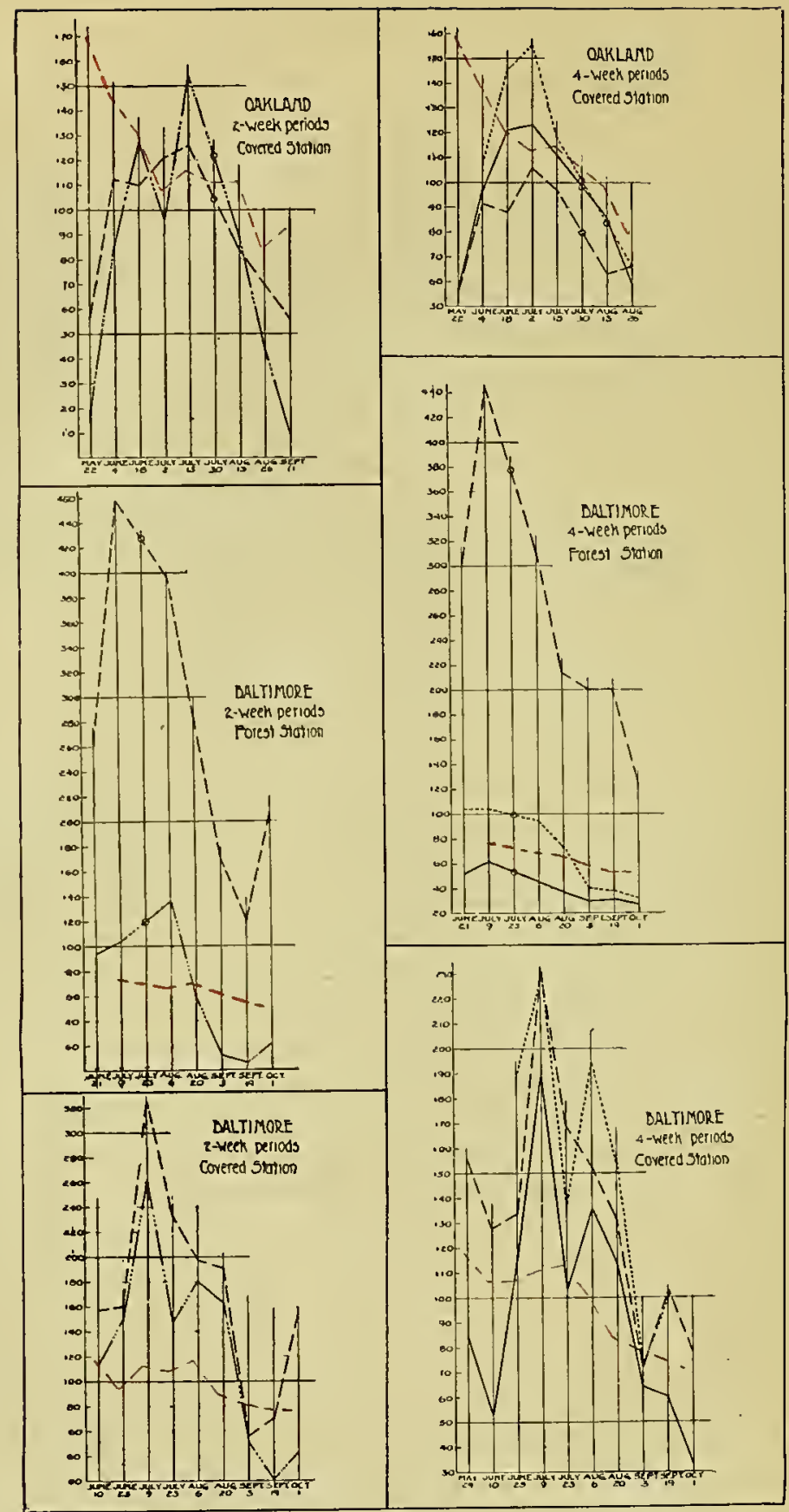

FIG. 5. Graphs of 2-week and 4-week data for covered and forest stations, as named.

Black, as in figs. 1 and 3 .

Red, Evaporation index. 
the lengths of the culture periods do not in any degrec account for the differences in the plant measurements nor interfere with the general comparisons here made. In comparing growth for the exposed and covered cultures, no attempt will be made to account in detail for the differences between the two sets of plants in terms of climatic conditions, since the climatic influenes acting on the covered plants are not even so well known as in the case of the exposed stations, and it has already become clear that a really satisfactory interpretation of growth rates by means of such climatic measurements as are here employed is nearly hopeless at present. After the peculiarities of the covered plants have been pointed out, however, some suggestions as to the probable causes of these peculiarities will be brought forward.
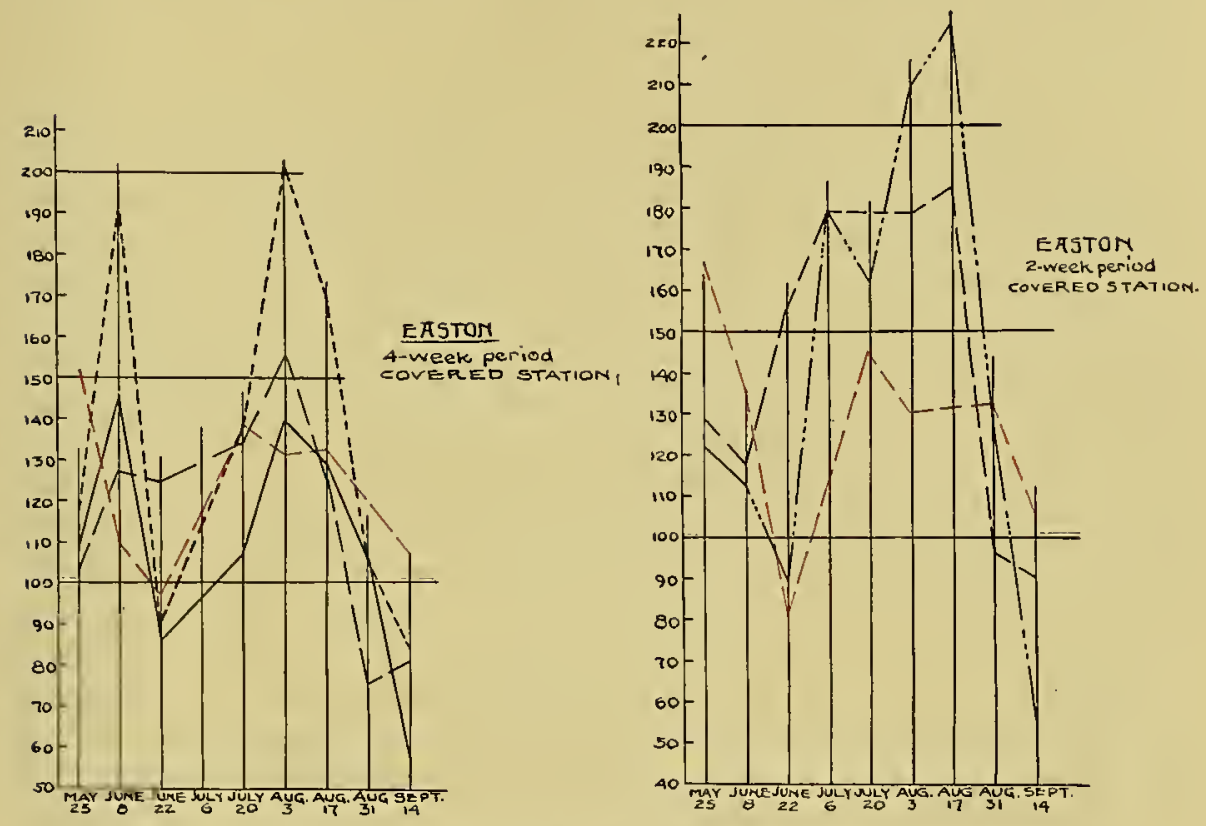

FIG. 6. Graphs of 2-week and 4-week data for Easton covered station.

(Lines as in fig. 5.)

The Oakland covered station.-The covered and exposed cultures for Oakland differ less than do the corresponding sets for Baltimore and Easton, but they show the general features outlined above. The plants of the 2-week covered cultures for Oakland exhibit a much higher value of the leaf-product than clo the corresponding exposed cultures, for the periods beginning June 18 , July 2, and July 15, and the stem-height value is greater for the covered station than for the exposed station, for the periods beginning June 4, July 2 and July 15. The highest value of leaf-product occurs for the period beginning July 15 for the covered, and in the period beginning July 16 for the 
exposed 2-week plants. Each set of cultures show two seasonal maxima in the plant graphs, but these are much higher in the case of the covered plants than in the case of the exposed. In the 4-week graphs for the covered plants, leaf area is higher than dry weight for the whole season, while the exposedstation graph for leaf area is well below that for dry weight, from the period beginning May 23 to the period beginning July 16, inclusive. The maximum for all the growth measurements of the 4 -week exposed plants occurs for the period beginning June 19, while the maximum for the covered station occurs for the period beginning July 2. Also, the graphs for the 4-week plants all exhibit higher values than do the graphs for the 2-week plants for most of the culture periods of the season. This is especially true of leaf area. Covering the plants with glass seems to have produced a relatively high rate of leaf expansion, in spite of the fact that the evaporation value is somewhat higher for the covered than for the exposed plants.

The Baltimore covered station.-The 2-week plant data for the covered station at Baltimore are plotted to a scale one-half as great as the scale used in plotting the exposed plant values, on account of the high values of stem height and leaf-product shown by the covered culture beginning July 9 . The values of both leaf-product and stem height for this station are both uniformly above the corresponding values for the exposed station. Also, the tendency of the covered plants to elongate relatively more rapidly than did the exposed plants is shown by the stem-height values for Baltimore covered station for botll the 2- and 4-week periods. It is interesting to note that the covered plants do not show specially high values of the plant growth rates for the period beginning August 6, as do the exposed plants. The 4-week graphs for the covered plants show very well the tendency of leaf area to reach values relatively higher than those for dry weight, the leaf-area graph being well above the dry-weight graph for the entire season.

The Easton covered station.-For Easton the covered plants, as compared with the exposed, show the general tendencies noted above. The 2-week growth rates of the covered plants, especially for stem height, are higher than the corresponding rates of the exposed plants. It will be observed that the maximum growth for the season, in both the covered and exposed 2-week cultures occurs for the period beginning August 3. The 4-week plants of the covered cultures show leaf area relatively higher than dry weight. The values for the culture period beginning June 22 are relatively low for the covered as well as for the exposed cultures.

\section{THE CLIMATIC CONDITIONS, COVERED STATIONS}

(See figs. 5 and 6 , red lines)

Of the three climatic factors generally dealt with in this study, evaporation alone was measured for the covered stations, so that the climatic data are much less satisfactory in this case than in the case of the exposed stations. 
It is safe to suppose that the climatic conditions under the glass differed from those for the corresponding exposed stations in certain definite ways, period by period. The rate of evaporation for the covered stations was considerably greater than for the exposed as will be seen by comparing the values given in the tables. We may be certain, also, that some of the incident light was absorbed by the glass and that the light intensity under the cover was thus less than the intensity of the light falling on the exposed plants. Also, we may be reasonably sure that the air temperature under the glass was somewhat higher than that outside, especially on quiet days when circulation of air was slight, and there was little tendency toward equalization of air temperatures. In considering the behavior of the covered cultures as related to climatic conditions, it may be mentioned that evaporation is known to have been more intense and light intensity lower for these than for the corresponding exposed stations and periods, while air temperature was probably higher for the covered than for the corresponding exposed stations.

The differences between the behavior of the plants under glass and that of the plants in the open seems to be primarily attributable to differences in light conditions for the two sets of cultures. The more rapid stem elonga ion occurring under glass is exactly what would be expected if the air temperature was higher and the light intensity was lower than in the case of the corresponding cxposed cultures. The fact that leaf area is relatively high for the covered plants, as compared with their final dry weight, may possibly be related to a smaller amount of dry matter produced by photosynthesis per unit of leaf area in the covered cultures. Such a difference might be expected if the light energy available for photosynthesis were cut down by interposing between the plant and the light source a screen that absorbed a part of the light.

Whatever may be the true explanation of the behavior of thesc plants under glass (and the true explanation will surely be much more complicated than is here suggested), the facts indicate very clearly that the growth of the plants under glass was quite different from the corresponding growth in the open. This point must be important in physiological experiments conducted in greenhouses.

\section{Results for the Baltimore Forest Station}

(See fig. 5)

The Baltimore Forest Station was located about 150 yards from the exposed and covered stations at that place. Evaporation was the only climatic feature measured for this station. The sunshine intensity was of course very low, due to the shading and screening effect of the leaves of the trees above the experimental plants. Air temperature was also probably 
considerably lower than that experienced by the exposed and covered plants. The modification of growth habit in the case of the forest plants is very striking, as can be seen by an inspection of the plant graph for this station. The soy-beans were short erect growers in the open, and were erect with long stems under the glass of the covered station, but were runners in the forest. This effect on stem growth, which obviously cannot be explained as an effect of temperature alone in the case of these cultures, is relatively very great, the highest 2-week value for stem elongation being over four and a half times as great as the seasonal average for all periods and stations, and the highest 4 -week value was a lictle less than four and a half times the seasonal average. As compared with plants grown in the open, the 4-week forest plants also show the same reversal in the relative positions of the leaf-area and dry-weight graphs as was shown by the covered plants. The leaf-area graph is above the dry-weight graph for the entire season in the forest. These cultures are thus more like the covered ones than they are like the exposed ones. This may possibly be accounted for by supposing that the similarity in the behavior of the plants in the covered and forest stations at Baltimore was related to a corresponding similarity in the light conditions for these two sets of cultures, but the problem is doubtless very complex.

\section{THE PLANT DATA AS MEASURES OF THE CLIMATIC EFFICIENCY FOR GROWTH OF THE STANDARD PLANTS}

\section{INTRODUCTORY}

As has been stated, the investigation of which this study is a part was planned with the idea of obtaining some quantitative measures of the climatic complex for each of the various stations, in terms of plant activity. Since the soil used was the same, since its moisture content was kept high enough to support good growth at all times, for all stations and for all periods, and since seeds of the same lot were used in all cases, it is supposed that the differences in the growth rates for the various periods and stations must have been due to effective environmental differences other than those of soil conditions. On account of the auto-irrigation of the cultures, precipitation was practically without direct influence upon the cultures of the exposed and forest stations, and it was of course quite without direct influence upon the cultures of the covered stations. The influential environmental conditions that differed from station to station and from period to period in these tests were those usually considered as climatic, with the omission of precipitation. The plant data, as set forth in the tables and graphs, may therefore be regarded as approximate measures of the integrated non-precipitation conditions of the several climatic complexcs under which the plants grew. These 
measures of course refer specifically to this particular variety of soy-bean plant and to the particular set of soil conditions that was common to all cultures. With another soil, or with anotlier kind of plant, the plant values would of course have been more or less different from those here recorded. It remains to be found out whether or not soy-bean is a suitable standard plant for use in this sort of climatic integration when the needs of agriculture, forestry and general ecology are primarily considered. From what has been said in the preceding sections it appears, however, that soy-bean is at least especially well suited to preliminary and pioneer studies like the present one. ${ }^{20}$

From this point of view, each of the graphs of the plant values (shown by the black lines in figures 2-6) may be regarded as a representation of the seasonal march of the non-precipitation portion of the climatic environment for the particular station in question, the graphs for the exposed stations representing the "natural" conditions, while those for the covered and forest stations refer to the more or less modified climates experienced by these cultures. Some of the more outstanding features of these plant graphs have been mentioned in the preceding sections of this paper, and other features will become evident from a careful study of the graphs themselves, or of the tables from whose data the graphs were constructed. Much more might be said in this connection than has been said, but the newness of the present point of view, together wth the obvious complexity of the numerical results here presented, make it undesirable to attempt a careful study of these data at the present time. The tables and graphs of this paper render the numerical values available for future study, when this aspect of climatology and ecology shall have begun to attract more general and appreciative attention than it now enjoys.

It should be emphasized that the plants have automatically weighted and integrated all the fluctuating and differing conditions for the several culture or exposure periods, and that the final summation is given in terms of the amount of growth produced in 2 weeks or 4 weeks from the seed. Dividing this final summation by the number of days in the corresponding period gives the average plant producing power of the non-precipitation part of the climatic complex for the given period and station.

It has been noted that these plant values generally show a seasonal march for each station, the growth index being relatively low for periods near the beginning and end of the season, and relatively high for midsummer periods, and it has been suggested that temperature may be considered as the main controlling condition in the bringing about of these seasonal marches, various modifications being superimposed upon the temperature influence by other climatic conditions such as the intensity, duration and seasonal distribution of light, and the intensity and seasonal distribution of evaporation.

20 A study somewhat similar to this one, using wheat, pea and brome-grass as standard plants, was carried out by Sampson assisted by the author. See: Sampson, A. W. Climate and plant growth in certain vegetative associations. U. S. Dept. Agric. Bull. 700. 72 p., 37 fig. Govt. Printing Office: Washington, 1918. 
SEASONAL AVERAGES OF MEAN DAILY INTENSITY VALUES FOR THE SEVERAL STATIONS

Aside from the characteristics of the seasonal marches of the climatic conditions in question (which are best seen in the seasonal graphs themselves, figs. 2-6), it is of interest to average all the corresponding plant-index values for the season for each station, thus obtaining a seasonal average or mean daily plant-producing power, as a single index for each growth criterion for each station. This has been done for all the stations, for the 2 -week and for the 4 -week periods and for each growth criterion, and the resulting seasonal

TABLE X

Relative seasonal daily means for the several stations, by each of the five growth criteria. The letter $H$ denoles high values; $M$, intermediate values; and $L$, low values. (The covered station and the forest station are included for completeness.)

\begin{tabular}{|c|c|c|c|c|c|c|}
\hline STATION NAME & $\begin{array}{c}\text { NUMBER } \\
\text { OF } \\
\text { DAYS }\end{array}$ & $\begin{array}{l}\text { 2-WEEK } \\
\text { STEM } \\
\text { HEIGHT }\end{array}$ & $\begin{array}{l}\text { 2-WEEK } \\
\text { LEAF } \\
\text { PRGDECT }\end{array}$ & $\begin{array}{l}\text { 4-WEEK } \\
\text { STEM } \\
\text { HEIGHT }\end{array}$ & $\begin{array}{l}\text { 4-WEEK } \\
\text { LEAF } \\
\text { AREA }\end{array}$ & $\begin{array}{l}\text { 4-WEET } \\
\text { DRT } \\
\text { WETGHT }\end{array}$ \\
\hline Oakland. ................. & 125 & LS6 & $\mathrm{L} 77$ & L71 & L71 & L79 \\
\hline Chewsville................ & 154 & LS7 & LS4 & L75 & L74 & L7S \\
\hline 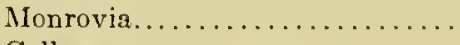 & 154 & L79 & L80 & L66 & L71 & L79 \\
\hline College.................... & 154 & $\mathbf{M 9 5}$ & M101 & M80 & M110 & M119 \\
\hline 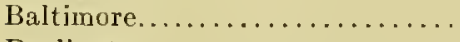 & 153 & H125 & H119 & $\mathrm{H} 104$ & M115 & M105 \\
\hline 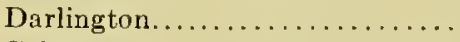 & 151 & H113 & H118 & H106 & H148 & $\mathrm{H} 144$ \\
\hline Coleman............ & 168 & M96 & M107 & M80 & M117 & M113 \\
\hline Easton.............. & 171 & $\mathbf{M} 95$ & M105 & M75 & L82 & L83 \\
\hline Princess Anne............... & 169 & M106 & 1196 & M92 & M117 & M116 \\
\hline Oakland, covered.... & 一 & $\mathbf{1 9 2}$ & L78 & MS1 & M118 & M93 \\
\hline Baltimore, covered..... & - & $\mathrm{H} 172$ & $\mathrm{H} 125$ & $\mathrm{H} 136$ & $\mathrm{H} 154$ & M95 \\
\hline Easton, covereri........... & - & $\mathrm{H} 145$ & $\mathrm{H} 142$ & H116 & $\mathrm{H} 137$ & M109 \\
\hline Baltimore, forest. . & - & $\mathrm{HH}^{\mathrm{a}} 271$ & $\mathrm{LL}{ }^{\mathrm{a}} 62$ & $\mathrm{HH}^{2} 256$ & L69 & $\mathrm{LL}^{\mathrm{a}} 41$ \\
\hline
\end{tabular}

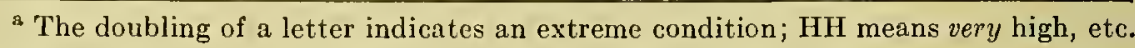

means are shown in the last column of each of the data tables (tables IVIII), where the corresponding seasonal averages for the climatic data are also given. It is to be remembered that the values are all relative, each one being stated in terms of the corresponding average for all stations and all periods, this unit being considered as 100 .

The seasonal averages for the various exposed stations are brought together in table $X$ and are shown graphically in figures 7 and 8, the former figure dealing with the 2-week and the latter with the 4-week plant data. The abscissas of these graphs are not quantitative; the vertical lines are equally spaced and each one represents one of the exposed stations. The stations are arranged in the order of their geographical locations, as far as this is possible in a linear series. The ordinates of these graphs represent the seasonal means. 


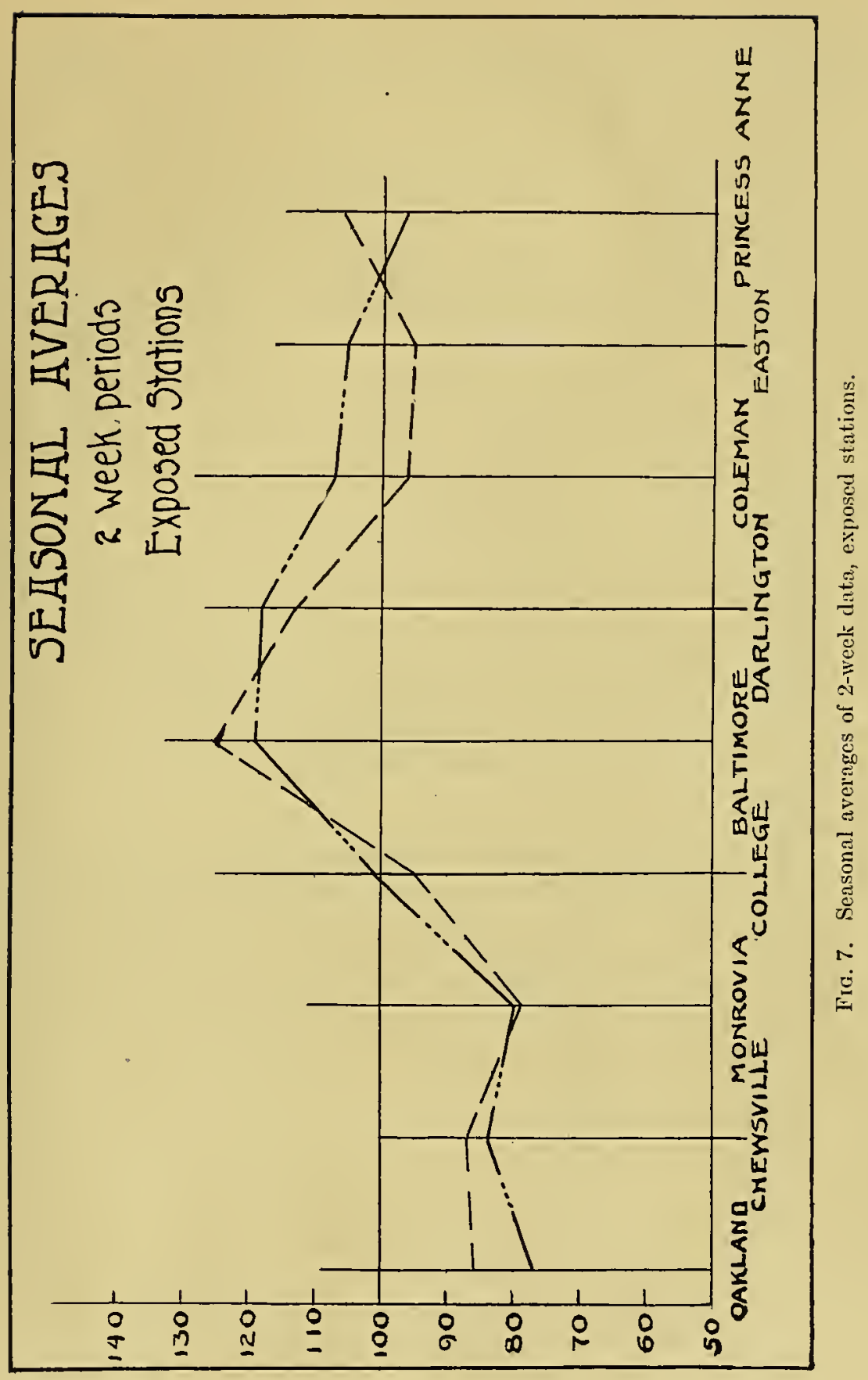


The 2-week seasonal averages of the two growth measurements taken for the nine exposed stations, represented graphically in figure 7 , show that the plant-producing power of the climatic complex is about the same whether it is measured by stem height or leaf-product. The range of variation for stem elongation is from 79 (Monrovia) to 125 (Baltimore). In terms of this growth measurement, the average intensity of the Monrovia climatic complex is 63 per cent of that of the corresponding Baltimore complex. Similarly, the leaf-product mean varies from a minimum of 77 (Oakland) to a maximum of 119 (Baltimore); as measured by leaf-product, the mean intensity of the Oakland climate is 65 per cent as efficient as the corresponding mean for the Baltimole climate. Precipitation is of course left out of account here, as in the other considerations of this paper. The nine stations fall into three groups, according to these mean values: Oakland, Chewsville and Monrovia have low relative values, Baltimore and Darlington have high values, and College; Coleman, Easton and Princess Anne have intermediate and similar values. (See the letters $\mathrm{L}, \mathrm{H}$ and $\mathrm{M}$ in table $\mathrm{X}$.)

Turning to the 4-week seasonal averages, as shown in figure 8 , it is seen thai the graph for stem height agrees very well with the two 2-week graphs just considered. It is also seen that the 4-week graphs for leaf area and dry weight agree in a satisfactory manner. According to these two graphs, the nine stations fall into the following three groups: Oakland, Chewsville, Monrovia and Easton constitute the groups with low values, Darlington is alone in the group with high values, and College, Baltimore, Coleman and Princess Anne make up the group with intermediate and similar values. (See the letters of table $\mathbf{X}$.)

It is to be remembered that the two series of data (2-week and 4-week) refer to the same total time interval. The plants of one series were registering the same climatic conditions as those of the other series; indeed, they were the same plants, for the 4-week measurements were obtained from the same plants as those from which the corresponding 2-week measurements had been secured. The fact that the seasonal averages of the leaf area values (4-week) do not show the same grouping of the stations as do the leafproduct values (2-week) is to be referred to the fact that the plant alters its internal conditions with growth and age. A soy-bean plant exposed two weeks is an entirely different instrument (as far as measuring environmental efficiency is concerned) from the same plant exposed 4 weeks. For this reason it seems desirable that such studies as the present one should be carried out with as short periods of exposure of the standard plants as is feasible. It is somewhat as though the instrument wore out and altered its characteristics with too long exposure. Since it is obviously impracticable to obtain a large number of plants that are approximately alike, excepting as seeds, it seems desirable to begin each observation with new seed (as was done in this investigation), and to take the final readings before the internal condi- 


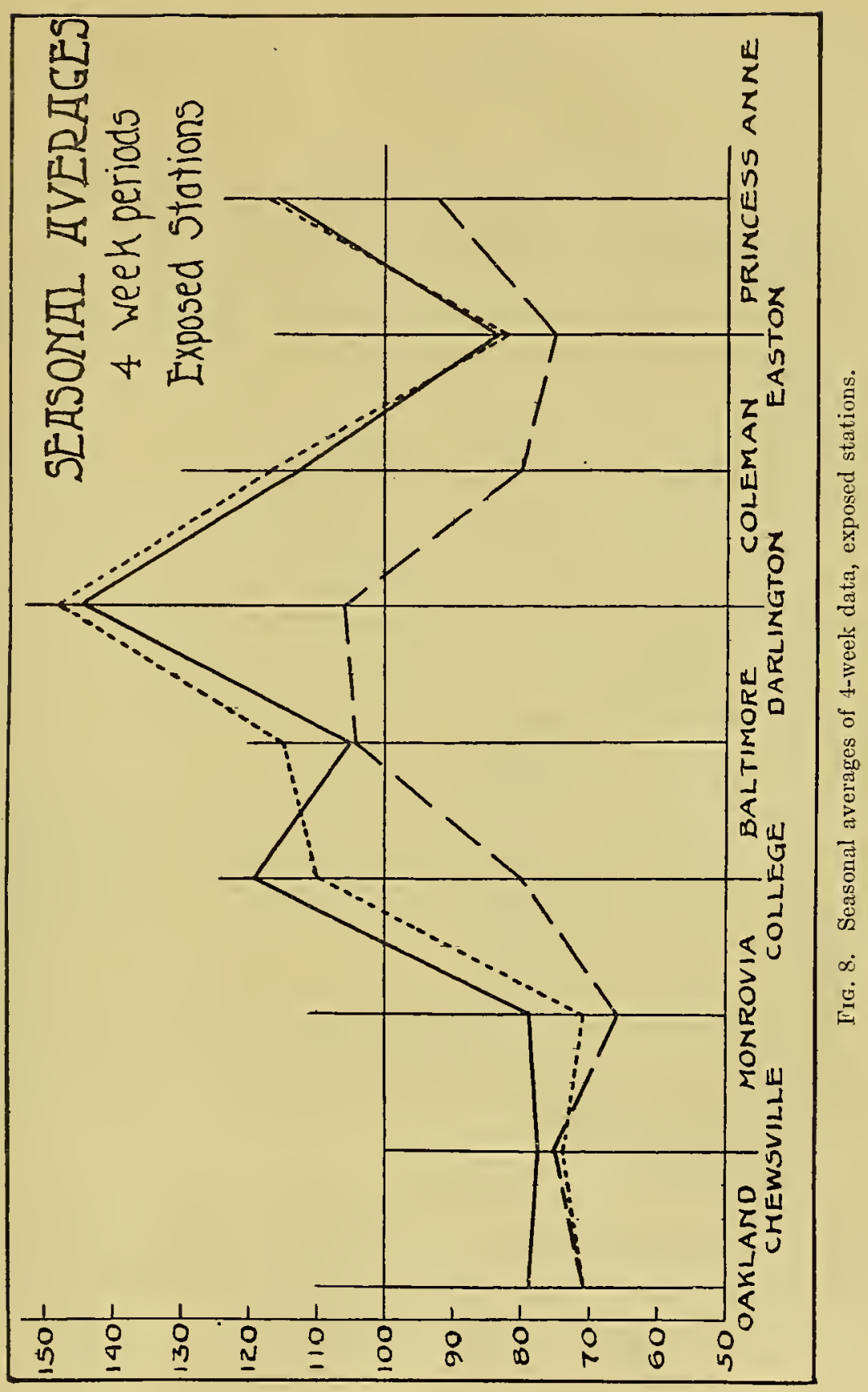


tions of the plants have been too seriously altered through age and the approach toward maturity. At the same time, the standard plants must of course be allowed to grow long enough so as to be influenced by the fluctuating environmental conditions and long enough to give easily-obtained measurements. McLean (1917) has given some attention to the difference between the behavior of the soy-bean plant during the first and second two weeks of its growth from the seed, under the same set of climatic conditions and fuctuations, pointing out that the plant becomes more sensitive to evaporation conditions as it grows older (since its leaf surface becomes larger). In the usc of standard plants as indicators of climatic efficiency the length of time chosen for the exposure period is clearly very important. It may be added that future studies may bring out certain advantages for a 3-week or 4-wcek exposure of soy-bean plants, as compared with a 2-week exposure, but-as has been pointed out elsewhere in this paper-details will be more apparent when the periods are relatively short, and the principles upon which this sort of work is based are more nearly fulfilled with short periods.

To summarize this discussion, the nine exposed stations arrange themselves in three groups by every one of the five criteria, the grouping is identical by three of the criteria (2-week stem height, 2-week leaf-product and 4-week sten height), it is identical by the two remaining criteria (4-week leaf area and 4-week dry weight), but is it somewhat different by these two separate series of criteria. The differences are: that the second series of criteria place Baltimore in the intermediate instead of in the high group, and Easton in the low instead of in the intermediate group.

It is a striking fact that all five growth criteria agree in placing Oakland, Chewsville and Monrovia in the group for low mean daily values, in giving Darlington high values, and in giving College, Coleman and Princess Anne intermediate values. Only for Baltimore and Easton, among the exposed stations, are there discrepancies.

If the five seasonal values are averaged for each exposed station, the result places Oakland (77), Chewsville (80) and Monrovia (75) in the group for low averages, gives intermediate values for College (101), Coleman (103), Easton (88) and Princess Anne (105), and gives high values for Baltimore (114) and Darlington (126). These average values are shown.in the third column of table XI.

The average data for the covered and forest stations, also shown in table $\mathrm{X}$, emphasize the influence of the glass covers and of the forest shade, etc.

It is perhaps important to cmphasize that the criterion of stem elongation gives the same grouping of the exposed stations by the 4-week as by the 2 -week values. The ratio of the 2 -rweek seasonal mean to the corresponding 4-week mean is shown for each exposed station below. 
Oakland................. 1.21

Darlington................ 1.07

Chewsville............... 1.16

Coleman................... 1.20

Monrovia.................. 1.18

Easton................... 1.27

College.................. 1.19

Princess Anne............. 1.15

Baltimore.

1.20

The average of these ratios is 1.18 . If, therefore, the stem height of the soy-bean, grown as a standard plant, be used as a measure of the climatic complex, and the measurement be expressed as relative average daily increments, as in this study, the 2 -week readings may be approximately reduced to 4-week readings (considering these as the standard) by dividing each 2 -week reading by the constant 1.18 .

\section{THE TOTAL SEASONAL EFFICIENCIES FOR THE SEVERAL STATIONS}

The efficiency of an environmental complex, or its power to produce growth in a standard plant, is to be considered as the product of two factors, intensity and duration. If the seasonal averages of the mean daily rates of growth,

TABLE XI

Relative generalized climatic-efficiency products for the several stations.

\begin{tabular}{|c|c|c|c|}
\hline STATION NAME & $\begin{array}{l}\text { NORMAL LENGTH OF } \\
\text { GROWING BEASON } \\
\text { (A) }\end{array}$ & $\begin{array}{c}\text { RELATIVE } \\
\text { GENERALIZED SEA- } \\
\text { SONAL AVERAGE } \\
\text { OF DAILY MEAN } \\
\text { INTENSITY (B) }\end{array}$ & $\begin{array}{c}\text { CRIMATIC } \\
\text { EFFICIENCY PROD- } \\
\text { UCT (AB) }\end{array}$ \\
\hline & days & & \\
\hline Oakland............... & 117 & 77 & 9009 \\
\hline Chewsville.............. & 156 & 80 & 12480 \\
\hline 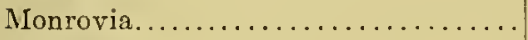 & - & 75 & - \\
\hline College....................... & 167 & 101 & 16867 \\
\hline 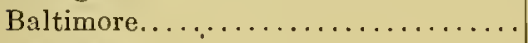 & 223 & $11 \pm$ & 25122 \\
\hline Darlington............ & 188 & 126 & 23688 \\
\hline Coleman............. & 205 & 103 & 21115 \\
\hline Easton.......... & 201 & SS & 17688 \\
\hline Princess Anne........ & 181 & 105 & 19005 \\
\hline
\end{tabular}

to which attention has thus far been confined, be taken as the intensity factors for the respective stations, for the season of 1914, and if the length of the entire growing season for each station be taken as the lduration factor, or the length of time through which the corresponding intensity is considered as effective, then the product of the length of the season and the corresponding intensity factor should give a value that may approximately represent the relative efficiency of the climatic complex for the station and year in question, by the given plant criterion. Precipitation is of course neglected, as it was not involved in this study.

The seasonal averages of the daily means for the growth rates, as used in this study (table $\mathrm{X}$ ), may be taken to represent the relative values of the 
climatic intensities dealt with, but the lengths of the growing seasons are only approximated by the total lengths of the test periods. Rather than to employ these lengths it will perhaps be better to use the mean (normal) lengths of the growing seasons for the several stations here considered. These may be obtained from Fassig's paper on this subject, ${ }^{21}$ and they are shown in table XI, along with the corresponding generalized climatic efficiency products, obtained by multiplying Fassig's mean length of the growing season by the corresponding average climatic intensity (including all five plant criteria) as dereloped in the preceding section of this paper. It is to be emphasized that the intensity factors are all for the summer of 1914 and that the duration factors are normal, or at least closely approximate normal values.

From table XI it appears that the lowest efficiency product is for Oakland, as would be expected, while the highest is for Baltimore. The Baltimore value is nearly thrice as great as is the value for Oakland. If we regard values above 20,000 as high and those between 10,000 and 20,000 as intermediate, the stations may be grouped as follows:-

Low values: Oakland.

Intermediate values: Chewsville, College, Easton and Princess Anne. High values: Baltimore, Darlington and Coleman.

These efficiency products may be taken to represent, more or less approximately, the relative values of the climatic conditions at the various stations, to produce plant growth when irrigation is resorted to, so that drought periods are avoided as far as soil moisture is concerned. While there is no reason for thinking that these values (obtained from 2-week and 4-week periods and soybean plants, with the particular soil used in this study) may give really quantitative information on these climates as related to plant growth in general, still the product indices here derived are perhaps more reliable than any other series of numerical values that might be readily obtained, and they illustrate a new method by which a beginning may be made aiming toward the quantitative comparison of climatic complexes.

One of the aims of ecological climatology should be to evaluate climates in somewhat the same manner as water-power, mineral deposits, and other geographically restricted sources of power for the accomplishment of human purposes, may be evaluated. The importance of this aim is very great for agriculture and productive forestry, and it is not less important for the fundamental principles of ecology. The above discussion presents one of the first serious attempts to compare the plant-producing powers of several climates by means of numerical indices.

${ }_{21}^{2}$ Fassig, O. L. The period of safe plant growth in Maryland and Delaware. Monthly Weather Rev. 42: 152-158. 1914. 


\section{GENERAL CONCLUSION}

The results and suggestions attained by the study licre reported leave the problem of agricultural or ecological elimatology still very far from solved, but the purpose of this investigation has been achieved if some of the more fundamental considerations that must be taken into account in this sort of inquiry have been emphasized. The main points brought out are summarized in the Abstract at the beginning of this paper and do not require repetition here. It is clear that this aspect of climatological science required other measures and other methods of treatment than those thus far developed by meteorological climatologists, and that much physiological knowledge must be built into the structure of the new science. It appears that the use of standard plants, in some such way as the soy-bean plants were used in this investigation, and the avoidiug of the immense complications due to soil conditions when the same soil is not employed in all eases, will lead to progress in this exceedingly difficult but both funclamentally and practically important field of human advancement. If the relations that hold between climatic conditions and plant growth are to be really understood it will be necessary for the climatological student to interest himself in plant physiology in no merely superficial way, and it will be necessary for much of the science of climatology, as it is now represented in the literature, to be very lightly stressed. The point that seems in need of cmphasis is that this new aspeet of climatology (or of ecology) will have to deal with climatic conditions as they affect plants; it will not need to give main attention to climatic fluctuations and differences per se, nor to the meteorological, physical and astronomical reasons for their occurrence. 



\section{VITA}

The writer was born December 26, 1888, at Baltimore, Maryland. He entered the Baltimore Polytechnic Institute in 1903, being graduated in 1907. During the year 1908-1909 be taught in the public schools of Baltimore. In 1909 he entered the Collegiate Department of the Johns Hopkins University, receiving the degree of Bachelor of Arts in June, 1913. During the years 1914-1917 he attended the Johns Hopkins University as a graduate student in Plant Physiology, Physical Chemistry and Botany. He was engaged in research for the Maryland State Weather Service during the year 1915-1916, and carried on research for the U. S. Forest Service at the Utah Experiment Station of the Forest Service during the summer of 1916. 

. 
LIBRARY OF CONGRESS

|| || || || || ||||||||||||||||||||||||||||||||||||

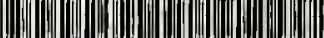

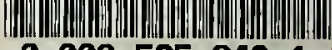

0 0025952431
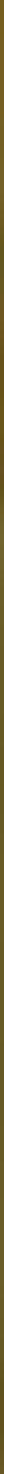

\section{(2002 595243}

.

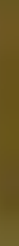

tin

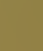

